BETWIXT AND BETWEEN: THE PERCEIVED

LEGITIMACY OF CAMPUS POLICE

By

JAMES CHRISTOPHER WADA

A dissertation submitted in partial fulfillment of the requirements for the degree of

DOCTOR OF PHILOSOPHY

WASHINGTON STATE UNIVERSITY

College of Education

AUGUST 2007

(C) Copyright by James Christopher Wada, 2007

All Rights Reserved 
(C)Copyright by JAMES CHRISTOPHER WADA, 2007

All Rights Reserved 
To the Faculty of Washington State University:

The members of the Committee appointed to examine the dissertation of JAMES CHRISTOPHER WADA find it satisfactory and recommend that it be accepted.

\begin{tabular}{l} 
Chair \\
\\
\hline
\end{tabular}




\section{ACKNOWLEDGEMENTS}

The completion of a dissertation and $\mathrm{PhD}$. was a very complex journey. What I have learned from the journey is that it could not be completed without the support of others. Consequently, it is important that I acknowledge and share my success with the people who traveled with me on this journey.

Primarily, I have to thank my family. My family has encouraged me and supported me through this process. Without family support, I am not sure if a process this vast would have been possible or even imaginable for that matter. I have to specially thank my Uncle, Dr. Gus Tanaka, who always believed that I was a scholar.

Without my friends, my life would be empty. I have an eclectic group of friends and from them all, I have learned many valuable lessons. My friends have always been supportive and proud of my educational voyage. Without, at times, their inspiring words of encouragement, I am not sure what the outcome of this venture would have been. Consequently, I have a great deal of gratitude towards my friends. I specially have to thank Shawn, Anthony, Nikki, Seth, Mallory, and Ben. I also have to thank my hometown friends in Ontario, Oregon, who I know were always giving me good wishes.

While I was working on my Masters of Arts, I was encouraged as well as inspired to work on my PhD from the faculty at Boise State University. Consequently, I have to give thanks to the faculty members in the Criminal Justice Department at Boise State University. I would also like to give special thanks to Dr. Andrew Giacomazzi and Dr. David Mueller for always looking out for my best interests.

Dr. Nick Lovrich, Dr. Travis Pratt, and Dr. Mike Gaffney were my first contacts at WSU. Without their help, support, and friendship, I am not sure what the outcome of 
my graduate education would have been. I am truly grateful to have learned from them and truly grateful to have them as friends.

At WSU, I have been surrounded by great colleagues/friends both in the Criminal Justice Department and the College of Education. I imagine that these friendships will last a lifetime. My friends, here at WSU, kept me focused, humble, and sane. In the Education Department, I have to specially thank Jason, Justin and Xyan. In the Criminal Justice Department, I have to specially thank Travis, Cortney, Ryan, and Jen. Their friendship was instrumental in my success.

The College of Education has been paramount to my educational success. The faculty in the college nurtured my learning and gave me the skills necessary to become a scholar. Within the college of education, I have to specially thank Dr. Len Foster. Dr. Foster was my first contact in the College of Education. Dr. Foster's presence as a scholar and mentor, ultimately led me to choose higher education as my area of study. Finding a place where I "fit" was vital to my success. I am very thankful to Dr. Foster for helping me find this place.

I have to specially thank Dr. Eric Anctil. Dr. Anctil’s ability to mix scholarship with humor demonstrated, to me, what learning could be. I also know that in many instances Dr. Anctil went "above and beyond” to help me with my academic career. Without out his efforts, I am unsure where I would be right now. I am truly grateful to him.

I also have to specially thank Dr. Willie Heggins. Dr. Heggins explained to me one day that the $\mathrm{PhD}$. is something more than for myself. He explained that higher education is something that is accomplished for family, friends, and community. The 
explanation elucidated the meaningfulness of what I was doing. Dr. Heggins words showed me that my education was not about me in a vacuum. The worth of my studies was to make positive changes in the world around me. It was from Dr. Heggins' explanation of graduate studies that the meaning of my education became something more. I became mindful of the value of what I was doing and moreover, the importance of the people around me. I am very grateful to Dr. Heggins for teaching me this lesson. Lastly, I have to specially thank Dr. Forrest Parkay. Dr. Parkay has been a mentor, friend, and role model to me. Without Dr. Parkay's mentoring, words of encouragement, and interest in my studies, I do not know if completing this process would have been possible. Dr. Parkay once imparted on me that in higher education "the possibilities are limitless.” This concept has been very important to my success as a student and I believe that this concept will be very important for my future success as a scholar. I am extremely grateful and honored to have had Dr. Parkay as my chair and teacher.

The term mentor, I believe, has become a very overused word in American discourse. Because the word has become so overused, it has become a cliché in many respects. Consequently, I believe, the word has lost much of its meaning. However, as I have used the word mentor, I want it to be clear that I use this word with the sincerity I believe it deserves. The professors, that I have discussed, have truly mentored me. They have been my templates on how to be a professor and they have demonstrated how I would like to present myself as a scholar. My hope is that I can inspire others as they have inspired me. 
What I know is that I have been very fortunate in my life. I have been surrounded by family, friends, and professors that cared about me. Consequently, I am very aware that my success has been based on the grace of many people. It is to all these people that I wish to thank for traveling with me on this journey. 


\title{
BETWIXT AND BETWEEN: THE PERCEIVED \\ LEGITIMACY OF CAMPUS POLICE
}

\author{
Abstract \\ By James C. Wada, Ph.D. \\ Washington State University
}

August 2007

\section{Chair: Forrest W. Parkay}

Historically, campus police (CP) have evolved similar to "mainstream" police. However, the identity of CP has been unclear. First, CP may not be accepted by university administration because they are "cops," not part of academia. Second, students and other law enforcement agencies may not perceive CP as "cops" because they are based in a university system.

The legitimacy of police officers is crucial for public support and cooperation; without it, a police officer's effort to combat crime and maintain order is jeopardized. Although CP marginalization has been discussed in the literature, there are no empirical studies of CP legitimacy.

To explore the legitimacy of $\mathrm{CP}, \mathrm{CP}$ officers from a doctoral extensive land grant institution were interviewed. The analysis of interviews reflected three salient perceptions of CP: (1) In many instances the community did not regard CP as sworn police officers; (2) the public stereotypes CP; and (3) CP have to "sell" their profession to the public. Overall, the interviews indicated that CP perceive some level of marginalization by the public. 
To confirm the perceptions of CP, a convenience sample of 593 undergraduate students were surveyed. The surveys were used to compare student perceptions of legitimacy between $\mathrm{CP}$ and municipal police (MP) at the department and individual officer levels. Results of the surveys indicated that students have lower perceived levels of legitimacy for CP officers compared to MP officers ( $p=.01)$. Similarly, students have lower perceived levels of legitimacy for the CP department compared to the MP department ( $p=.05)$. Consequently, it appears that the perceptions of CP were justified. Survey results indicated that students do, indeed, perceive CP as a less legitimate law enforcement authority compared to their "mainstream" counterpart.

Victor Turner's theory of liminality was used to explain CP marginalization. Turner describes liminality as a transitional period between two social standings. However, in some instances, a person or group may never transition out of that liminal period. These unfortunate few are consider "permanently" liminal. The analysis of CP interviews and student surveys indicated that CP appear to be "permanently" liminal, trapped in an ambiguous state, "betwixt and between" two social standings. 


\section{TABLE OF CONTENTS}

$\begin{array}{lll}20 & \text { page }\end{array}$

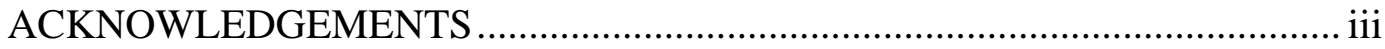

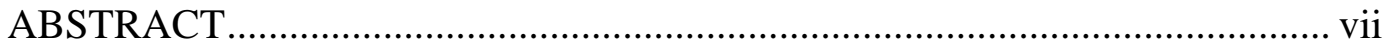

LIST OF

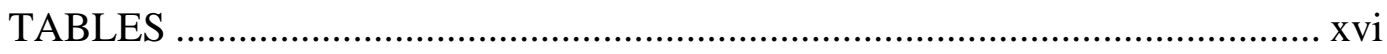

LIST OF

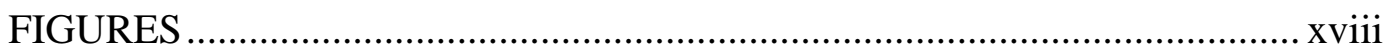

\section{CHAPTER}

1. INTRODUCTION ...................................................................... 1

Purpose of the Study …............................................................

Need for the Study ….............................................................4

Research Questions ............................................................6

Design of the Study..........................................................

Theoretical Framework ...........................................................8

Liminality, the Rites of Passage and Campus Police...........8

Delimitations and Limitations..................................................10

Delimitations ...............................................................10

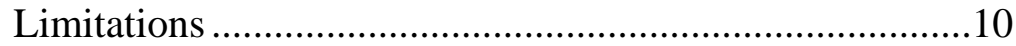

2. REVIEW OF LITERATURE ...................................................12

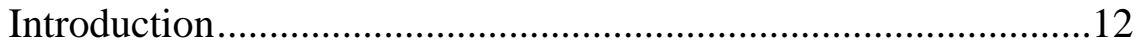

History of American Policing ....................................................12

Pre-modern Policing ..................................................13

Modern Policing.......................................................15 
Political Era of Modern Policing ....................................16

Professional Era of Modern Policing ..............................17

Community Era of Modern Policing................................19

History of Campus Policing.....................................................21

Informal Control of the Student Body .............................21

Yale University Campus Police ......................................22

Watchmen-Janitor and the Watchmen-Guard Eras............23

Campus Pseudo-Police Era ...........................................24

Modern Campus Police Era ...........................................26

The Devolution of In Loco Parentis ...............................27

Professional “Modern” Campus Police ...........................29

Community Oriented Policing and Modern

Campus Police ...............................................................30

The Rites of Passage and the Police Academy ...............................31

The Theory of Liminality and the Rites of Passage ......................35

Pre-liminal Phase and the Rites of Passage ......................36

Liminal Phase and the Rites of Passage ............................36

Post-liminal Phase and the Rites of Passage .....................37

Police Legitimacy, Public Support, and Crime Control ................38

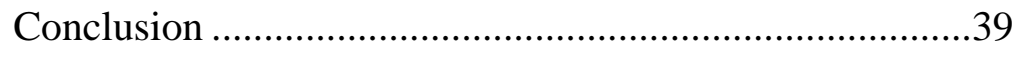

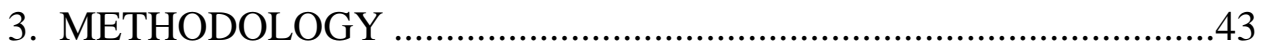

Overview of Methodology .......................................................43

Mixed Method, Two-Phase Design ...........................................44

Selection of Subjects............................................................44 
Washington State University Campus

Police Officer and Pullman Police Officers

Pilot Study Interviews with Washington State

Campus Police

Campus Police Officer Interview Protocols ................................48

Student Survey Protocols .........................................................51

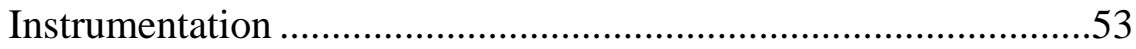

Campus Police Officer Interview Instrument ...................53

Washington State University Student Surveys ...................55

Student Survey Instrument..................................55

Legitimacy Predictor Variables ...........................58

Individual Level Variables..................................59

Contextual Level Variables..................................62

Student Survey Threats ......................................64

Conclusion ...........................................................................66

4. CPO INTERVIEW FINDINGS ................................................68

Introduction.....................................................................68

Interview Questionnaire Development ....................................68

Examination of Salient Themes ......................................69

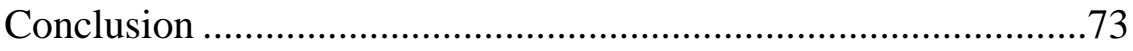

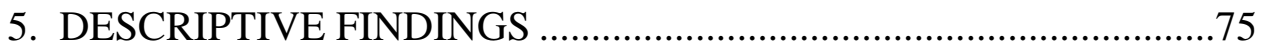

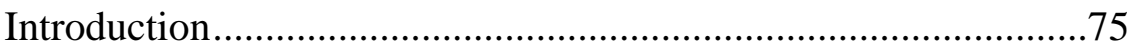

Context of Survey Respondents..............................................75

Survey Respondent Demographics ................................76 
Conclusion

6. SCALE DEVELOPMENT AND BI-VARIATE FINDINGS

Introduction

Legitimacy Scale Development ...............................................99

Assumption Testing of the Dependent Variable...........................91

Factor Analysis of the Legitimacy Scale .........................92

Internal Consistency Checks.........................................95

Means Comparison Between PP and CP:

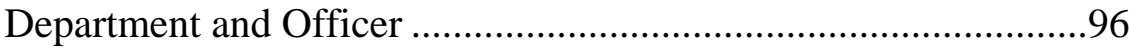

PP/CP Department Means Comparison ...........................96

PP/CP Officer Means Comparison ..................................97

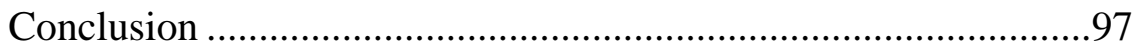

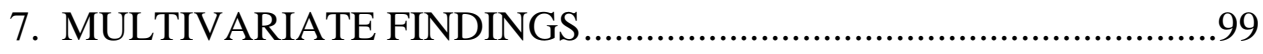

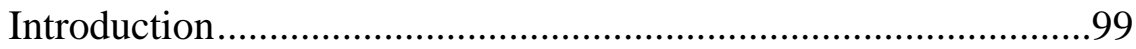

Legitimacy Predictor Variables ..............................................99

Assumptions of Multiple Regression.......................................103

Practical Issues with the PP and CP Data .......................103

Assumption Testing of the PP and CP Data ...................105

Regression Models ..............................................................107

PP Department Legitimacy Multiple

Regression Analysis..................................................107

PP Officer Legitimacy Multiple Regression

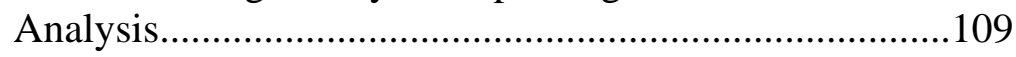

CP Department Legitimacy Multiple

Regression Analysis...................................................111 
CP Officer Legitimacy Multiple Regression

Analysis...........................................................................113

Equality of Regression Coefficient Tests ......................................115

PP and CP Predictor Comparison and Coefficient Testing ..........115

PP and CP Department.....................................................115

PP and CP Officer ……………………………………....116

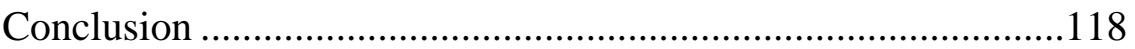

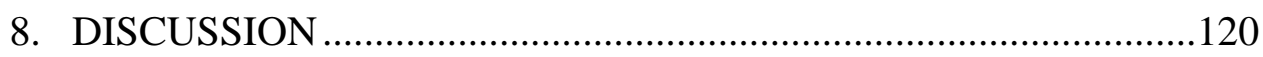

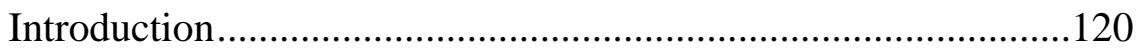

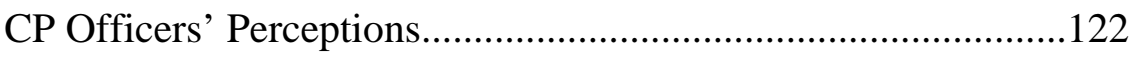

Community Legitimacy Perceptions of PP and CP ......................124

Predictors of PP and CP Legitimacy Perceptions ..........................129

Predictor Variables.............................................................131

Predictors of Legitimacy ..................................................131

PP Department Legitimacy Predictors...............................132

CP Department Legitimacy Predictors ...............................135

PP Officer Legitimacy Predictors .....................................136

CP Officer Legitimacy Predictors.....................................139

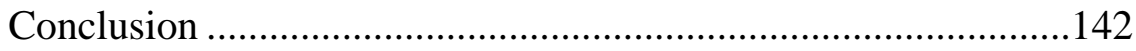

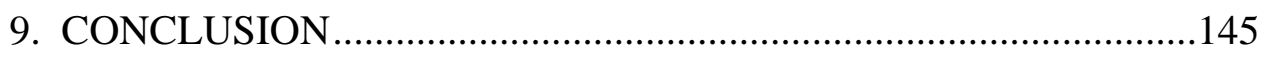

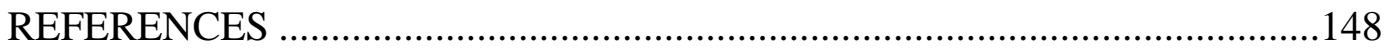


A. INFORMED CONSENT: STUDENT CP SURVEYS .164

B. PERCEPTIONS OF WASHINGTON STATE CAMPUS POLICE SURVEY.

C. INFORMED CONSENT: STUDENT PP SURVEYS .170

D. PERCEPTIONS OF PULLMAN POLICE SURVEY 171

E. INFORMED CONSENT: CAMPUS POLICE INTERVIEWS 176

F. CAMPUS POLICE INTERVIEW QUESTIONS 177

G. HUMAN SUBJECTS APPROVAL .178

H. IDENTIFIED MAJORS 179

I. PPO FACTOR ANALYSIS 181

J. CPO FACTOR ANALYSIS 182

K. T-TEST PP AND CP DEPARTMENT 183

L. T-TEST PP AND CP OFFICER .184

M. COLLINEARITY DIAGNOSTICS 185

N. PP DEPARTMENT NORMAL PROBABILITY PLOT AND RESIDUAL PLOT

O. PP OFFICER NORMAL PROBABILITY PLOT AND RESIDUAL PLOT. .188

P. CP DEPARTMENT NORMAL PROBABILITY PLOT AND RESIDUAL PLOT.

Q. CP OFFICER NORMAL PROBABILITY PLOT AND RESIDUAL PLOT. 190

R. PP DEPARTMENT REGRESSION MODEL SUMMARY 191

S. PP OFFICER REGRESSION MODEL SUMMARY 193

T. CP DEPARTMENT REGRESSION MODEL SUMMARY .196 
U. CP OFFICER REGRESSION MODEL SUMMARY ......................198 


\section{LIST OF TABLES}

\section{page}

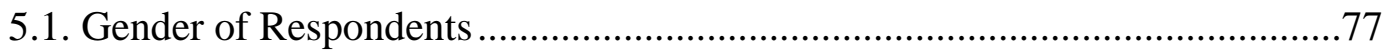

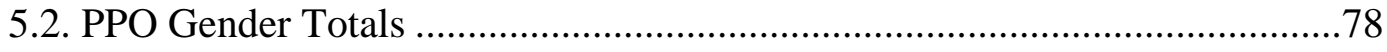

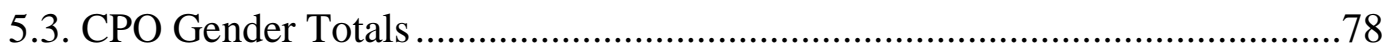

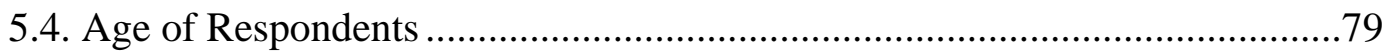

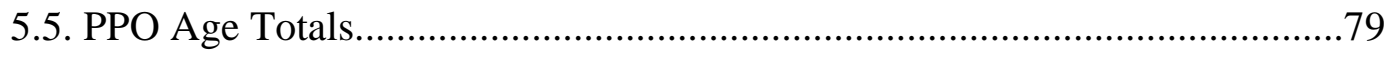

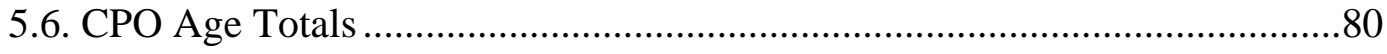

5.7. Total in State, Out of State, or Foreign Students ......................................81

5.8. PPO in State, Out of State, or Foreign Student Totals..................................81

5.9. CPO in State, Out of State, or Foreign Student Totals ................................81

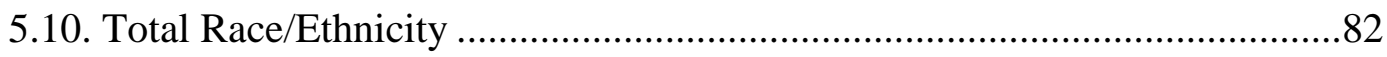

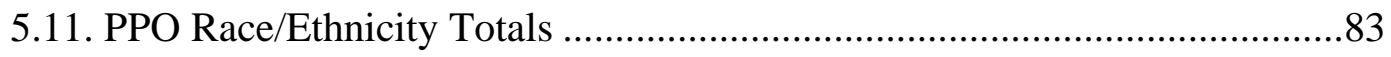

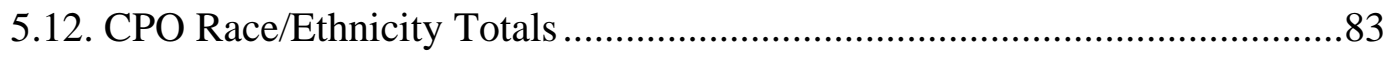

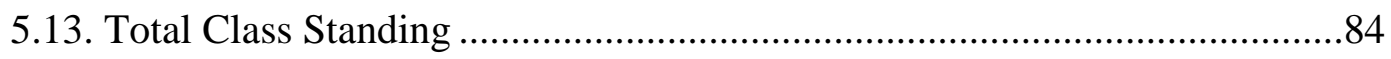

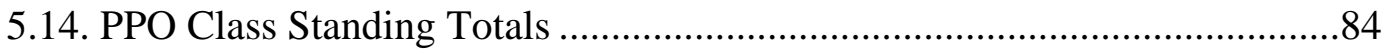

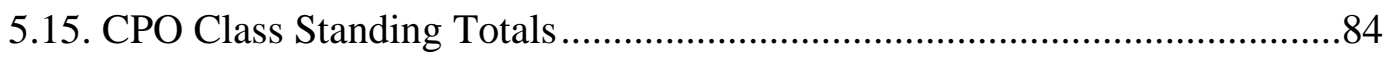

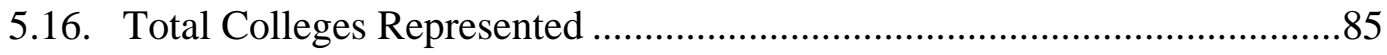

5.17. PPO Colleges Represented Totals .......................................................86

5.18. CPO Colleges Represented Totals .......................................................86

6.1. PP Scale and CP Scale Tests of Normality ............................................91

6.2. PP Rotated Component Matrix ..........................................................92

6.3. CP Rotated Component Matrix..............................................................94 
7.1. Adjective Scale Rotated Component Matrix 102

7.2. Mahalanobis Distances for PP Department and Officer Models ..................106

7.3. Mahalanobis Distances for CP Department and Officer Models..................107

7.4. Coefficients for Model Variables PP Department ......................................109

7.5. Coefficients for Model Variables PP Officer............................................111

7.6. Coefficients for Model Variables CP Department....................................113

7.7. Coefficients for Model Variables CP Officer ............................................114

7.8. Significant Coefficients for Model Variables and Z-Test PP/CP

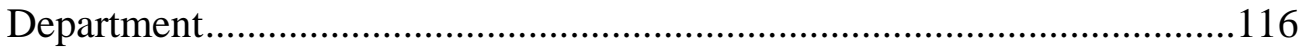

7.9. Significant Coefficients for Model Variables and Z-Test PP/CP

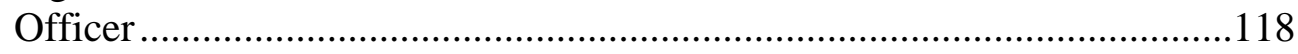

8.1. Do CP and PP attend the same police academy.......................................123

8.2. Significant Coefficients for Model Variables and Z-Test

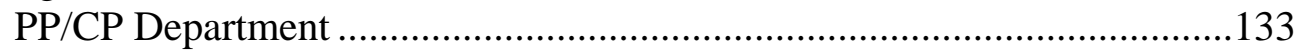

8.3 Significant Coefficients for Model Variables and Z-Test PP/CP Officer. 


\section{LIST OF FIGURES}

page

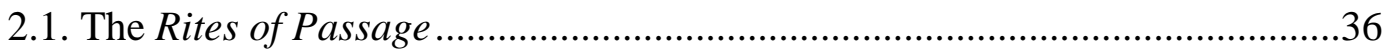

2.2. The Rites of Passage and Marginals ...........................................................38

2.3. Liminality: Municipal Police, Campus Police and the Rites of Passage ........41 


\section{CHAPTER ONE}

\section{INTRODUCTION}

Communities have always attempted to control crime through a variety of responses. Historically, criminality was handled through an informal system. However, as society became more complex, more formal measures of social control were created. It appears that, historically, social control was handled through community predictability. In other words, social control was, in part, a result of the predictability or the homogeneity of the community. As society became more complex, informal social control could no longer regulate this predictability. Thus, a formal system of social control (policing) had to be developed.

It appears that formal structures of policing have been in existence since the 1300s. These structures of policing have evolved juxtaposed to the culture of the state and its citizenry. The early premise of police was to create an agency that would maintain the general security of the state and individuals (Manning, 1997). Consequently, policing has evolved to fit the general needs of the state and community.

Many scholars have argued that the university campus is just a microcosm of the "real” or "outside” world (Bennett-Johnson, 1997). In fact the university campus has been considered to be its own city in many respects. Therefore, many universities have incorporated their own policing system onto their campus. In other words, campus police have evolved to fit the general needs of the university environment.

The role of campus police has evolved in a similar fashion to "mainstream" policing (Paoline \& Sloan, 2003). However, even though both mainstream policing and university policing have evolved similarly, Smith (1988) argues that campus police 
officer’s identity has been obscured. First, Smith argues (1988) that campus police officers are not accepted by university administration because they are "cops," and not part of academia. Conversely, students and other law enforcement agencies do not perceive campus police officers as "cops” because they are based in a university system. The obscured identity has placed campus police officers in an uncertain role. The uncertain identity of campus police officers reflects the perceptions others have of them as police. Based on the ambiguity of their identity, in many instances, CP do not appear to be perceived as "real" cops by the public and, thus, their legitimacy is questioned.

The legitimacy of a police officer is crucial for public support and public cooperation. According to Tyler (2004), without public support and/or public cooperation, a police officer's effort to combat crime and maintain order is jeopardized. Consequently, when legitimacy is diluted, police/citizen contacts become strained. As police/citizen contacts become strained, police effectiveness is destabilized. Consequently, for campus police officers to gain legitimacy or be recognized as "real" cops, their marginalization as police officers first needs to be understood.

From an anthropological perspective, it appears that the marginalization or the lack of legitimacy for campus police officers is related to liminality. As posited by Turner (1987), liminality is a separation between one's previous social position and a new social position that has yet to be confirmed. Liminality is, therefore, a transitional period between two social standings. In one instance, campus police officers have separated themselves from their civilian lives. However, according to Wensyel (1987) and Nichols (1987), their full inculcation into policing is not fully accepted. Consequently, campus police officers are neither perceived as civilians nor police. Campus police are 
somewhere in-between or in a transitional state. This transitional state, as described by Turner (1969, p.95), is “betwixt and between.”

\section{Purpose of the Study}

There are many studies that discuss the perceptions people have of mainstream police (Brown \& Benedict, 2002; Hennigan, Maxson, Sloane, \& Ranney, 2002; Sims, Hooper \& Peterson, 2002; Smith, 2005; Reisig \& Giacomazzi, 1998; Reisig \& StroshineChandek, 2001; Weitzer \& Tuch, 2005). There are also studies that compare and contrast “mainstream” police and campus police (Bromley \& Reaves 1998; Heinsler, Kleinman, \& Stenross, 1990; Hummer, Austin, \& Bumphus, 1998; Paoline \& Sloan, 2003). Furthermore, there are studies on community perceptions of campus police (Pan \& Miller, 1987; Shipman, 1994). However, these studies are relegated to discerning the favorability of campus police in terms of their technical proficiency. What appears to be lacking in the literature is the perceptions of campus police based on their legitimacy. In other words, there are no empirical studies that indicate that campus police officers are not perceived as “real cops” (in terms of legitimacy) as suggested by Smith (1988), Hinkle \& Jones (1991), and Heinsler, Kleiman, \& Stenross (1990).

Furthermore, there are no studies that compare the levels of legitimacy between “mainstream” police and campus police. Consequently, there are no studies that determine if a campus police officer and a “mainstream” police officer's perceived legitimacy levels are different. Therefore, the purpose of this study is to fill a major gap in the campus policing literature. The gap in the literature is the perceived legitimacy gap between "mainstream" police and campus police. There appear to be many studies of 
perceptions of police, crime on campus, and, to a lesser extent campus police. However, the legitimacy perceptions citizens have between “mainstream' police and campus police appear to be non-existent.

Anecdotally, scholars in campus policing maintain that campus police are not identified, under many circumstances, as “real cops” (Heinsler, Kleiman, \& Stenross, 1990; Hinkle \& Jones, 1991; Smith, 1988). However, it does not appear that this identification of campus police has been empirically studied. The identification of campus police officers, in terms of scholarship, as not "real cops" appears to be more of an intuitively based idea. Consequently, citizen perceptions of campus police legitimacy will be investigated.

\section{Need for the Study}

Crime and criminal activity are far less prevalent on college campuses than the outside world (Hensen \& Stone, 1999). However, just because crime and criminality are less prevalent on college campuses than the outside world should not minimize its significance. According to Smith and Fossey (1995), universities have been described as "dangerous places.” The Virginia Tech shooting in Blacksburg, Virginia, April 16, of 2007 is a recent example of the dangerous nature of a university. In the Virginia Tech shootings, student Seung Hui Cho shot and killed 31 students and 1 professor (Johnson, 2007). The Virginia Tech incident is considered the deadliest shooting spree in U.S. history (NBC-2.com, n.d). Although, the Virginia Tech mass shooting may seem like an isolated incident, university shootings have a historical occurrence in higher education. Mass shootings at universities have occurred as far back as 1966, when at the University 
of Texas, Charles Whitman shot and killed 16 people and wounded 31 (MSNBC, n.d). In 1970, four students were killed and nine were wounded by National Guard troops at Kent State University (MSNBC, n.d.). In fact, a major impetus to develop modern campus policing was based on the tragic incidents of Kent State and the University of Texas (Esposito \& Stormer, 1989).

Griffith, Hueston, Wilson, Moyers, and Hart (2004) and Michals and Higgins (1997) argue that large universities have crime problems commensurate with small cities. Bennett-Johnson (1997) asserts that criminal activity that was once endemic to the outside world has now overflowed onto college campuses. Since crime appears to be endemic of our "outside” population, it seems logical that as college matriculation grows, so will the criminal problems that the outside world houses (Gehrand, 2000; Hummer, Austin, \& Bumphus, 1998).

Bennett-Johnson (1997) argues that crime affects the environment in which students learn. In other words, as Keel (2004) suggests, a student's sense of safety and security affects their academic performance. Thus, according to Bordner and Peterson (1983) and Nichols (1987), the university, under many circumstances, has an obligation for the safety of its students. A student cannot grow intellectually, without the proper environment that supports his or her growth. Or simply put, students must feel safe in order to increase their levels of learning. Therefore, as Janosik (2001) and Evans (2001) argue, a university must provide a safe and secure environment for students.

Universities have used campus police to help provide safe and secure environments for students since 1894, when Yale University hired New Haven police officers as full time campus police officers (Bordner \& Peterson, 1983; Ianarelli, 1968; 
Powell, Pander, \& Nielson, 1994; Paoline \& Sloan, 2003; Smith, 1988; Sloan, 1992). In other words, campus police have existed in the university setting to help provide safe and secure environments since the turn of the century. However, as Sloan (1992) and Bromely (2000) assert, academic studies of campus police have largely been disregarded by researchers. Moreover, according to Sloan (1992), what literature does exist on campus police focuses on "practical observations" (p.85). Thus, it could also be argued that the need for this study is to add an academic perspective to the campus policing literature.

Furthermore, according to Tyler (2004), without public support and/or public cooperation, a police officer's effort to combat crime and maintain order will be compromised. As Sunshine and Tyler (2003) argue, police legitimacy is the key factor in maintaining positive public support and cooperation. Consequently, if the goal of the university is to promote a safe and secure environment, it seems essential that the university is aware of the factors that could lead to higher levels of safety and security. Therefore, it could be argued that the primary need for this study is to examine the legitimacy levels of campus police. Once the legitimacy levels of campus police are understood, university administrators would have a better understanding of creating a safe and secure environment, which in turn could facilitate a healthier environment to support student development.

\section{Research Questions}

The following questions were designed to investigate Washington State University Campus Police (CP) Officers’ perceptions as well as WSU students’ 
perceptions of CP officers and how the respondent's age, gender, ethnicity, environment, and police experience contribute to those perceptions.

1. To what extent do CP officers' feel that they are not perceived as "real" police?

2. To what extent is there a perceived legitimacy difference between a CP department and municipal police department?

3. To what extent is there a perceived legitimacy difference between $\mathrm{CP}$ officers and "mainstream" police officers?

4. What selected independent variables returned significant perceived legitimacy levels (for municipal department/officer and CP department/officer)?

\section{Design of the Study}

The study incorporated a mixed-method, two-phase design. Consequently, the study incorporated qualitative and quantitative data as well as phases of data collection. The first phase consisted of qualitative data collection. The qualitative phase of the study was field interviews with CP officers at WSU. The CP officer interviews were used to develop the hypothesis. Asking questions concerning how CP officers felt the public perceives them, uncovered a primary question. In other words, did campus police officers feel that they were perceived as "real cops?”

After the interviews of $\mathrm{CP}$ officers were conducted, surveys were distributed to a convenience sample of WSU students. The two surveys were equally distributed among the sample of students. One survey measured student perceptions of PP officers, while the other survey measured students' perceptions of CP officers. The student surveys provided the quantitative data to test the hypothesis that was developed in the qualitative phase 


\section{Theoretical Framework}

\section{Liminality, the Rites of Passage, and Campus Police}

Victor Turner's theory of liminality will be used as the theoretical framework for the study. In the 1960s, anthropologist Victor Turner expanded on the theory of liminality based on the work of Gennep (Alexander, 1991). Gennep (1960) a German ethnographer and folklorist developed a schema based on a person's passage from one social standing to another. Gennep (1960) described this movement as the rites of passage. Furthermore, Gennep argued that rites of passage could be reduced into three subgroups. These subgroups are: rites of separation, transition rites, and rites of incorporation. The rites of separation suggest that as a person attempts to move to a new social standing, that person must separate himself or herself from his or her original standing. A person's separation from his or her original standing transitions him or her into a subgroup within the rites of passage that Gennep classified as the liminal phase. In the liminal phase a person is neither in his or her old standing nor his or her new standing. The word limen in Latin denotes "threshold” (Turner, 1969, 1987). In other words, liminality connotes a point, in the rites of passage, where the person is on the cusp of change. The final stage of Gennep's rites of passage is rites of incorporation. This passage identifies a point where the person moves out of the liminal stage and reenters the social community with his or her new standing (Gennep, 1960).

While Gennep (1960) argued that after the liminal phase a person reenters the social community with his or her new standing, Turner (1974) argued that in some instances a person may never move out of the liminal phase. In other words, some people may permanently remain in a state of ambiguity they are neither here nor there. Turner 
identified these people as permanent liminals. Furthermore, Turner posited two types of permanent liminals, marginals, and liminars.

According to Turner (1974) marginals and liminars are somewhat similar. Both marginals and liminars are both "betwixt and between" two social standings. However, liminars may voluntarily set themselves apart from the community. However, the liminars will still lose their ambiguity after reintegration.

Marginals, unlike the liminars, may remain in an ambiguous state. In other words, marginals may never be placed in a final social standing. However, marginals will always aspire to become part of that social standing they originally sought.

The work of Turner $(1969,1974$, and 1987) will be applied to CP officers and Pullman Police (PP) officers. It will be shown that both groups (PP and CP) left their original community. Therefore, these recruits separated themselves from their original social standing (a civilian) to become a police officer. The initial phase of separating a person from his or her community has been described as the rites of separation by Gennep (1960).

The recruits entered the police academy with the intention of changing their social standing from a civilian to police officer. The police academy, through the transition rites, placed these recruits into a position where they were neither a civilian nor a police officer. This position is considered a liminal stage or a transitionary period where the recruits are "betwixt and between" (Turner, 1969, 1974, 1987). As the recruits departed from the academy they were be reintegrated back into the community as police officers. This is what Gennep (1960) described as the rites of incorporation. 
It appears that Gennep’s work on rites of passage can be applied to policing. Furthermore, it appears that Gennep’s work on liminatliy can be directly applied to CP officers' legitimacy perception. After the police academy PP officer recruits reenter the community with a new social standing. In other words, newly integrated PP officers lose their civilian status, reenter the community, and are perceived as a legitimate law enforcement authority. Conversely, campus police recruits are reintegrated back into the community with a new social standing, but are not perceived as legitimate as their “mainstream” counterparts. In other words, CP officers exist in a permanent liminal state, where they are neither civilians nor fully accepted as "real cops." They are "betwixt and between.”

\section{Delimitations and Limitations}

\section{$\underline{\text { Delimitations }}$}

The study is limited to making legitimacy comparisons between CP officers and PP officers. Secondly, legitimacy comparisons between CP officers and PP officers only were identified by a convenience sample of undergraduate students at WSU. Finally, only campus police from WSU were interviewed to identify how campus police feel they are perceived by the public.

\section{Limitations}

$\mathrm{CP}$ officers were interviewed concerning what they believe are the perceptions of students. Consequently, the findings in the interviews may only be generalizable to Washington State University Campus Police. 
Secondly, a convenience sampling technique of students was used. The student samples were limited to accessible undergraduate classes. Thus, the generalizability of the student responses may not be indicative of all Washington State University Students. However, as Goodwin (2002) has argued, perceptual studies of undergraduate students are highly generalizable. Thus, although, the convenience sampling technique is a less rigorous sampling method than a random sample, based on the subjects and methodology, the responses should be generalizable to a larger population.

Lastly, Washington State University students were surveyed on their perceptions of only CP officers and PP officers. Because the Washington State University Department of Public Safety (WSUDPS) has a relatively small number of officers (DPS, n.d) and is housed within a rural community (see U.S. Census Bureau, n.d.), it is difficult to determine if those two factors effect WSU students' perceptions of CP officers. Furthermore, because Pullman Police Department is similar in scope to WSUDPS (see PPD, n.d. and U.S. Census Bureau, n.d.) the survey findings may only be generalizable between the two police departments under study. Or put another way, because of the size and location of WSUDPS, perceptions of legitimacy may be different from students at universities with larger campus police departments in urban cities. For example, the University of Washington Police Department employs forty-five sworn officers (Franklin, n.d.) and is housed within the city of Seattle, which is an urban city with a population of over a half million persons (U.S. Census Bureau, n.d.). Consequently, the perceptions of students may be based on other factors that are outside the scope of this study (i.e. university population, city population, crime rates, etc.). 


\section{CHAPTER TWO \\ REVIEW OF THE LITERATURE}

Introduction

It appears that as society became more complex, so did the need for professional law enforcement. Similarly as the university campus became more complex, so did the need for professional campus police officers. Consequently, it appears that campus policing has evolved parallel to "mainstream” policing.

Currently, sworn campus police have the same training and, in most instances, attend the same police academy as any other sworn police officer. However, it appears that in many instances campus police are not recognized as "real” cops. In other words, although all sworn police officers are trained exactly to the same standards, CP officers appear to be perceived as less legitimate than their "mainstream” colleagues.

It appears that liminality can help explain the perceptual dilemma facing campus police. According to Turner (1979) some people or groups that move out of their original social standing never move into the social standing that they once sought. These people or groups are considered somewhere "betwixt and between.”

\section{History of American Policing}

The history of policing in American can be divided into two major categories. The two major categories can be considered pre-modern and modern policing. Reiner (2000) describes these categories as a communal to a state dominated form of policing. It appears that these two evolutions of policing can be attributed to the complexity of society and the values of the community. Although a complete examination of the history 
of American policing is outside the scope of this study, a brief understanding is necessary in order to understand and juxtapose with campus policing.

\section{Pre-modern Policing}

Policing came to the United States with the first settlers (Bayley, 1985). Policing at this time was based on close social relationships. In other words, policing at this time was informal in nature. In other words, people could police themselves without a formal structure of enforcement. What can be identified in the pre-modern time period are the many different forms of informal policing.

It appears that the different forms of informal policing could be attributed to the values of the particular community. In other words, informal policing systems were differentiated by their geographical location and culture they supported (Fosdick, 1921). In the south, the first forms of policing were slave patrols. The Center for Research on Criminal Justice (CRCJ) (1974) reveal that in the early 1700s southern legislative state codes allowed for the formation of slave patrols. The slave patrols were commissioned with the duty to provide slave owners with human property control. The slave patrols could also charge slaves with misdemeanors and felonies. In other words, slave patrols protected slave owner property rights by controlling slaves.

Slave patrols were a group of men on horseback who enforced a specific geographical area. According to the CRCJ (1974), legislatively, all white males were obligated for service in the slave patrols. It was not until the end of the Civil War that slave patrols were disbanded. 
In rural areas in the North and West, it is suggested by the CRCJ (1974) that colonist would police their own by initiating the posse commitatus. The posse commitatus can be literally translated in the "power of the community” (p. 21). The posse commitatus was an armed group of civilians who could be summoned into action by the magistrate.

However, in larger cities, as far back as 1636 night watchmen were incorporated into early colonial policing. Night watchmen were composed of ordinary citizenry who took turns on duty. The duty of a night watchmen was to "watch and guard” (p.59) the city. During the 1800s the night watchmen's duties had expanded to limited patrol or walking a beat. In this time period, the duty of a night watchmen had become a paying job. However, for the most part, most men who undertook the duty of a night watchmen had a primary job in the daytime and worked as night watchmen in the evening. Thus, the duty was not a full time position.

During the $19^{\text {th }}$ century, the complexity of the cities became too difficult for night watchmen alone. One of the primary problems with night watchmen was that their duties were reserved only to night functions. Thus, city problems during the day were largely un-addressed. Consequently, larger cities began to institute a day watch. The first day watch was officially established in Boston in 1838 (Fosdick, 1921). The day watch was intended to add another policing layer to the city. Originally, the day watch was designed to be totally independent of the night watch. Thus, the city's watchmen system was highly fragmented. As can be imagined, two separate policing systems, independent of one another in the same town, were problematic. 
During the mid $19^{\text {th }}$ century many riots broke out in larger cities. What was gleaned from the riots was that the fragmented night and day watch systems could not adequately handle the problems. The lack of organization between night and day watchmen, illustrated the inadequacy of the system. To combat the inadequacy of the day and night watch system, New York, in 1844, passed legislation to combine the day and night watches into one formal unit. This legislation eliminated the night watch and day watch system and created one policing system (Fosdick, 1921). The New York legislation was the framework for modern policing in America. Consequently, it is argued that modern policing grew out of the watch system (Walker, 1977).

What can be identified by the different pre-modern policing systems is a communal form of policing. Slave patrols, the posse commitatus, and night watchmen were volunteers commissioned by their community to help police their own. In other words, a very informal system of policing could be used based on the uncomplicated nature of the society that was being policed. However, as cities became more complex the informal system of policing became strained. Consequently, a formal policing structure was developed.

\section{Modern Policing}

Modern policing can be divided into three general eras: the political era of policing; the professional era; and the community era. The three general eras of policing appear to be based on New York legislation in 1844 that created a formalized full time policing structure. According to Fosdick (1921), the New York legislation is the framework for modern U.S. policing. However, like pre-modern police, modern policing 
cannot be regarded in a univariate sense. Modern policing has also varied based upon the complexity of society and the values of the community. These three variations of modern policing will be discussed.

\section{Political Era of Modern Policing}

The first era of modern policing is largely considered 1840-1920. Many scholars consider this era the political era of policing. In this time period, police agencies were formed through local political offices. Moreover, police officers were appointees of the political party. Consequently, policing was based on political patronage. Policing, therefore, was controlled by separate political entities. The political control, which led to a fragmented system of policing, led to inconsistent police practices (Johnson, 1981). Since the police departments answered to politicians, most police agencies were utilized as the "strong arm" of the political party it represented. Thus, the political era of policing was a time that was satiated with graft and corruption (Vila \& Morris, 2001; Peak, 1993).

Although the political era was satiated with graft and corruption, the police still filled a vital community role. Because police were appointed from their local political districts, they often policed their own neighborhoods. Because they policed their own neighborhoods, they often took care of community problems that no other city agencies would. Thus, policing, at that time, was utilized as a social service activity filling needed community gaps.

The political influences in policing continued until the early $20^{\text {th }}$ century (Sparrow, Moore, \& Kennedy, 1990). However, social reform movements became 
indicative in the early 1900s. Policing was an area that social reform focused upon, which led to the next era of modern policing.

\section{Professional Era of Modern Policing}

The second era of poling is considered the professional era. The professional era had a two-fold purpose (Thurman, Zhao, \& Giacomazzi, 2002). First, reformers wanted to establish policing integrity. Secondly, reformers wanted to professionalize the police.

As discussed earlier, policing in the political era was controlled through the local political machine (Vila \& Morris, 1999). Because police were controlled through the local political machine, corruption and graft were high. Because of the corruption and graft, the public did not view the policing as a legitimate organization.

Reformers, in an effort to combat corruption attempted to remove the influence of politics from the police. As previously discussed, in the political era of policing, police were appointees. Thus, police matriculation was based on political patronage.

Consequently, police matriculation was based solely on their ties to the political party. One of the changes to remove political patronage from policing was the creation of the Civil Service Commission (Fosdick, 1921). Civil service commissions were entities separate from the police agencies. The commissions were responsible for hiring, promoting, disciplining, and firing police officer within their administrative district. Thus, a separate entity had the oversight and control of police human resources. Consequently, the control of police was outside the influence of politics. The Civil Service Commission helped foster police organizational integrity. 
As discussed earlier, the professional era of policing had a two-fold purpose. First, was the removal of politics from police, which would foster organizational integrity. The second purpose of the professional era was to develop professional police. According to Peak (1993) during the professional era of policing, reformers attempted to make the job of policing legitimate through professionalism. Police, in the political era, were appointees. Consequently, a police officer's matriculation was based on party membership. In other words, police matriculation was based solely on party membership rather than policing skills. The professional era of policing supplanted professionalism in policing through a number of policy and paradigm changes.

First, police were given conditions to their private lives. Officers could no longer work in the community they lived; have ordinary conversations with the public; etc. These private life conditions were imposed to create a separation between the police and the public. The separation between the police and the public was used to lower the levels of outside influence and corruption (Vila \& Morris, 1999).

Secondly, police training, technology and standards were implemented. The Civil Service Commissions created standards for police (i.e. physical, educational, etc.). Police became trained in police practices. Technology was supplanted on the profession. For example cars and car radios were being implemented in police departments. The use of science was being applied in criminal investigations (i.e. polygraphs, fingerprints, etc.) (Villa \& Morris, 1999; Peak, 1993).

Lastly and arguably most importantly the professional era of modern policing marked the police as a crime fighter. Historically, in the political era, police had multiple roles and duties. According to Fosdick (1921) and Fogelson (1977), in many instances 
police performed a variety of tasks that were not related to crime control. Many of these tasks were service oriented and under the rubric of social work. Crime control, therefore, was only part of their duties as a police officer. Consequently, based on their multiple duties, police were largely inefficient in fighting crime. The professional era of policing focused the role of police from multiple service-oriented tasks to a strict crime control orthodoxy. In other words, a police officer's sole role, in the professional era, became crime control. Police officers focused on responding to calls and catching criminals (Walker, 1992). Thus, the main duty of a police officer became catching the "bad" guy. By the mid 1940s patronage had been virtually eliminated from policing. Thus, police were outside the control of local political entities, which fostered organizational integrity. Furthermore, police professionalism had been achieved through a strict crime control methodology. Based on the removal of patronage system and crime control efficiency, policing became legitimized. The professional era of policing continued to be the hegemonic model of policing until the 1960s.

\section{Community Era of Modern Policing}

The legitimacy of the police was reexamined in the 1960s. There appear to be two general factors in the 1960s that changed the public's view of the police as a legitimate organization. First, in the 1960s, the crime rates became a national problem (Coles \& Kelling, 1999). This elucidated that the strict crime control methodology was not working. Secondly, in the 1960s, there was a general distrust of the government. The professional era had exacerbated this idea by separating the police from the community. 
These two factors were, arguably, the impetus for the current evolution in American policing, the community era.

The role of crime-fighter, in the professional era, had separated the police from the community. The crime-fighter role had placed a chasm between the police and the community. There became a distinct division between the public and the police. This division resulted in a strained relationship between the police and the public. Scholars (Wilson \& Kelling, 1982; Skolnick \& Bayley, 1986) purported that the police could not control crime without the cooperation of the public. Therefore, public relations became a primary concern for police administrators. In other words, reintroducing police back into the community.

Furthermore, in the professional era, police were focusing on crime that had already occurred. Or put another way, police were reactive in their approach to reducing crime (e.g. responding to calls). Goldstein (1999) argued that police would be more efficient if they were proactive in their attempt to control crime rather than reactive. The concept of public cooperation and proactive policing has been termed communityoriented police (COP).

COP is a very elusive term. In other words, there is not an exact definition. However, in general, COP's primary principle is that police cannot fight crime alone. Crime is a community problem. Thus, the police and the community must become partners to solve problems. According to Goldstein (1990) when the community is involved in problem solving, the police have more reliable access to information that can readily identify problematic variables in the community. Once these community problems are identified, the police can proactively develop solutions to curtail the threat. 
What can be identified in the history of policing are era and evolutions. These era and evolutions appear to be based on the complexity of society and the perceived perceptions of the public. The historical transitions have taken the police from a simple watchmen to a more complex community-oriented police officer.

Campus policing evolutions appear to have followed a similar pathway as "mainstream" policing. As the complexity of society and the perceived perceptions of the public changed, so did the role and nature of campus police.

\section{History of Campus Policing}

According to Brubacher \& Ruby (2004) the period from the colonial college to the civil war were times of "rowdies, riots, and rebellions" (p. 50). Harvard University, the College of New Jersey, the University of Virginia, and, Yale University in the 1700s and 1800s all experienced student rebellions and rioting (Esposito \& Stormer, 1989). In other words, anti-social behaviors have always been present in American universities.

\section{Informal Control of the Student Body}

However, during the times of the colonial colleges, it was university administrators and professors who were given the primary responsibility for detection, apprehension, and punishment of anti-social behavior (Brubacher \& Ruby, 2004; Gelber, 1972). Neil (1980, p. 28) indicates that legal authority to punish students for misdemeanors was given to the administration and faculty in 1965 by the Massachusetts General Court. The university administration and faculty could sanction students with fines or whippings. 
Universities, in this time period, were highly homogenous. The population consisted of young white males. Thus, the control of the student body could be, in general, handled through informal means, such as professors and student review boards (Barr \& Desler, 2000). However, as the informal means became ineffective to manage the student body more formal control structures had to be initiated.

\section{Yale University Campus Police}

In 1894 a major change in campus control was established. Yale University and the town of New Haven, Connecticut were having mass confrontations between the students of Yale and the townspeople. Many of the confrontations ended up with rioting that the New Haven Police had to control. The city administration and Yale University administrators decided to have New Haven Police Officers assigned to the campus. Since, these were city police officers, students became untrusting of their rationale for policing the university. Because students distrusted city police officers, Yale University hired the New Haven Police Officers as full time Yale University Campus Police Officers. Consequently, in 1894, it was Yale University that created the first university police department (Powell, Pander, \& Nielson, 1994; Paoline \& Sloan, 2003; Sloan, Lanier, \& Beer, 2000; Ianarelli, 1968; Smith, 1988; Powell, 1971; Bordner \& Peterson, 1983; Esposito \& Stormer, 1989; Gelber, 1972; Neal, 1980; Powell, 1994; Bromley \& Reaves, 1998; Powell, 1971a). This formalization of campus police, at Yale, appears to be an exception rather than the rule in that time period (Nichols, 1987). It does not appear that the wide spread use of modern campus policing was expressed until the later part of the 1960s (Smith, 1988). 


\section{Watchmen-Janitor and the Watchmen-Guard Eras}

What can be identified pre-1960s modern campus police and post-Yale campus is a watchmen-janitor style campus security to a watchmen-guard style of campus security (Gelber, 1972). Esposito and Stormer (1989) explain that the first type of formalized policing (watchmen-janitor) on university campuses were custodian and maintenance men. It was in the 1920s that watchmen-janitors were drafted from the maintenance and physical plant departments of the university to perform campus security duties (Nichols, 1987). The watchmen-janitors were given no formal training in law enforcement. In fact their duties were not law enforcement duties per se.' Their duties appeared to be more of preventative duties (i.e. checking locks, closing windows, etc.) or basically keeping an “eye” on things (Nichols, 1987). The custodial and maintenance duties were the primary functions of this staff with policing duties as their tertiary responsibility. The security duties of the custodians and maintenance men were primarily property protection. In other words, the policing duties entailed physical plant security. It should be no surprise that, historically, most university security departments were organized under the Office of the Physical Plant.

The next evolution in campus policing is the watchmen-guard era. According to Gelber (1972), it was shortly after World War II that the old style of watchmen-janitor security began to transform. According to Powell et al. (1994) and Sloan (1992) the watchmen-janitor duties later were expanded from protecting college property to enforcing campus rules. Esposito and Stormer (1989) argue that a watchmen-guard style of campus policing was added to campus security when a differentiation was adopted between custodial/maintenance duties and security duties. Moreover, the watchmen- 
guard style of security also focused on student behaviors as well as protecting college property, whereas the watchmen-janitor only focused on property protection. However, the enforcement duties of the watchmen-guard were still rather unsophisticated (i.e. curfew, drinking, parietals, etc).

According to Geller (1972) there is really no singular event that caused the evolution from watchmen-janitor to watchmen-guard campus security. The change appears to be based on multiple events. Gelber (1972) suggested that the multiple events that may have been responsible for the change from a watchmen-janitor to a watchmenguard were based on: larger numbers of student enrollment; more buildings on campus; traffic issues; changes in the nature of crime; university reorganization; and inadequate services provided by outside security contractors. Thus, it appears the there was no single event that changed the watchmen-janitor style of campus security to a watchmen-guard style of campus security. However, the multiple events could be considered changes in complexity of the university. Consequently, it could be argued that as the complexity of the university changed, the need for a more complex type of campus security officer was needed.

\section{Campus Pseudo-Police Era}

According to Smith (1988) with inclusion of the G.I Bill, the "baby boomers," and the specialization of academics led to an unprecedented growth in higher education. As the population of the university increased, it became more parallel to the population of the outside world. The new population began to create new problems on campuses. These problems were more complex than the informal system of watchmen-guard style 
security could manage. It was during the 1950s that many universities began to use retired police officers as campus security in order to deal with the problems associated with university growth. In other words, universities began to see the need for trained law enforcement officers on university campuses. According to Sloan (1992) many campus security agencies moved out of the Physical Plant Department and worked under a different university administration. The move away from physical plant authority was to create a separate identity. The separate identity was to promote security enforcement legitimacy as well as autonomy. Similarly to promote legitimacy, campus security began to organization professional associations. The first professional associations was created in 1953 and known as the Campus Security Associations. This organization was created as a regional agency and later changed its name to the Northeast College and University Security Association. Later in 1958, eleven directors of security in the southwest created the National Association of College and University Traffic and Security Directors. After a name change in 1968, the organization was changed to the International Association of College and University Security Directors (Powell, 1971). However, currently the organization that grew out of the eleven security directors in 1958, is the International Association of Campus Law enforcement administrators (IACLEA, n.d.)

Regardless, of pseudo-police changes at this time, a campus security officer's authority was still limited. Campus police did not have the same official power as “sworn” police officers (Nichols, 1987). Campus police, at this time, were no more than security guards. Their duties of campus security were still custodial. In other words, their policing powers only included: detection, apprehension, and reporting. They had no official power of arrest (Sloan, 1992). 


\section{Modern Campus Police Era}

The 1960s and 1970s is regarded as the era that changed the role of campus security into the modern campus police (Paoline \& Sloan, 1993). The modern campus police can be marked as a time when the university recognized the need for their own “sworn” police officers or campus police officers that had the power of arrest; but were still part of the university culture.

Out of the 1960s and 1970s, brought widespread intentional law breaking in the form of protest. The traditional role of campus security that had been developed in the 1950s was unable to deal with this disorder. Kent State and Jackson State are examples of campus disorder that could not be handled by campus security at that time (Esposito \& Stormer, 1989). Outside policing agencies were brought in to these universities to handle the disorder. In both instances, student protestors were shot by the outside policing agencies.

Many university administrators, at that time, were frustrated with the way in which outside law enforcement was handling disorder on university property. University administrators, at this time, felt that they must take care of their own campus problems or the outside world would do it for them. This was the beginning of the end of the watchmen-guard style of security.

Consequently, with the ineffectiveness of 1950s watchmen-guard style of security and the dissatisfaction of external police, university administrators saw the need for a professional campus police department. As conceptualized by university administrators, a professional campus police unit would have a two-pronged identity. First, campus 
police would consist of highly trained law enforcement officers. Secondly, these officers would be aware and responsive to the needs of the university (Nichols, 1987).

\section{The Devolution of In Loco Parentis}

Furthermore, according to Esposito and Stormer (1989) an impetus for the change in campus security to campus policing occurred when court ruling of Gott v. Berea College 1913 ended based on Dixon v. Alabama Board of Education in 1961. Esposito and Stormer (1989) and Reaves and Goldberg (1995) argue that the adjustment in court rulings moved a student's status from a ward of the state to a student citizen.

According to Melear (2003), in the case Gott v. Berea College 1913, students of Berea College were frequenting a restaurant owned by Gott. The university mandated that Berea Students could not frequent establishments that were off-campus.

Furthermore, the university administration warned any Berea College students that they would be expelled if they frequented an off-campus establishment. Some Berea College students in disobedience went to Gott's restaurant and were eventually dismissed from the university. Gott, the restaurant owner, filed suit claiming that the college's mandate was unjust.

The court ruled that the college was acting in loco parentis of the students. In other words, the university functioned as the parent of the student. Thus, the college had the authority to issue rules and the students were obligated to follow those rules.

As discussed earlier Dixon v. Alabama Board of Education 1961 appears to have ended the Gott decision, which changed the definition of the student. In Gott v. Berea College 1913, the courts determined that the college was acting in loco parentis. 
Therefore, the college administration was acting in the best interest of the student and could circumvent a student's ability to make his or her own decisions. However, in Dixon v. Alabama Board of Education 1961, the courts ruled that state supported institutions must provide students with due process rights when they are being expelled for misconduct (Kaplan \& Lee, 1995).

According to La Roche (2005), in Dixon v. Alabama Board of Education 1961, six Alabama State College students were expelled from the college based on two incidents the university administration found disruptive to the orderly function of the institution. First, African American students tried to be served at an all white lunch counter and a sit in occurred. Secondly, some of the students who tried to be served at the all white lunch counter participated in demonstrations and rallies in different cities. Based on these two incidences, the president of the college found the students' behavior to be disruptive to the university and consequently six Alabama State College students were expelled.

While the lower court upheld the expulsion of the students, the Appeals Court overturned the decision. The Appeals Court ruled that students must be afforded notice and the right to be heard (Kaplan \& Lee, 1995). The Dixon case provided the general standards of student due process.

The Gott and Dixon cases are important to campus policing because it changed the nature of the student and their relationship with police. Based on Gott, a student was considered a ward of the university. Thus, the university administration could impose rules and punishments based on arbitrary measures. The Dixon case gave students the right to due process, which in turn defined the student as a citizen. Because the student 
was now defined as a citizen, the administration had to provide the student with the same rights that were afforded to regular citizens. Therefore, the administration could no longer impose arbitrary rules and punishments. A university's rules and punishments had to be legally appropriate. In other words, rules and punishments became legally formalized. The formalization of rules and punishments created a need for a formalized entity that had the legal power to enforce those rules.

\section{Professional "Modern" Campus Police}

Consequently, it was in the later half of the 1970s that campus policing began to emerge as a professional agency. Professional campus policing involved many changes to the identified roles of antiquated campus security and campus security administrations. Primarily, campus police were granted full police powers in many jurisdictions. As Paoline and Sloan (2003) assert that when campus police were granted full police powers, they received “official legitimacy.” (p. 615). In other words, campus police had the same power as “regular” police (Reaves \& Goldberg, 1995). Consequently, they became more autonomous agencies. They no longer had to rely on outside police entities with arrest powers.

Campus police training also became comparable to "mainstream” police. Campus police attended professional training in the form of the police academy (Sloan, Lanier, \& Beer, 2000). Furthermore, campus police agencies began to create policies and programs that would raise their levels of efficiency and effectiveness (Paoline \& Sloan 2003). 


\section{Community Oriented Policing and Modern Campus Police}

However, because of the nature of the university, campus police are based on prevention and service rather than control or arrest (Bordner \& Peterson, 1983; Nichols, 1987; Esposito \& Stormer, 1989). In other words, campus police must promote an environment that fits the mission of the university -- a conducive place for scholarly learning. As purported by Smith (1988), a campus reputation for safety and security is more valuable than how efficient it is in catching and prosecuting criminal behavior (Smith, 1988). Therefore, according to Bromley (1990) a university’s campus police should be more service oriented and less reactive. The policing framework for service orientation and proactive policing, as discussed earlier, is a policing model referred to as community oriented policing (COP). It appears that COP is the current evolution in campus policing.

As discussed earlier, campus policing has largely paralleled “mainstream” policing (Sloan, Lanier, Beer, 2000). Mainstream policing in the last fifteen years has ideological moved from a traditional policing strategy to a COP strategy. Since COP is a policing strategy that is proactive and community-oriented rather than a traditional reactive form of policing, scholars (Griffith et al., 2004; Sloan et al., 2000) have argued that COP is complementary to the mission of the university. In other words, COP helps create a conducive place for scholarly learning. As purported by Smith (1988), a campus reputation for safety and security is more valuable than how efficient it is in catching and prosecuting criminal behavior (Smith, 1988). Thus, it should be no surprise that COP is rapidly becoming the current trend in contemporary campus policing. 
As suggested by the history of American police, the evolutions of police have been, in general, determined by society and its level of complexity. It, therefore, should not be surprising that campus police have evolved, in part, by the same standards. In other words, campus police have evolved, in part, based on the campus culture and the level of campus complexity.

As discussed in both the history of American policing and history of campus policing sections of this study, as the role of police and campus police evolved, the need for professional training was conceptualized. The professional police training (police academy) would prepare the recruit with the technical knowledge to capably perform his or her duty on the street. While the academy was to prepare a recruit to have the technical skills to prepare them for the street, the academy also appears to have an additional purpose. Scholars (Hopper, 1977; Prokos \& Padovic, 2000; Fielding, 1988; Beck \& Wilson, 1998) argue that the academy is a socializing institution that also creates the character of a police officer. Thus, it could be argued that the academy has a two-fold purpose: to teach the technical knowledge of policing; and to create the character of a police officer. Moreover, the academy is a place where the recruit is no longer a citizen, but has not yet learned the skills and character to be a police officer. Therefore, the recruit is somewhere "betwixt and between."

The Rites of Passage and the Police Academy

Hopper (1977, p. 149) suggests, “On entering the police academy, young men begin one of the most complicated rites of passage in our society. This rite of passage 
consists of the series of instruction, ceremonies, and tests through which their status changes from that of ordinary citizen to that of policeman.”

Furthermore, Hopper (1977) argues that a cadet, in the academy, is not a policeman. Hopper, posits that the a cadet is in an ambiguous state. Hopper likens a cadet between a child and an adult. Thus, for a cadet to move into the role of the police officer, he or she must move out of this ambiguous state. Consequently, to move out of this ambiguous state, recruits must learn to become police officers through academy training.

For a person to become a police officer, according to Prokos and Padavic (2000), he or she must become certified as a police officer by the state sanctioning body ${ }^{1}$. The

\footnotetext{
${ }^{1}$ For example, the Revised Code of Washington (RCW) and Washington Administrative Code (WAC) are presented here:
}

RCW 43.101.200 Law enforcement personnel -- Basic law enforcement training required -Commission to provide.

(1) All law enforcement personnel, except volunteers, and reserve officers whether paid or unpaid, initially employed on or after January 1, 1978, shall engage in basic law enforcement training which complies with standards adopted by the commission pursuant to RCW $\underline{43.101 .080}$. For personnel initially employed before January 1, 1990, such training shall be successfully completed during the first fifteen months of employment of such personnel unless otherwise extended or waived by the commission and shall be requisite to the continuation of such employment. Personnel initially employed on or after January 1, 1990, shall commence basic training during the first six months of employment unless the basic training requirement is otherwise waived or extended by the commission. Successful completion of basic training is requisite to the continuation of employment of such personnel initially employed on or after January 1 , 1990.

(2) Except as otherwise provided in this chapter, the commission shall provide the aforementioned training together with necessary facilities, supplies, materials, and the board and room of noncommuting attendees for seven days per week. Additionally, to the extent funds are provided for this purpose, the commission shall reimburse to participating law enforcement agencies with ten or less full-time commissioned patrol officers the cost of temporary replacement of each officer who is enrolled in basic law enforcement training: PROVIDED, That such reimbursement shall include only the actual cost of temporary replacement not to exceed the total amount of salary and benefits received by the replaced officer during his or her training period.

[1997 с 351 § 13. Prior: 1993 sp.s. с 24 § 920; 1993 sp.s. с 21 § 5; 1989 с 299 § 2; 1977 ex.s. с 212 § 2.]

\section{WAC 139-05-200 Requirement of basic law enforcement training.}

(1) All fully commissioned law enforcement officers of a city, county, or political subdivision of the state of Washington, except volunteers and reserve officers, whether paid or unpaid, and officers of the Washington state patrol, unless otherwise exempted by the commission must, as a condition of continued employment, successfully complete a basic law enforcement academy or an equivalent basic academy sponsored or conducted by the commission. Basic law enforcement training must be commenced within the 
state sanctioning body provides the training for police certification in the form of a police academy. The police academy provides the trainee with a state designed curriculum for police certification. The police academy curriculum, in general, covers three main themes: procedure, policies, and practices (Prokos \& Padavic, 2000; Fielding, 1988). ${ }^{2}$

initial six-month period of law enforcement employment, unless otherwise extended by the commission.

(2) Law enforcement personnel exempted from the requirement of subsection (1) of this section include:

(a) Individuals holding the office of sheriff of any county on September 1, 1979; and

(b) Commissioned personnel:

(i) Whose initial date of full-time, regular and commissioned law enforcement employment within the state of Washington precedes January 1, 1978; or

(ii) Who have received a certificate of completion in accordance with the requirement of subsection of this section, and thereafter have engaged in regular and commissioned law enforcement employment without break or interruption in excess of twenty-four months duration.

(3) Each law enforcement agency of the state of Washington, or any political subdivision thereof, must immediately notify the commission by approved form of each instance where a commissioned officer begins continuing and regular employment with that agency.

(4) Failure to comply with any of the above requirements of basic law enforcement training will result in notification of noncompliance by the commission to:

(a) The individual in noncompliance;

(b) The head of his/her agency; and

(c) Any other agency or individual, as determined by the commission.

WAC 139-05-240 Requirements of basic law enforcement academy. Each recruit in a basic law enforcement academy will receive a certificate of completion only upon full and successful completion of the academy process as prescribed by the commission. The performance of each recruit will be evaluated as follows:

(1) Academic performance. A standardized examination process will be utilized by all basic law enforcement academies sponsored or conducted by the commission in evaluating the level of scholastic achievement of each recruit. Such process will include the application of a designated minimum passing score to each subject area and the availability of a retesting procedure. Failure to achieve the required minimum passing score will result in termination of academy assignment.

(2) Practical skills. A standardized evaluation process will be utilized by all basic law enforcement academies sponsored or conducted by the commission in evaluating the level of practical performance of each recruit. Such process will include the application of pass/fail grading to designated instructional objectives for physical performance and the availability of a retesting procedure. Failure to achieve a final passing grade in each practical skills dimension will preclude a certificate of completion.

(3) Conduct. Failure to maintain an exemplary standard of conduct or to adhere to all rules, regulations, and policies of a basic law enforcement academy sponsored or conducted by the commission may result in termination of academy assignment.

720 six months

${ }^{2}$ Washington Adminstrative Code (WAC):

WAC 139-05-250

Basic law enforcement curriculum. The basic law enforcement curriculum of the commission may include, but not be limited to, the following core subject areas with common threads of communications, community policing, and professional ethics throughout:

(1) Orientation and history of policing; 
Prokos and Padavic (2000), Fielding (1988) and Beck and Wilson (1998) argue that the police academy is the first step for new recruits to be socialized as police officers.

Fielding (1988) and Beck and Wilson (1998) argue that two types of police socialization take place at the academy: formal socialization and informal socialization. The formal socialization is manifested in the academy through curriculum in terms of the policies, procedures, and practices. The curriculum is expected to change the recruits into novice police by supplanting technical knowledge. However, as Prokos and Padavic (2000) and Fielding (1983) point out, technical knowledge is only one aspect of the academy socialization process. An informal socialization also occurs within the academy.

While the formal process of socialization is shaped by the curriculum of the organization, the informal socialization is developed from the culture of the profession itself. Informal socialization is the process by which recruits develop a police character. In other words, the informal socialization process edifies a recruit into who they are and the values they hold. According to Van Maanen (1975), the informal socialization process moulds the attitude of an individual recruit into collective patterns.

Thus, the purpose of the academy is to create a social identity transformation. In other words, the academy is used to change the recruit into a novice police officer. The academy creates a social identity transformation by striping away the old person and

(2) Criminal law;

(3) Criminal procedures;

(4) Patrol procedures;

(5) Crisis intervention;

(6) Emergency vehicle operation course;

(7) Report writing;

(8) Traffic law;

(9) Firearms;

(10) Defensive tactics; and

(11) Criminal Investigation. 
creating a new one. Or put another way, the academy de-socializes and then re-socializes a cadet. According to Fielding (1988), the academy is, at times, unpleasant and difficult. The difficulty and unpleasantness generates an esprit de corp, which in turn helps desocialize and re-socialize the recruits into novice police officers (Harris, 1973). The academy, therefore, is a position between two fixed points with the intent of resocializing a person into something they were not before.

The Theory of Liminality and the Rites of Passage

Gennep (1960, p. 2) argued that life is a series of "passages.” Whether the passage is through age, occupation, or status is irrelevant. The relevancy is that people, in their life course, will progresses through one or more of these passages. Gennep (1960) suggested that the progression is accomplished through the rites of passage.

Gennep reasoned that the rites of passage could be broken down into three distinctive categories: rites of separation, rites of transition, and rites of incorporation (Turner, 1987). Turner (1969) expanded on Gennep’s theory of the rites of passage and critically focused on the subgroup rites of transition, which Gennep also referred to as the liminal phase. Alexander (1979) has argued that the liminal phase is the most important phase in the rites of passage because it is the point at which change occurs.

Turner $(1987,1969)$ has discussed Gennep’s subgroups in the rites of passage as the pre-liminal, liminal, and post-liminal stages. The subgroups, as defined by Turner, appear to emphasize the importance of the liminal period. In other words, the liminal stage appears to be the basis for the rites of passage. The rites of passage, in general, involve three phases of human transition as illustrated in figure 2.1. 


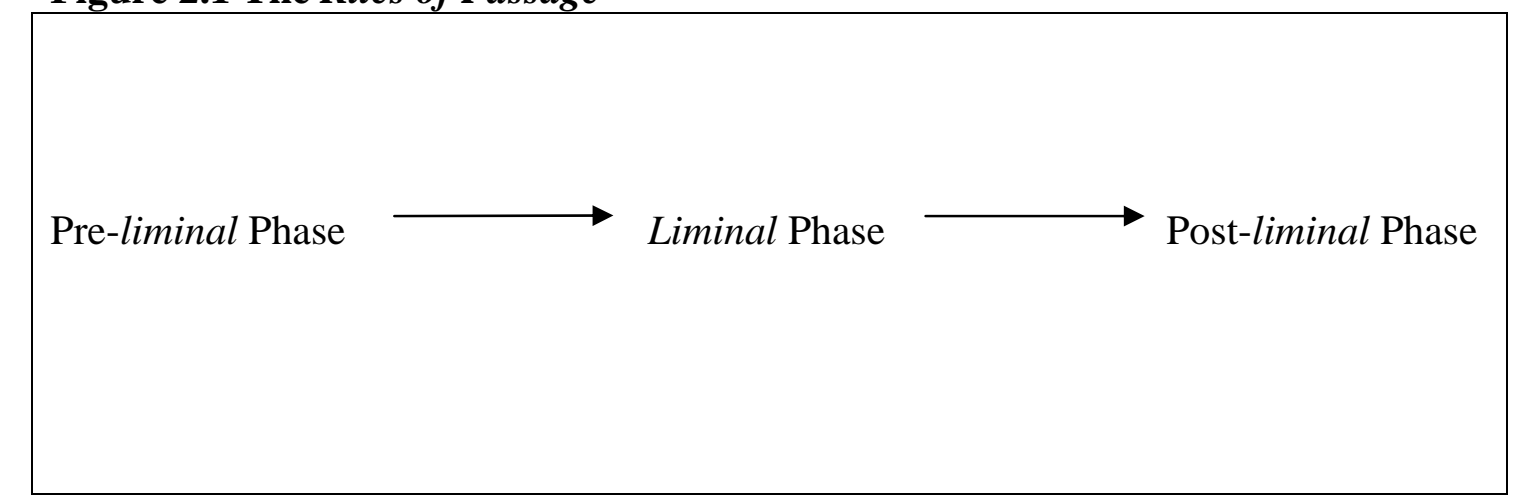

Note: Adopted from Turner (1969), The Ritual Process: Structure and Anti-structure

\section{Pre-liminal Phase and the Rites of Passage}

The first phase, according to Turner $(1987,1969)$ is the pre-liminal phase. In the pre-liminal phase, a person is separated from a social group and/or social structure. Turner (1969) explains that the separation from the group is symbolic in nature that identifies a detachment from a fixed social point. The detachment from a fixed social point elucidates an objective of progression to a new social group and/or social structure. However, before matriculation can occur in the new social group and/or social structure can occur, there is a transition period or the liminal stage.

\section{Liminal Phase and the Rites of Passage}

The liminal stage is fraught with ambiguity. The liminal "passenger" is somewhere in-between the old fixed point, but has not yet achieved his or her new social and/or structural standing (Turner, 1969, p. 94). Therefore, the liminal "passengers” have no identity or standing. Turner $(1974,1987)$ portrays the liminal "passenger” as structurally and socially invisible. The liminal period strips the person of the old and initiates them to their new position in life. The initiation in the liminal phase is a ritual or 
ceremony with the purpose to pass the subject from one social world to another. Liminal "passengers" in the liminal phase have no status. Thus, they are undistinguishable from other liminal "passengers.” Because, the liminals are the undistinguishable from one another and are treated similarly during the liminal process, group homogeneity is developed. Since liminals have no understanding of the new position they seek, they are passive to instruction. They also obey their instructors unconditionally. Turner (1969, p. 95) asserts, "It is though they are being reduced or ground down to a uniform condition to be fashioned anew and endowed with additional powers to enable them to cope with their new situation in life.”

\section{Post-liminal Phase and the Rites of Passage}

After the liminal phase the neophyte enters the third phase of the rites of passage or the post-liminal phase. The subject has detached from his or her old standing, transitioned through the liminal phase, and is re-integrated back into community. The subject is re-integrated into the community with the rights and privileges the new position demands. The subject has moved from social invisibility back to social visibility. In other words, the change is complete (Turner, 1987).

However, a subject does not always progress through the rites of passage implicitly. Turner (1974) argues that a subject does cannot always resolve their ambiguity in the liminal phase. These subjects are marginals as illustrated in figure 2.2. Marginals will aspire to a higher social or structural social group, but culturally may never be seen as a legitimate member of that social or structural group. In other words, 
some liminal passengers may become trapped in the liminal space or permanently

liminal.

Figure 2.2 The Rites of Passage and Marginals

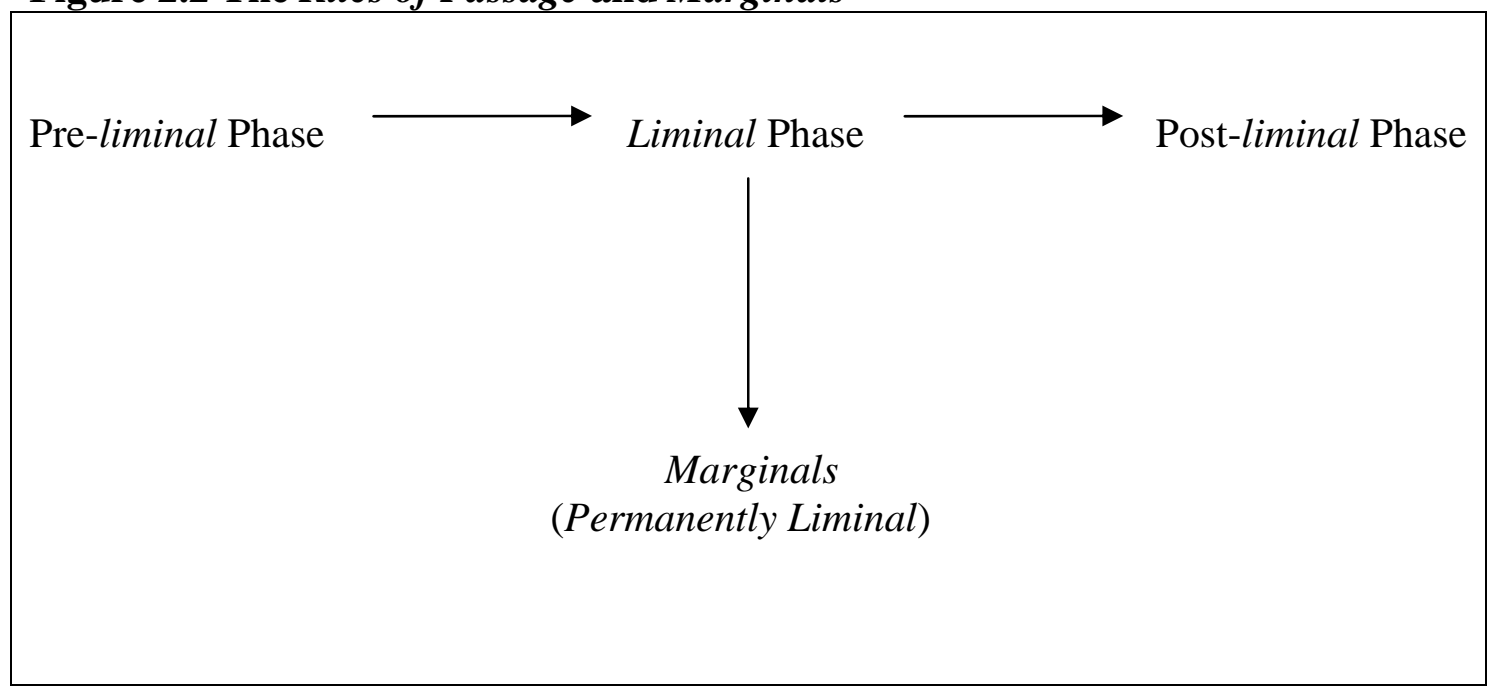

Note: Adopted from Turner (1969), The Ritual Process: Structure and Anti-structure

Police Legitimacy, Public Support, and Crime Control

In the 1800s, Sir Robert Peel, the father of modern policing argued that police could only be effective with public approval. Peel further articulated that police could not control crime without voluntary deference by the public (Gehrand, 2000).

Awerbuck (1999) suggested that there is no such thing as new ideas. Or put another way, the historical assumptions of Peel appear to still be true. In contemporary policing, for higher levels of crime control to exist, the police must have public support and respect. Simply put, the public must perceive the police as a legitimate authority for compliance.

According to Sunshine and Tyler (2003), police legitimacy has an overreaching effect on determining the levels of public's compliance with the law, willingness to cooperate with the police, willingness to assist the police, and empowerment of the 
police. Consequently, if the police can enhance their legitimacy, they can have higher levels of community compliance and trust (Tyler, 2004). Higher levels of compliance and trust will lower the levels of crime while, conversely, lower levels of legitimacy will have the opposite effect.

Brown (2002) suggests that low levels of legitimacy perception can cause civil wide disorder and public distrust. Public district reduces the ability of the police to control crime, since the pubic is less likely to provide the police with crucial community information. Thus, the consequences of lower levels of perception of police legitimacy can increase crime.

Therefore, it needs to be understood that the levels of legitimacy will influence the public's reaction to the police. Police legitimacy is a social value held by the public. Police legitimacy is the social value that precipitates the community feeling that the police and institution of policing are an entitled authority. According to Sunshine and Tyler (2003) and Tyler (2004), if the public sees the police as an entitled authority, the public will be more likely to cooperate with the police. More cooperation with the police will result in lower levels of crime and disorder. Therefore, the social value of police legitimacy becomes a crucial variable for creating safe and secure environments.

\section{Conclusion}

It appears that campus law enforcement followed the same basic patterns as “mainstream” policing. When the community was homogeneous and simple, problem behaviors could, therefore, be handled by the community. In other words, the communities could police themselves. However, as the community became more 
complex, so did the need for more formalized policing structures. As with both "mainstream" police and campus police, their early evolutions were a "watchmen" style of policing. However, as the communities of both the city and university became too complex for the watchmen, a more modern model of policing was created.

One of the factors that modernized the institution of policing was the police academy. In the mid 1960s and 1970s, as universities began to create their own professional police departments, campus police began to be required to attend state sanctioned police academies. In other words, campus police recruits were required to attend the same academy as their mainstream police counterparts. The police academy was created to professionalize the police by teaching technical knowledge to police recruits. However, the academy also formally and informally edifies a recruit into the character of a police officer. Therefore, the academy is the transition period for a recruit to become a police officer.

The academy, theoretically, can be considered the liminal phase of becoming a police officer. A recruit, in the academy is neither a citizen nor a police officer. A recruit, at that point, is ambiguous. The liminal phase and the academy are used to reeducate and re-socialize the person giving them the skills to move to the new social position or structure. Consequently, the ultimate goal of a recruit is to graduate from the academy and thus be reintegrated back into the community with their new status (postliminal phase).

However, it has been acknowledged that liminals "passengers” can get caught in the liminal phase and never move out of it. These liminals are called marginals. A marginal attempts to attain a new social position or status, but can never achieve that 
position or status. It appears that campus police can be considered marginals as illustrated in figure 2.3.

Figure 2.3 Liminality: Municipal Police, Campus Police and the Rites of Passage

Civilians (Pre-liminal Phase - Separating people or things from their usual social setting)

(Post-liminal Phase - New social status

is confirmed and recognized)

Police Academy (Liminal Phase - The period of transition)

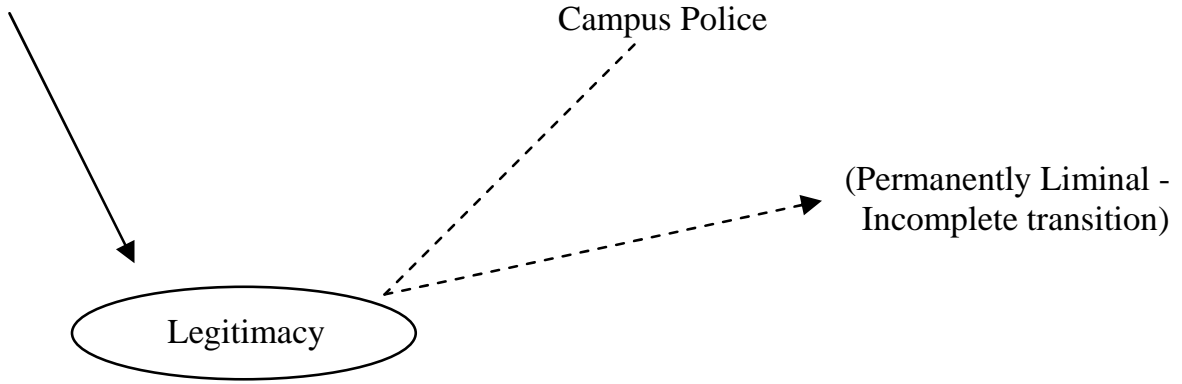

Campus Police

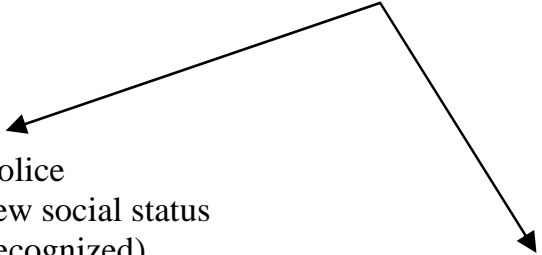

Note: Modification of Turner (1969), Rites of Passage

They leave their original community or status (pre-liminal phase). They attend, in most instances, the same academy as their "mainstream” policing counterparts (liminal phase). However, once out of the academy, campus police officers do not appear to be recognized as "real" police. Thus, they are in a permanent position of liminality, where they want to be recognized as a police officer, but cannot seem to be accepted at that position. Thus, their legitimacy as a "real cop" is questioned (see figure 2.3).

Consequently, marginals, in terms of law enforcement, theoretically are not identified as police. Not being identified as being a police officer causes questions about 
the legitimacy of the position. It has been suggested that when police are not considered legitimate, it is more difficult for the police to capture voluntary compliance from the public. Furthermore, without voluntary compliance, it is more difficult for police to develop collaborative relationships with the community. Voluntary compliance and community collaboration are necessary for higher levels of crime control. Thus, it becomes crucial that a campus police officer's legitimacy is understood if a university desires to promote a safe and secure campus. 


\section{CHAPTER THREE}

\section{METHODOLOGY}

\section{Overview of Methodology}

The purpose of this chapter is to clarify the methodology of this study as well as the rationale for the methodology selected. As discussed earlier, the purpose of this study is to identify the perceptions of CP officers as well as the perceptions of WSU students. To better understand perceptions of campus police, this study used a mixed method, twophase design. In a mixed method two-phase design, two data strings were collected. The first phase was a collection of qualitative data in the form of campus police interviews, while the second phase consisted of quantitative data in the form of student surveys.

According to Gillham (2002), a purely qualitative or quantitative methodology can be methodologically limiting. By incorporating a multi-methodological framework, the limitations of both pure methodologies can be taken into account. Thus, by using multiple methods of research, the limitation of each methodological perspective can be checked by the other methodology. In other words, validity will be increased by studying the same research question from different lenses. According to Cresswell (1994), studying a research question from different standpoints adds to the richness of the study by incorporating multiple sources of information. Studying a single phenomenon from different standpoints is called triangulation. Incorporating triangulation, according to Davis (1994), with its multiplicity of methods, adds more pieces to a puzzle. Thus, validity is increased by creating a balance between the strengths and weaknesses of each pure methodological technique. 
The type of mixed methodology design used for this study incorporated a mixed method, two-phase design. In a mixed method, two-phase design, a staging process occurs. Initially, conclusions were drawn on the first qualitative thread of data gathered. The qualitative thread leads to a hypothesis. The second thread of quantitative data was used to test the hypothesis that was captured by the first data thread (Cresswell, 1994). According to Mertens and McLaughlin (2004), a mixed method approach is a robust tool for hypothesis testing.

\section{Mixed Method, Two-Phase Design}

The mixed method, two-phase design, as suggested earlier, is a methodological approach that, in part, consists of a two-string sequential data collection design. With this study, the first string of data collection was qualitative and consisted of interviews. The qualitative data addressed how CP officers' believed they were perceived by the community. The second string of data collection was quantitative. The quantitative data consisted of WSU students and their perceptions of CP officers and Pullman Police Officers. The purpose of the second phase or survey collection was to test the hypothesis that was identified and developed from the initial interviews.

\section{Selection of Subjects}

\section{Washington State University Campus Police Officer and Pullman Police Officers}

The primary purpose of this study was a comparison of legitimacy between two types of police organizations as perceived by WSU students. The organizations selected were the Washington State University Department of Public Safety and the City of 
Pullman Police Department. The City of Pullman Police Department is what many would consider a "mainstream” police agency. Consequently, the Pullman Police Officers as well as the Pullman Police Department were compared to the WSU campus police officers as well as the WSU Public Safety Department. The Pullman Police Department and WSU Public Safety Department were chosen as comparison departments based on four specific methodological considerations.

First, the two departments have relatively the same number of patrol officers. Pullman has 27 patrol officers (PPD, n.d.), while WSU Public Safety Department has 18 (DPS, n.d.). Secondly, the populations of both the city and the campus are approximately the same. The population of Pullman was 24,675 according to the 2000 census (U.S. Census Bureau, n.d.), while the 2005-2006 university student population was 18,030, with a fulltime staff of approximately 6,000 persons according to the Office of Institutional Research at Washington State University (2007). In other words, there are approximately 24,000 students, staff, and faculty at WSU. Third, the Chief (Weatherly, 2005) of the Pullman Police Department, explained that the Pullman Police Department and the Washington State University Public Safety Department collaborate on enforcement. In other words, PP officers and CP officers are not limited by their community (Pullman or Washington Statue University Campus) jurisdictions. Consequently, both agencies can carry out their enforcement in either the city or the campus jurisdictions.

In 2005, it appears that alcohol and thefts appeared to be the most frequent crime problems on campus, with 186 alcohol arrests and 165 thefts respectively for CP. There were also fifty-five drug arrests, 40 burglaries, 28 simple assaults, 11 motor vehicle 
thefts, two arsons, one weapon arrest, one aggravated assault, one robbery, and seven rapes (Department of Public Safety, n.d.a).

Similarly, in 2005, alcohol and thefts appeared to be the most frequent crime problems off campus with 407 alcohol arrests and 464 simple thefts respectively for PP. There were also 168 DUI and drug arrests, 153 burglaries, 114 simple assaults, three motor vehicle thefts, three arsons, 50 weapon complaints or arrest, two robberies, and ten rapes (Department of Public Safety, n.d.a). Although, PP handle more cases, the types of cases are similar for both departments.

Lastly, both the PP and CP are required to attend the Washington State Criminal Justice Training Commission, or what most would call the police academy (see revised Washington Statute 43.101.200). In other words, both agencies’ officers are commissioned by the same sanctioning body. Consequently, both agencies’ officers attended the same academy and, therefore, have the same basic police training.

Based on these four methodological considerations, it appears that an accurate comparison could be made between a PP officer and a CP officer. According to Shadish, Cook and Campbell (2002), there is a high degree of validity when comparisons are generalizable to persons, settings, and time. Based on the selection of the two departments, it appears that a high level of genralizabiltiy could be concluded. Consequently, validity was high, and the two groups of police being studied were methodologically sound. 
Pilot Study Interviews with Washington State Campus Police

In October of 2005, interviews were conducted with CP officers. The interviews were part of a class study in EdAd 521: Social Foundations of Education at Washington State University. The interviews were used to identify campus police officers’ perceptions of university police work. Five CP officers from Washington State University were interviewed. These officers were asked a series of open-ended questions. The questions were used to identify the officer’s perceptions of university police work and community oriented policing (COP) as a policing strategy. The answers given by the officers were then compared and contrasted to the literature.

Interestingly, a major identifiable theme from the interviews was that $\mathrm{CP}$ officers felt that a large portion of the public does not perceive them as legitimate or "real” police. In fact, as perceived by the CP officers, the public identifies them, in many instances, as nothing more than security guards. Thus, in many instances, their credibility, respectability, and law enforcement legitimacy was questioned. From those initial interviews, the theme of legitimacy became an interesting focal point for study.

In a seminal work by Bordner and Peterson (1985), campus police from an urban university were studied. The urban university studies employed sixty-one campus police officers (p.231) with a student population of 20,333 (p.244). The university was located in a large southern city with a population of two million persons.

The researchers used a mixed methodology. Primarily, campus police observation and interviews were used in order to discover perceptions and attitudes of campus police, while other research methods were used in order to compliment the campus police interviews and observations. Bordner and Peterson (1985) used content 
analysis of university newspapers, departmental documents, and departmental statistical records to compliment the campus police interviews and observations.

Based on the pilot study and the work of Bordner and Peterson (1985), three questions seemed apparent. First, would CP officers' feelings of the public’s perceptions be consistent in later interviews from the pilot study? Secondly, would CP officers' feelings of the public's perceptions be similar to the Bordner and Peterson (1985) study. Lastly, the Bordner and Peterson (1985) study did not identify if CP officers perceptions are consistent with the public. In other words, would the feelings of CP officers be justified? Consequently, the study was developed to determine the levels of congruency between citizen perceptions of $\mathrm{CP}$ and $\mathrm{CP}$ officers' perceptions of how they feel they are identified by the public.

As suggested earlier, five CP officers were interviewed in October of 2005. One of the primary themes uncovered in the interviews was the perceived legitimacy levels of campus police. Consequently, the first string of data collection was a re-test of CP officers' feeling concerning community perceptions. However, the interviews were conducted with a new questionnaire that specifically addresses the theme of legitimacy (see appendix C).

\section{Campus Police Officer Interview Protocols}

As part of a formal study protocol, the study was approved by the Washington State University Institutional Review Board (IRB No. 9214) (see appendix G) and subject participation was voluntary. The target population for the first phase of data collection was CP officers. Since it was not apparent how many CP officers would be willing to be 
interviewed, the researcher incorporated a purposeful and a snowballing sampling technique. In other words, the sampling consisted of choosing "typical” individuals because they represent the archetypal person under study. Thus, any person who was a $\mathrm{CP}$ officer and had patrol duties was considered for the sample population. Once the sample of CP officers were interviewed, generalizable results for the population were expected to emerge.

According to Mertens and McLaughlin (2004, p. 146), "qualitative sampling is relatively flexible." As a general rule in case studies, the $\mathrm{N}$ can be a low as one (Mertens, 1988). However, as with any study, the more cases the more generalizable the results. Consequently, any and all CP officers willing to be interviewed were used in the sample.

Administration of the survey occurred during an officer’s regularly scheduled shift. Furthermore, a meeting with the Chief of Washington State University Department of Public Safety was scheduled on December 5, 2006 before conducting any CP interviews. The meeting with the Chief had a two-fold purpose. First, the meeting was to discuss the nature of the study. Secondly, the meeting was to elicit the approval of the study by the chief.

After discussing the nature of the study, the protocols, and IRB approval, the Chief approved the study and the following week, December 14, 2006 sent out an email to all CP officers. The Chief's email discussed the pilot study that the researcher had conducted a year earlier and that the researcher wanted to conduct more interviews. The Chief also discussed the voluntary nature of the study. The letter ended with the researcher's contact information. The Chief's approval of the study and letter of support to the officer, the researcher felt, would create officer "buy in.” The following day 
(December 15, 2006), the researcher also emailed, on the CP officer list serve, the nature of the study and questions that would be asked of the officers. The researcher also let the officers know that the researcher could interview them at any time and location. The purpose of the follow up letter to the Chief was to add more detail and de-mystify the interview. The researcher received two responses to my emails and set up interviews with those officers on December 18, 2006. After interviewing the two officers that responded to the email, a third officer was asked by one of the participating officers to be interviewed. Consequently, on December 18, 2006, a total of three CP officers were interviewed. The officers who were interviewed suggested that they could ask other officers if they would be willing to be interviewed. Based on the interviewed officers' solicitation, two more officers agreed to be interviewed on December 22, 2006. Unfortunately, no other officers responded to the email or could be solicited into the interview process. On March 14, 2007, a final email was sent out on the CP officer list serve asking if any officers had changed their minds and would consider being interviewed. No officers, based on the final email, agreed to be interviewed. Consequently, a total of five CP officers were interviewed. Since there are $17 \mathrm{CP}$ officers that the chief identified with patrol duties, five interviews resulted in less than a third of the WSU Campus Police Department patrol division being interviewed.

The CP officers were informed prior to the interview the nature of the study $-\mathrm{a}$ dissertation study regarding CP officer legitimacy issues and the number of interview questions. The officers were also provided with the questions. Furthermore, CP officers were re-informed that their chief was aware of the study and gave his consent for the researcher to administer the questionnaire. Initially, the officers were notified that the 
study was voluntary and that they could refuse to participate. Furthermore, officers were notified that even if they agreed to be interviewed, they could stop at anytime and they did not have to answer any question that they felt was uncomfortable. The officers were informed that no names or ranks would be used that could identify an individual officer. The officers were also informed that notes would be taken. However, the notes would not identify an officer by name. Each officer would be identified by a letter (i.e., Officer A, Officer B, etc.). Finally, the officers were asked if the interview could be recorded with a digital voice recorder in order to reduce researcher bias and to preserve the integrity of the officer's answers. However, for any officer who did not wish to be recorded only hand notes would be used to record his or her responses. No officer refused to be recorded. It was at this point that officers were given the opportunity to ask questions concerning the study or protocols.

The CP officers who agreed to participate in the interview were required to sign a Washington State University Internal Review Board Human Subjects Form. The form provided participants with a written description of the study, as well as a waiver form that by signing acknowledged their voluntary participation (see Appendix E). The CP officers were also informed that the information from the interview will be kept strictly confidential and no identifiable characteristics would be addressed in the final write up.

\section{Student Survey Protocols}

The subjects for the survey portion of the study were undergraduate students at WSU. The students surveyed were enrolled at WSU during the fall semester of 2006. Courses surveyed in this phase of the study were: CRMJ 101, section 01 (Introduction 
to Criminal Justice Administration) N=76; CRMJ 365, section 01 (Juvenile Justice and Corrections) N=71; PSCHE 105, section 02, 03, and 04 (Introduction to Psychology) N=215; SPMGT 377, section 01 (Legal Aspect of Sport) N=56: T\&L 402 and 405, section 01 (Instructional Practicum I) N=85; And POLS 101, section 03 (Introduction to Political Science) $\mathrm{N}=86$. The survey protocol was approved by the Washington State University Institutional Review Board (IRB No. 9214) (see Appendix G), and participation was voluntary. Participants were surveyed during their normal regularly scheduled course times.

The method of participant selection was based on a convenience sample of WSU undergraduate students. As discussed earlier, the students were selected from courses at WSU. The courses were chosen based on the researcher's access to them. Consequently, the student selection, for the study, was not random and therefore involved a risk of bias. However, the characteristics of undergraduate students should be, in general, similar (Goodwin, 2002). Therefore, the risk of bias, in terms of undergraduate perceptions, should be reduced.

Wintre, North, and Sugar (2001) have argued that undergraduate students may not be accurate representations of the outside population. For example, university students tend to be from higher socio-economic class and, in general, have higher cognitive skills than their peer groups that do not attend a university. However, Goodwin (2002) explained that perceptual studies are largely unaffected by characteristics of undergraduate students. In other words, in the case of perceptual studies, undergraduate opinions can be generalizable. Furthermore, in terms of this study, perceptions of legitimacy need to be based on the clientele that the campus police serve. Therefore, 
undergraduate perceptions appear to be the foundation for understanding campus police legitimacy levels.

Since the purpose of the study was to determine student perceptions of legitimacy between a PP officer and a CP officer, two surveys were used to capture those legitimacy perceptions. Consequently, the two different surveys were equally administered in each course. For example, in POLS 101, section 03a (Introduction to Political Science), the N was equal to 86 students. Therefore, approximately 43 students received a survey for PP officers, while approximately the other 43 students receive the surveys for CP officers (see Appendices B and D).

\section{Instrumentation}

The following section will describe the three types of instruments used in this study. The first instrument assessed how CP officers felt that they were perceived by the public. The second and third instruments were surveys that determined student perceptions of the Washington State University Department of Public Safety and Pullman City Police Department. The two student surveys were labeled “Perceptual Studies of Pullman Police” and “Perceptual Studies of Washington State University Campus Police.”

\section{Campus Police Officer Interview Instrument}

A questionnaire was administered individually to each of the six or seven CP officers who agree to participate in the interview. The questionnaire incorporated a series of four open-ended questions related to their assessment of students' perceptions of CP 
officers in terms of legitimacy. The first question asked officers if they believe there is a perceived difference between campus police and "mainstream" police. Secondly, the CP officers were asked to give examples that might make light of their beliefs. Third, officers were asked, what may make their occupation appear less legitimate than "mainstream” police? Lastly, officers were asked, what could be done to increase their public perception of legitimacy? (see Appendix F).

The goal of qualitative analysis involves classifying information in order to make sense out of the data that are gathered (Cresswell, 2003). Cresswell (2005) suggests that in order to interpret the qualitative data certain steps must be followed. First, the data must be organized and prepared for analysis. Second, a general sense of the data must be explored. Third, the data must be coded. The coding disaggregates the information into categories. Fourth, once the data are coded into categories they must be further reduced into themes. The themes allow the researcher to further detail the event being studied.

The questions developed for the $\mathrm{CP}$ officer interviews grew out of the researcher's original pilot study. As discussed earlier, the pilot study concerned CP officer perception of Community Oriented Policing. However, once the information was coded and then developed into themes, a theme of legitimacy became a major focal point. Consequently, the interview questions specifically regarding "legitimacy" perceptions were developed from a pilot study. However, once the new questions were administered, the same process for analyzing data, in general, as outlined by Cresswell (2005), was conducted. Information gleaned from the interviews was developed into themes. ${ }^{3}$ The interviews of CP officers completed the first string of data collection,

\footnotetext{
${ }^{3}$ Coding was not conducted, since the actual interview questions were, in general, themes identified from the pilot study.
} 
which identified research questions. Consequently, the second phase of data collection involved surveys of WSU Students in order to test the research questions identified in the first data collection phase.

\section{Washington State University Student Surveys}

The second phase of data collection was surveys taken by students and WSU. While the first phase of data collection was interviews, the second phase consisted of surveys that provided the information necessary to perform quantitative measurements. The quantitative measurements were used to determine if student perceptions are congruent or inconsistent with CP officers' feelings as well as make inferential prediction concerning multiple independent variables.

\section{$\underline{\text { Student Survey Instrument }}$}

The student survey instruments were labeled "Perceptual Studies of Pullman Police Officers" and "Perceptual Studies of Washington State University Campus Police Officers.” The first page of the survey discussed the purpose of the study. The first page also described the confidential nature of the survey. Lastly, the first page allowed the student to indicate: 1). If they do not wish to participate in the survey; 2). If they have already participated in the survey; and 3). If they are under the age of 18 . The first page of the survey, basically, clarified and summarized the IRB consent form as well as indicated why a student would not want to take the survey (see appendices A and C).

The actual survey instrument was divided into six sections. The first section of the survey instrument asked basic demographic questions. While the first section 
respondents were allowed to check their responses, the second section respondents had to write out answers.

The third section of the survey was a modified "police legitimacy scale" developed by Sunshine and Tyler (2003). The scale used nineteen items to identify levels of legitimacy ${ }^{4}$. Sunshine and Tyler's (2003) scale used a five-point Likert scale with a one representing "agree" to a five, which represents "disagree." Questions six, seven, eight, nine, seventeen, eighteen and nineteen were reversed coded. The reverse coding was developed to help alleviate acquiescence bias, which will be explained later in this chapter. The Sunshine and Tyler (2003) legitimacy scale had an alpha reliability of .84. In other words, the items on the survey were valid in their attempt to measure legitimacy. Once the student surveys were completed and analyzed, a factor analysis was conducted and a corresponding alpha rating was recalculated using the researcher's sample population. The factor analysis and recalculated alpha reliability will be discussed in Chapter Six. The Sunshine and Tyler (2003) scale was the basis for calculating the perceived legitimacy levels of PP and CP and was conceptualized as the dependent variable of this project.

The fourth section of the survey was an adjective scale. In this section, students determined their stereotyping level of a CP officer or a PP officer (dependant of the survey) based on eight adjectives. Four adjectives were negative (i.e., aggressive) and four were positive (i.e., helpful). Furthermore, each adjective was measured based on a Likert scale. In other words, the respondents could determine their stereotyping level of an officer based on a seven point Likert scale with a one suggesting that the adjective

\footnotetext{
${ }^{4}$ Legitimacy as operationalized by Sunshine and Tyler (2003, p. 539) is the "perceived obligation to obey the directives of a legal authority, trust in the institution of policing and in individual police officers in one's neighborhood, and affective feelings toward the police."
} 
does "not at all" describe the officer and a high of seven which indicates that the adjective "very much" describes the officer.

The original adjective scale was designed by Hopkins, Hewstone, and Hantzi (1992) and used to identify student stereotyping perceptions toward School Liaison Officers (SLO). The scale that was used for this study is a modified scale of Hopkins et al. (1992) and Jackson (2002) that was used to identify student stereotyping of police officers that are assigned to public schools i.e. student resource officers (SROs) and SLOs. Once the surveys were collected and analyzed, conclusions between student stereotyping of CP and PP based on adjectives, were analyzed determined. As with the Sunshine and Tyler (2003) legitimacy scale, an alpha reliability was conducted to determine how well the adjectives actually measure what they are supposed to be measuring. As with the modified Sunshine and Tyler (2003) scale, the adjective scale's alpha reliability will be discussed in the Chapter Seven. ${ }^{5}$

The fifth section of the student survey asked a series of true or false questions. The true/false section identified student perceptions of police powers for $\mathrm{CP}$ officers or PP officers (dependant of the survey). This section allowed the researcher to make descriptive student perceptual comparisons between a PP officers' and a CP officers' policing powers.

The final section of the surveys asked for "yes" or "no" responses. The primary purpose of section six was to identify contact with police officers. Furthermore, section six was used to determine if police contacts were positive. In other words, did the student feel that the officer treated them fairly during the contact? The information in this

\footnotetext{
${ }^{5}$ The Hopkins, Hewstone, and Hantzi (1992) and the Jackson (2002) adjective scales were not measured for reliability.
} 
section was used to identify police legitimacy perceptions based on contact (positive or negative) with an officer.

\section{Legitimacy Predictor Variables}

Eleven independent variables were chosen based on prior literature from municipal/state police, campus police, as well as CP interviews, in order to identify significant perceived legitimacy levels (Bordner \& Peterson, 1983; Garcia \& Cao, 2005; Griffith et al., 2004; Hopkins et al., 1992; Hurst, Browning, \& Browning, 2000; Miller \& Pan, 1987; Murphy \& Worrall, 1999; Reisig and Giacomazzi, 1999; Reisig \& Parks, 2000; Sloan, 1992; Weitzer \& Tuch, 1997; White and Menke, 1982; Worrall, 1999; Zamble \& Annesley, 1987). These 11 independent variables were: 1) Does the respondent live on campus; 2) Is the respondent a fraternity or sorority member; 3) Is a member of the respondent's family a police officer; 4) Respondent's home city (urban/rural); 5) Respondent’s race/ethnicity; 6) If the respondent had contact with a by a police officer (campus or municipal) was the contact negative (perceived as treated unfairly); 7) If the respondent new someone who had contact with the police (campus or municipal) was the contact negative positive (perceived as treated unfairly); 8) Respondent's gender; 9) Respondent's class standing in college; 10) Respondent’s age; 11) And a positive adjective scale. These independent variables were further reduced into individual level variable and contextual variables. 


\section{Individual Level Variables}

In the current study, the research incorporated family member a police officer; racelethnicity; gender; class standing; age; stereotyping of the police, and if the respondent had contact with a by a police officer (PP or CP dependant of the survey) was the contact negative (perceived as treated unfairly), as the individual level variables.

There does not appear to be studies of family members of police officers in terms of shaping attitudes or perceptions of legitimacy. However, according to Barling, Kelloway, and Bremermann (1991), family socialization influences the development of a child's occupational interests. In fact, according to Barling et al. (1991) children, especially sons tend to follow in the career paths of their fathers. Similarly, Goodman (1957), in a study of values and attitudes of children, argued that boys chose occupations based on the proximity of acquaintances. In other words, in terms of the Goodman (1957, p.12) study, children develop occupational desires based on a "relative’s or friend's occupation." Consequently, it seems likely if a family member of a respondent is a police officer that will increase the likelihood of a positive response.

It appears to be almost unarguable that research tends to indicate that blacks view the police less favorably than whites (Hurst, Browning \& Browning, 2000; Murphy \& Worrall, 1999; Reisig \& Parks, 2000; Weitzer \& Tuch, 1997; Worrall, 1999). Similarly, Hispanics also tend to view the police less favorably than whites (Garcia \& Cao, 2005; Weitzer \& Tuch, 1997). Because the community members under the current project were highly homogenous (see table 5.10), ethnicity was divided into two distinct groups for analysis, white and non-white. 
The effects of gender and police perceptions have been mixed (Brown \& Benedict, 2002). For example, Reisig and Giacomazzi (1999), in a study of perceptions of police in a northwest town of 25,000 residents, found that females view the police more favorably than do men. Similarly, Hopkins et al.'s (1992) study of SLOs in 13 public schools found that girls were more favorable toward police in general and SLOs specifically than males. In contrast, Correia, Reisig, and Lovrich (1996), in a study of citizen perceptions of Washington State Police found that males view the police more favorably that females, while Worrall (1999), from his national telephone survey, found no gender differences in perceptions of police. Although the campus police literature is slight, two studies appear to measure perceptions of campus police. However, the perceptual measurements were in terms of satisfaction with services and effectiveness of service (Griffith et al., 2004; Miller \& Pan, 1987). In the Griffith et al. (2004) study, the researchers surveyed students at West Texas A\&M University on their satisfaction with campus police services. According, to Griffith et al. (2004), gender was the only independent variable (out of age, ethnicity, and gender) to explain the variation in satisfaction. Moreover, it was the female respondents who significantly contributed to higher levels of satisfaction with campus police. Similarly, Miller and Pan (1997), in a study of undergraduate students at Purdue University, found that females have more respect for Purdue campus police officers than did males.

Age has also been shown to be a significant predictor of perceptions of police (Brown \& Benedict, 2002). Police studies have indicated that younger persons are less favorable toward police than older persons (Correia et al. 1996; Reisig \& Giacomazzi, 1998; Worrall, 1999). Conversely, in the Miller and Pan (1997) study of campus police 
at Purdue University, one of the researchers' alternative hypothesis was that undergraduate under the age of twenty-two would have less favorable views toward Purdue University police than older students. However, the findings of the Miller and Pan (1997) study indicated that typical undergraduate students (under 22) at Purdue University had moderately favorable perceptions of campus police. Similarly, Griffith et al. (2004) found that age did not significantly predict satisfaction perceptions of campus police at West Texas A\&M University.

Although, it does not appear that class standing has been studied, in terms of perceptions of police, class standing was added as an independent variable in this project. In a sense, it seems intuitive that a higher class standing would identify, in general, an older student. An older student (higher class standing), in terms of age and police perceptions, should equate to higher levels of favorability (Correia et al. 1996; Reisig \& Giacomazzi, 1998; Worrall, 1999).

An adjective scale developed by Hopkins et al. (1992) was used to identify student stereotyping of SLOs at 13 public schools. The original Hopkins et al. (1992) study incorporated eight adjectives (four positive and four negative) on a 1-7 point Likert scale to determine levels of positive and negative stereotyping of SLOs. Hopkins et al. (1992) explained that the adjective scale was also used to identify students' perceptions of police in general. Consequently, the adjective scale is more than just a measurement of stereotyping. The scale can also be used as an instrument to identify a student's overall perception of the police as well.

The final individual level variable that will be discussed is negative contact with an officer. Wilson (1985) argued that police and citizen interactions are a primary 
element in determining an individual's attitude toward the police. Citizen evaluations are much more positive when a citizen believes a police officer treated him or her fairly (Correia et al. 1996). In other words, satisfaction with the police has been shown to be directly related to personal experience with the police (Brandl, Frank, Worden, \& Bynum, 1994; Reisig \& Correia, 1999; Sims et al., 2002). Similarly, Sloan (1992) found that students who had negative involuntary contacts with campus police (i.e. traffic tickets) were less likely to believe that campus police maintain collegial relationships with students.

\section{Contextual Level Variables}

The first contextual level variable in the current project was, does the respondent live on campus? Although, CP can enforce rules of law both on and off campus, in general, their primary enforcement jurisdiction is located on campus. Thus, any oncampus infractions would, in general, be handled by CP. Contextually, it would seem that where a person resides would determine contact, in general, by the specific police agency (PP or CP). In other words, campus students should, in general, have more contact with CP and off-campus students should have more contact, in general, with PP. As suggested by White and Menke (1982), citizens who have had contact with police appear to have been less favorable views of police. Therefore, theoretically, CP should have less favorable views by on-campus students, while conversely, off campus students should have less favorability of PP. The second contextual level variable was dependent on the respondent's Greek affiliation. Greek Row (the area of the city where the fraternity and sororities are located) has a "targeted" foot patrol in place. Or put 
another way, PP have a mandatory foot patrol (on the weekends) on Greek Row (Weatherly, 2006). Consequently, it would seem that PP will have more contact with Greek members than CP. Similarly, based on the study by White and Menke (1982), Greek members should have less favorability for PP based on police contact.

Third, Zamble and Annesley (1987) theorized that the rural community members would have higher levels of favorable views toward the police than urban community members. Based on the literature, Zamble and Annesley (1987) conducted a study comparing attitudes of rural community members' (population of less than 100,000) between urban community members (population of several million) view of police. The results of the study indicated that rural community members had more positive attitudes toward local police as well as a more positive global perspective of police than did urban community members.

The final contextual level variable in the current project was dependent if the respondent knew someone who had contact with the police (campus or municipal) and the contact was negative (perceived as treated unfairly)? According to Repenning, Powell, Doane, and Dunkle (2001, p.4), an individual's social reality is gathered from four sources: personal experience; significant others, social groups and institutions; and mass media. Significant others, and social groups and institutions appears to inculcate a person's social reality. Social reality is a process where a person formulates opinions from second hand knowledge. Lederman, Lederman, and Kully (2004) similarly argue that social reality can ultimately form an individual's perception of truth. Davis (1990) in a study of attitudes of police discovered that respondents indicated lower levels of favorability of police, when a family member was perceived to be treated negatively 
during an arrest. Similarly, Rosenbaum, Schuck, Costello, Hawkins, and Ring (2005) found that direct contact with police does not shape attitudinal perceptions, in general, regardless of the perceived experience. However, Rosenbaum et al. (2005) discovered that vicarious beliefs significantly contribute to attitudinal perceptions of police both positive and negative.

\section{Student Survey Threats}

There appeared to be two main threats to the survey research. The first threat would be caused when the respondent would respond in socially desirable ways. In other words, the respondent would answer the questions the way he or she believed were socially correct or would answer the questions the way he or she believed the researcher wanted. Consequently, the respondent would not answer the questions with his or her true opinions. The threat of social desirability was controlled with a variety of methodological considerations. First, social desirability was controlled by discussing the anonymity of the survey. In other words, the researcher discussed the private nature of the survey in that no names were attached to the survey. Therefore, the respondents were able to answer the questions truthfully, since they were certain that their names could not be applied to any particular survey. Secondly, respondents were briefed on the how to take the survey. The respondents were instructed that the survey was an opinion survey in that there were no wrong or right answers. The briefing gave the respondents the confidence to answer the survey with their true opinions.

The second threat to the survey was acquiescence bias. Acquiescence bias is when a respondent anticipates the answers to the survey questions. In other words, there 
is a tendency for the respondent to agree with particular statements. Acquiescence bias is more susceptible to surveys with questions that are logically formulated. To account for acquiescence bias, questions in the "legitimacy" scale section were reversed coded. In other words, the "legitimacy" scale in both "A" and "B" surveys did not follow a linear pattern of response. Consequently, the respondents were not able to anticipate an answer to a particular question. Likewise, the adjective scale was also developed with reverse coding. Consequently, stereotyped levels of responses could not be patterned. The respondent, therefore, had to read each question carefully and critically examine his or her response. Lastly, independent samples were used in order to control for acquiescence bias. Independent samples are samples that are totally independent of one another (Coladarci, Cobb, Minimum, \& Clarke, 2004). Or put another way, samples are independent when observation in one group is in no way related to observations in another group. This assumes that one sample does not effect the selections of the other sample. For example, in this study, each respondent only answered one survey, either a CP officer or a PP officer. Therefore, each respondent's survey was independent of another survey.

The researcher could have performed dependant sampling. In dependant sampling, the samples are not independent of one another. In other words, only one sample is used to make comparison (i.e., treatment and control groups or pre and post tests) (Bachman \& Paternoster, 1997). Consequently, the researcher could have given both instruments (PPO and CPO surveys) to each respondent. Giving each survey to each respondent would have been a dependant sampling methodology. In this instance, a measure would be identified to determine the legitimacy levels an individual perceive 
between CP officers and PP officers. However, if both surveys were given to an individual respondent, the respondent may have tacitly understood that the surveys were being used to measure a difference between the two organizations. Becoming cognizant that the surveys were trying to measure differences or similarities between a CP officers and a PP officer may have caused the respondent to respond differently. To control for respondent bias, it appeared more appropriate to conduct independent samples or one survey per respondent. Consequently, with only one survey, the respondents would not be able to make any conclusion about the nature of the survey and respond appropriately.

\section{Conclusion}

This study utilized a mixed methodology design. A mixed method design according to Merten and McLaughlin (2004) is not just a simple conjoining of qualitative and quantitative data. A mixed methodology is a complex way of looking at a single phenomenon. Looking a single phenomenon in a complex way strengthens that understanding (Toseland, 1994). In other words, a mixed methodology can create more credibility on a single subject based on the multiple sources of information (Harrison, 1994; Sherman \& Strang, 2004). Mixed methodology combines a story with numbers, which adds a holistic dimension to research (Sherman \& Strang, 2004).

The methodology in this study incorporated a mixed method, two-phase design. This design allowed the researcher to first gather qualitative data in the form of interviews. The interview data developed a hypothesis for the study, which was the basis of the dependent variable. Secondly, quantitative data were collected in the form of 
student surveys. The survey data tested the hypothesis that emerged from the qualitative data string.

In the study design, CP officers were interviewed on a series of questions developed from an earlier pilot study and the work of Bordner and Peterson (1985). The primary objective of the CP officer interviews was to develop a working hypothesis. As discussed earlier, an earlier interview of CP officers suggested that they, in many instances, were not perceived as legitimate by the public. It is the absence or presence of a perceived legitimacy difference that the interviews were examining. Secondly, a student survey was given to selected student at WSU. WSU students are, arguably, a CP officer's and a PP officer's primary clientele. Consequently, student surveys were the quantitative measurement that tested the hypothesis gathered from the first data string. It is the extent of the perceived legitimacy difference and the factors associated with the difference that the quantitative phase of this study tried to capture. 


\section{CHAPTER FOUR \\ CPO INTERVIEW FINDINGS}

Introduction

The purpose of Chapter Four is to discuss the findings in the first phase of this project. Since the study incorporated a mixed-methodology, two types of data were collected. Because of the diversity in the types of data collected, each will be discussed separately. Consequently, Chapter Four will only present the findings from the qualitative data obtained from the $\mathrm{CP}$ officer interviews. The findings for Chapter Four provided the information necessary to answer the first research question, to what extent do CP officers' feel that they are not perceived as "real” police?

\section{Interview Questionnaire Development}

As discussed earlier, the interview questions were constructed based on two earlier studies - first, a pilot study that the researcher conducted in 2005 to determine the perceptions of COP by CP officers at WSU. Although, the pilot study was to determine perceptions of COP by CP officers, interviews revealed a legitimacy perception that appeared to require further investigation. Secondly, because the pilot study identified legitimacy issues, it was necessary to develop legitimacy questions for further study. Bordner and Peterson (1983) conducted a study to understand, describe, and compare campus police to municipal departments. As part of the Bordner and Peterson (1983) study, the researchers interviewed campus police officers from a large metropolitan university. One salient theme that was discovered from the campus police 
interviews was the officers' belief that they were seen as something less than sworn law enforcement agents.

Based on the finding from the earlier pilot study and the Bordner and Peterson (1983) study, specific questions were developed in order to identify themes, The themes were based on campus police officers' opinions on the extent to which CP officers believed they were perceived by the public as well as efforts that can be incorporated in their profession in order to identify and overcome the marginalization the officers encounter from the public.

\section{Examination of Salient Themes}

Although the Bordner and Peterson (1983) study was conducted almost twentyfive years ago, it appears that perceptions of campus police (in terms of how they believe they are perceived by the public) have changed very little over a quarter century. One of the major themes identified from the current interviews and literature (Bordner \& Peterson, 1983) follows: In many instances the community did not regard campus police as sworn police officers.

Officers interviewed from the Bordner and Peterson (1983) study argued that:

"Students and faculty just think of us as security. It is really disappointing that most people don't think even think of us as 'real pigs'”(p. 135).

"People think of us as high class security or counterfeit police. While our image has improved since we became a police department, most people don't think of us as real police. They look down on us and don't give us the same respect or perks” (p. 135).

"Nine tenths of the community think of us as security. They think we don't do anything and they look down on us and show us no respect. They think we are inadequate just because they think of us as security and not police" (p, 66). 
Similarly, the findings from the CP officers' interviews at WSU almost mirrored the

feeling and perceptions of the Bordner and Peterson (1983) interviews twenty-five years

previous:

"I do see a little bit of difference in what the public perceptions is. I am not sure why it is occurring, but I think it is just something that... a lot of people, I just don't think they even realize for whatever reason whether it be television shows or whatever, they just think that if you are on campus it is just going to be campus security” (CPO, A).

"I think that new students that are out of the area that don't know us at all, they sometimes question what your authority is, what your jurisdiction is, and what your job is" (CPO, B)?

"I think you are always going to have a difference perception of how campus law enforcement is viewed anyway. You hear time and time again campus cop or campus security. So you are always going to carry around that stigma” (CPO, C).

"Just the other day I wrote a ticket for speeding, I believe, and he asked me, 'well is this a real ticket, is this through the university?' Last year I ran into some gang bangers and they are like, 'Are you guys security or real cops or what do you guys do or stuff like that'” (CPO, D).

"But many who don't have a college or university near by that have its own police department. They will just say, 'can you arrest people?' or 'Do you go through the academy?' You get this whole list of questions. And it is just something that you are used to being a university cop. Expect the questions and then give them the answer" (CPO, B).

"I have had parents, I've had students, and I have had other officers refer to us as campus security. And then when you have to correct them, by enlarge you end up going over their head" (CPO, C).

“[W]hen people think of a university they just don't think of a police department. I used to be that way. There are still some universities out there that when I hear they have a police department and I think 'really.' And I am a campus cop” (CPO, D).

"Every once and a while now and then a parent from a student or someone from the east coast or something like that. They'll call "are you campus security?” And I usually just say no and say that I am actually a police officer. Sometime they understand that and sometimes they don't" (CPO, E). 
More interesting, the CP officers from WSU also identified being marginalized from their own "mainstream” colleagues. In other words, other cops (municipal) did not recognize or give $\mathrm{CP}$ the respect of being a sworn law enforcement agent.

“The cops are you know, I shouldn't say you get a sense of distain, but you are viewed as differently, as nothing more than a glorified babysitter in a lot respect” $(\mathrm{CPO}, \mathrm{C})$.

"I think even among police officers there is a stigma about campus police officers, 'Oh there not real cops'” (CPO, D).

"[T]he funny thing is that when I contact fellow officers, sometimes they are not aware of who we are and what we do" (CPO, E).

A second theme that developed from the interviews and the Bordner and Peterson (1983) study was: The public's stereotyping of campus police.

One of the respondents of the Bordner and Peterson (1983) study argued that:

"We have to establish who we are four times a year and that's hard. A lot of people misunderstand who we are and what we are here for. They think of us as security servants. Every three months a new batch of people come in here and we have to teach that new batch what we are all about. City police don't have this problem. In the city community already knows who you are and what you can do - they grow up knowing what your function is and what your power are" $(p, 66)$.

CP officers at WSU also argued the difficulty of the community misunderstanding who

they are:

"Well, most of the people we deal with are college students 18-19 years old. They just got out of highs school and they show up on college campus. I think a lot just don't realize that there is a police department here. It could be one reason. I think they just don't realize that a college would have police officers that an actual police officer shows up. I think a lot of them are just under the impression -- campus security and not an officer. Maybe... I think there is a lot of confusion. Some colleges only have security and other have police. I think that is where the confusion comes from" (CPO, A). 
"But as far as other people who coming to the university they might questions whether we are real police or not, because some universities just have security others have police department” (CPO, D).

"There are a lot of university that just have security guards and that is usually what people expect. They don't expect university to actually have a police department” (CPO, D).

"If they have not been socialized to this kind of environment they might be kind of ignorant. [I] agree probably that incoming freshman may not realize who we are and what we do but I think that come to that realization pretty quickly” (CPO, E).

"Perhaps when they went to college they maybe did not have a police force on college or if they did go to college they had a cougar security type thing, where these people are unarmed. I know the are a lot of university that still keep unarmed campus security and check doors" (CPO, E).

"Again. The fact that they just do not know. They just don't know" $(\mathrm{CPO}, \mathrm{B})$

The final theme developed from the CP interviews and the Bordner and Peterson (1983)

study was the idea of: Campus police having to sell their profession to the public.

"Most of the community thinks of us as security they tend to look down on us unless they have had contact with us. When they have contact they think better of us" (p, 70).

CP officers at WSU also argued the importance of having to indoctrinate a new group of students and/or community members each year to the functions, roles, and duties of a campus police officer, something a municipal police would not have to do.

"I think we have to educate our citizens whether it be student or faculty and staff that works here on campus. I am not sure really how we would do that. But anything that we could do to expose faculty, staff, and students to the police department and to let them know what we offer what we do day-to-day on a daily basis” (CPO, A).

"A lot of the times I give alcohol awareness programs to the freshman that come to school. I will start out sometimes saying this is who we are. Yes, 
we are fully commissioned. We all went to the academy. I know some of the Pullman officers do that as well and they give programs talking about the WSU police department. Put it out in the media. Anytime we do public education programs specify what we do. And also public recognition from other departments would be a big help” (CPO, D).

"I think just talking to other departments and explain what we do really breaks down the stigma" (CPO, D).

"Well I am not sure that there is anything that will help increase other than the police here being proactive and go out there and make social contacts. People will realize after they talk to you that okay this guy is cop and not campus security" (CPO, E).

“They just don't know. Part of their incoming education when they first get here is through student affairs and through alive. They let them know. They tell them. This is campus police service. This is what they do. We try to have one of our COP officers there during part of this training to give some of that orientation and let them know things, like, here we are these are the type of incidents that campus police officer are involved in. If you are contacted by campus police, this is what you should expect" (CPO, B).

"People will realize after they talk to you that "okay" this guy is cop and not campus security” (CPO, E).

\section{Conclusion}

A previous pilot study conducted on CP officers at WSU in 2005 uncovered a feeling of marginalization. Similarly, a study by Bordner and Peterson (1983) also identified a feeling of marginalization by CP officers at a metropolitan university. Based on the Border and Peterson (1983) study and the 2005 pilot study conducted by the researcher, the understanding of CP officers' feelings of marginalization appeared to need further research. Consequently, interviews were conducted on CP at WSU. The interview questions were developed and refined from the earlier pilot study and the work of Bordner and Peterson (1983). 
Three themes were identified. First, based on the interviews, CP officers have different levels of feeling marginalized by the public. However, it was clear that the perception of marginalization was present. It was the extent of that perception that varied. Secondly, it appeared that marginalization was based on a "security guard" perception from the public. In other words, $\mathrm{CP}$ officers felt that the uniformed public identifies them with security guards rather than sworn law enforcement officers. Lastly, it appears that CP officers must always "sell" their profession to the public and their "mainstream" law enforcement colleagues. It appears that CP officers must, in performance of their duty, clarify and justify their law enforcement authority in terms of who they are and what they can do.

So, in fact, it appears that CP officers have a feeling (although differing levels) of marginalization from the public. In other words, it appears that $\mathrm{CP}$ officers often feel that the public does not identify them as "real" police.

However, identification of CP officers' feelings was only the first part of this project. The primary portion of the project was to determine if CP officers' feelings regarding community perceptions were realistic. In other words, do the perceptions of $\mathrm{CP}$ officers match the actual perceptions of the community? Consequently, while the purpose of chapter four was to identify the qualitative findings from the campus police interviews, the following chapters will use statistical methods to test the findings identified from the CP interviews. 


\title{
CHAPTER 5
}

\section{DESCRIPTIVE STATISTICS}

\author{
Introduction
}

As discussed in Chapter Four, surveys were administered to students at WSU. The surveys were used to identify students' perception of PP officers or CP officers as well as the demographic characteristics of the respondents. The surveys were distributed in undergraduate classes based on a convenience sample. Once the surveys were returned and evaluated, the demographics of the respondents were identified. The survey demographics were compared to the WSU undergraduate student population as well as between the PPO survey and the CPO survey. Demographics were evaluated to determine the extent of the generalizability between the samples and the population.

\section{Context of the Survey Respondents}

Washington State University is a doctoral extensive land grant institution with the main campus located on the east side of Washington state in the city of Pullman Washington. Washington State University has three branch campuses, which are located in Spokane, the Tri-Cities and Vancouver, Washington. The university was founded in Pullman, Washington in 1890. The university’s first name was Washington Agricultural College and Schools of Science. Later in 1905, the university changed its name to the State College of Washington, and in 1959 the name was changed again to it current title or Washington State University (About WSU, n.d.). Today, the university houses ten colleges and a graduate school with over 150 majors offered (About WSU, n.d.a). 
The Pullman core campus incorporates 620 acres, while total university acreage (branch campuses) is 1,875 (Future Students, n.d.). In 2006 the university enrolled 23,655 part-time and full-time students. Of the 23,655 full-time and part-time students 19,554 were undergraduates. Of the 19,554 part-time and full-time undergraduate students 9,402 were male, while 10,152 were female. Males accounted for $48 \%$ of the full and part-time undergraduate students, while females accounted for the remaining 52\% of the total population (Enrollment and Persistence, n.d.). The average age for undergraduate students at the Pullman campus was twenty-three (About WSU, n.d.b). Three thousand nine-hundred and seven students were from out of state or $16.68 \%$ of the total student population (Future Students, n.d.). In terms of racial/ethnic categories for full-time and part-time undergraduate students, 532 were nonresident aliens or $2.7 \%$ of the total population. Blacks, non-Hispanics accounted for $2.56 \%$ of the total student population or a raw total of 501 students. American Indians and/or Alaska natives accounted for $1.24 \%$ of the total population or a raw number of 243 students. There were 1,190 Asian and/or Pacific Islanders attending WSU or $6.1 \%$ of the total student population. In 2006 there were 825 Hispanics or $4.2 \%$ of the total undergraduate student population. 1,603 undergraduates did not self-report race/ethnicity or $8.2 \%$ of the total student population. Finally, white, non-Hispanics accounted for the highest total student population of undergraduate with 14,660 or $74.97 \%$ of the total undergraduate population (Enrollment and Persistence, n.d.).

As discussed in the methods section of this project, two student surveys were administered to undergraduate students in multiple classes within the main campus in Pullman, Washington. One survey measured student perceptions of CP, while the other 
survey measured student perception of PP. The two different surveys were equally divided between each class. In other words, in each class that was surveyed half of the students received the PPO survey, while the other half received the CPO survey.

A total of 593 surveys were completed. 298 respondents completed the PPO survey, while 294 respondents completed the CPO survey. Although a convenience sample was the method chosen for class selection, it appears that a fairly representative sample of the WSU student population was collected in each survey.

\section{Survey Respondent Demographics}

Of the 593 total survey respondents 277 indicated they were male, 314 indicated that they were female and one respondent chose not to indicate his or her gender (see table 5.1). Disaggregating the surveys, it appears that 136 males

\section{Table 5.1: Gender of Respondents}

\begin{tabular}{|ll|r|r|r|r|}
\hline & Frequency & Percent & $\begin{array}{c}\text { Valid } \\
\text { Percent }\end{array}$ & $\begin{array}{c}\text { Cumulative } \\
\text { Percent }\end{array}$ \\
\hline Valid & Male & 277 & 46.7 & 46.8 & 46.8 \\
& Female & 314 & 53.0 & 53.0 & 99.8 \\
& No Response & 1 & .2 & .2 & 100.0 \\
& Total & 592 & 99.8 & 100.0 & \\
Missing & System & 1 & .2 & & \\
Total & & 593 & 100.0 & & \\
\hline
\end{tabular}

completed the PPO survey as well as 161 females (see table 5.2). 141males, 153 females completed the CPO survey, while one person chose not to indicate his or her gender (see table 5.3). 
Table 5.2: PPO Gender Totals

\begin{tabular}{|ll|r|r|r|r|}
\hline & & & & \multicolumn{1}{c|}{$\begin{array}{c}\text { Cumulative } \\
\text { Percent }\end{array}$} \\
\hline Valid & Male & 136 & 45.6 & 45.8 & 45.8 \\
& Female & 161 & 54.0 & 54.2 & 100.0 \\
& Total & 297 & 99.7 & 100.0 & \\
Missing & System & 1 & .3 & & \\
Total & & 298 & 100.0 & & \\
\hline
\end{tabular}

Table 5.3: CPO Gender Totals

\begin{tabular}{|ll|r|r|r|r|}
\hline & & & \multicolumn{2}{c|}{$\begin{array}{c}\text { Valid } \\
\text { Percent }\end{array}$} & $\begin{array}{c}\text { Cumulative } \\
\text { Percent }\end{array}$ \\
\hline Valid & Male & 141 & 47.8 & 47.8 & 47.8 \\
& Female & 153 & 51.9 & 51.9 & 99.7 \\
& No Response & 1 & .3 & .3 & 100.0 \\
Total & 295 & 100.0 & 100.0 & \\
\hline
\end{tabular}

Institutionally, men accounted for $48 \%$ of the total undergraduate population (Enrollment and Persistence, n.d.). In terms of the project, approximately $47 \%$ of the undergraduate survey respondents were male (see table 5.1). Of the undergraduates students who completed the PPO survey approximately 46\% were male (see table 5.2), while $48 \%$ of the persons who completed the CPO survey were also male (see table 5.3). Consequently, it appears that gender samples are representative of the university population.

The age of the survey respondents had a range from 18 to fifty-one (see table 5.4), where the mean was 20.31 and the median age was 20. Individually the PPO survey had an age distribution of 18 to fifty-one (see table 5.5) with a mean of 20.25 and a median of 20. 
Table 5.4: Age of Respondents

\begin{tabular}{|ll|r|r|r|r|}
\hline & & & & Cumulative \\
& & Frequency & Percent & Valid Percent & Percent \\
\hline Valid & 18 & 122 & 20.6 & 20.7 & 20.7 \\
& 19 & 110 & 18.5 & 18.6 & 39.3 \\
& 20 & 137 & 23.1 & 23.2 & 62.5 \\
& 21 & 118 & 19.9 & 20.0 & 82.5 \\
& 22 & 50 & 8.4 & 8.5 & 91.0 \\
& 23 & 24 & 4.0 & 4.1 & 95.1 \\
& 24 & 6 & 1.0 & 1.0 & 96.1 \\
& 25 & 6 & 1.0 & 1.0 & 97.1 \\
& 26 & 2 & .3 & .3 & 97.5 \\
& 27 & 3 & .5 & .5 & 98.0 \\
& 28 & 3 & .5 & .5 & 98.5 \\
& 29 & 3 & .5 & .5 & 99.0 \\
& 31 & 2 & .3 & .3 & 99.3 \\
& 33 & 1 & .2 & .2 & 99.5 \\
& 36 & 1 & .2 & .2 & 99.7 \\
& 46 & 1 & .2 & .2 & 99.8 \\
& 51 & 1 & .2 & .2 & 100.0 \\
& Total & 590 & 99.5 & 100.0 & \\
Missing & System & 3 & .5 & & \\
\hline
\end{tabular}

Table 5.5: PPO Age Totals

\begin{tabular}{|ll|r|r|r|r|}
\hline & & & & Cumulative \\
& & Frequency & Percent & Valid Percent & \multicolumn{1}{c|}{ Percent } \\
\hline Valid & 18 & 67 & 22.5 & 22.6 & 22.6 \\
& 19 & 49 & 16.4 & 16.6 & 39.2 \\
& 20 & 69 & 23.2 & 23.3 & 62.5 \\
& 21 & 60 & 20.1 & 20.3 & 82.8 \\
& 22 & 27 & 9.1 & 9.1 & 91.9 \\
& 23 & 13 & 4.4 & 4.4 & 96.3 \\
& 24 & 3 & 1.0 & 1.0 & 97.3 \\
& 25 & 1 & .3 & .3 & 97.6 \\
& 26 & 1 & .3 & .3 & 98.0 \\
& 27 & 1 & .3 & .3 & 98.3 \\
& 28 & 2 & .7 & .7 & 99.0 \\
& 31 & 1 & .3 & .3 & 99.3 \\
& 36 & 1 & .3 & .3 & 99.7 \\
& 51 & 1 & .3 & .3 & 100.0 \\
Missing & System & 296 & 99.3 & 100.0 & \\
Total & & 298 & 100.0 & & \\
\hline
\end{tabular}


The CPO survey had an age distribution of 18 to 46 (see table 5.6) with a mean of 20.37 and a median of 20. The mean age of the surveys respondents was somewhat lower than mean WSU undergraduate population as identified by campus statistics (Enrollment and Persistence, n.d.b). However, the mean and median total between both PPO and CPO surveys were similar.

Table 5.6: CPO Age Totals

\begin{tabular}{|ll|r|r|r|r|}
\hline & & & & Cumulative \\
& & Frequency & Percent & Valid Percent & Percent \\
\hline Valid & 18 & 55 & 18.6 & 18.7 & 18.7 \\
& 19 & 61 & 20.7 & 20.7 & 39.5 \\
& 20 & 68 & 23.1 & 23.1 & 62.6 \\
& 21 & 58 & 19.7 & 19.7 & 82.3 \\
& 22 & 23 & 7.8 & 7.8 & 90.1 \\
& 23 & 11 & 3.7 & 3.7 & 93.9 \\
& 24 & 3 & 1.0 & 1.0 & 94.9 \\
& 25 & 5 & 1.7 & 1.7 & 96.6 \\
& 26 & 1 & .3 & .3 & 96.9 \\
& 27 & 2 & .7 & .7 & 97.6 \\
& 28 & 1 & .3 & .3 & 98.0 \\
& 29 & 3 & 1.0 & 1.0 & 99.0 \\
& 31 & 1 & .3 & .3 & 99.3 \\
& 33 & 1 & .3 & .3 & 99.7 \\
& 46 & 1 & .3 & .3 & 100.0 \\
& Total & 294 & 99.7 & 100.0 & \\
Missing & System & 1 & .3 & & \\
\hline Total & & 295 & 100.0 & & \\
\hline
\end{tabular}

According to WSU statistics $16.68 \%$ of the total student undergraduate population is from out of state (Future Students, n.d.). Overall, $86 \%$ percent of the undergraduate students that completed the surveys were from Washington State, while .5\% did not indicate their state status (see table 5.7). Out of the 298 
Table 5.7: Total in State, Out of State, or Foreign Students

\begin{tabular}{|ll|r|r|r|r|}
\hline & & & & \multicolumn{2}{c|}{$\begin{array}{c}\text { Cumulative } \\
\text { Percent }\end{array}$} \\
\hline Valid & In state & 511 & 86.2 & 86.6 & 86.6 \\
& Out of & 54 & 9.1 & 9.2 & 95.8 \\
& State & 25 & 4.2 & 4.2 & 100.0 \\
& Foreign & 590 & 99.5 & 100.0 & \\
Missing & Total & 3 & .5 & & \\
Total & System & 593 & 100.0 & & \\
\hline
\end{tabular}

respondents who completed the PPO survey, approximately 85\% were from Washington State (see table 5.8). Out of the 295 respondents who completed the CPO survey about $12 \%$ indicated that they were from outside the State of Washington (see table 5.9). It appears that the survey averages (in state) are somewhat smaller than the total student undergraduate population in state totals. However, the survey averages, albeit smaller, are still somewhat similar to the total in state population at WSU.

Table 5.8: PPO in State, Out of State, or Foreign Student Totals

\begin{tabular}{|c|c|c|c|c|c|}
\hline & & Frequency & Percent & Valid Percent & $\begin{array}{c}\text { Cumulative } \\
\text { Percent }\end{array}$ \\
\hline \multirow[t]{4}{*}{ Valid } & In state & 252 & 84.6 & 85.1 & 85.1 \\
\hline & $\begin{array}{l}\text { Out of } \\
\text { State }\end{array}$ & 31 & 10.4 & 10.5 & 95.6 \\
\hline & Foreign & 13 & 4.4 & 4.4 & 100.0 \\
\hline & Total & 296 & 99.3 & 100.0 & \\
\hline Missing & System & 2 & .7 & & \\
\hline Total & & 298 & 100.0 & & \\
\hline
\end{tabular}

Table 5.9: CPO in State, Out of State, or Foreign Student Totals

\begin{tabular}{|c|c|c|c|c|c|}
\hline & & Frequency & Percent & Valid Percent & $\begin{array}{c}\text { Cumulative } \\
\text { Percent }\end{array}$ \\
\hline \multirow[t]{4}{*}{ Valid } & In state & 259 & 87.8 & 88.1 & 88.1 \\
\hline & $\begin{array}{l}\text { Out of } \\
\text { State }\end{array}$ & 23 & 7.8 & 7.8 & 95.9 \\
\hline & Foreign & 12 & 4.1 & 4.1 & 100.0 \\
\hline & Total & 294 & 99.7 & 100.0 & \\
\hline Missing & System & 1 & .3 & & \\
\hline Total & & 295 & 100.0 & & \\
\hline
\end{tabular}


Approximately $14.1 \%$ of the full-time and part-time undergraduate students at WSU reported having a minority background. Blacks, non-Hispanics accounted for $2.56 \%$ of the total population. American Indians and/or Alaska natives had the lowest representation accounting for $1.24 \%$ of the total population. Asian and/or Pacific Islanders attending WSU had the highest representation, which accounted for $6.1 \%$ of the total student population. Hispanics accounted for $4.2 \%$ of the total student population. One thousand six-hundred and three undergraduates did not self-report race/ethnicity or $8.2 \%$ of the total student population, while $2.7 \%$ of the total population was non-resident alien (Enrollment and Persistence, n.d.).

Sequentially, the totals of both student surveys mirrored the reported multicultural background of undergraduate students at WSU. Native Americans were the lowest represented multicultural group that completed the survey with $1.7 \%$ of the sample, while Asians were the highest represented multicultural group with $5.2 \%$ of the sample (see table 5.10). Individually, both the PPO survey and CPO survey followed a similar pattern of multicultural student completion rates (see table 5.11 and 5.12). In other words, both surveys had a similar percentage hierarchy

Table 5.10: Total Race/Ethnicity

\begin{tabular}{|c|c|c|c|c|c|}
\hline & & Frequency & Percent & Valid Percent & $\begin{array}{l}\text { Cumulative } \\
\text { Percent }\end{array}$ \\
\hline \multirow[t]{7}{*}{ Valid } & $\begin{array}{l}\text { African } \\
\text { American }\end{array}$ & 11 & 1.9 & 1.9 & 1.9 \\
\hline & Asian & 31 & 5.2 & 5.2 & 7.1 \\
\hline & White & 479 & 80.8 & 80.9 & 88.0 \\
\hline & Hispanic & 17 & 2.9 & 2.9 & 90.9 \\
\hline & Native & 10 & 1.7 & 1.7 & 92.6 \\
\hline & Other & 44 & 7.4 & 7.4 & 100.0 \\
\hline & Total & 592 & 99.8 & 100.0 & \\
\hline Missing & System & 1 & .2 & & \\
\hline Total & & 593 & 100.0 & & \\
\hline
\end{tabular}


representation (i.e. Natives, African Americans, Hispanic, and Asians). Furthermore, it should be noted that the total percentages of multicultural groups in each survey remained relatively comparable.

Table 5.11: PPO Race/Ethnicity Totals

\begin{tabular}{|c|c|c|c|c|c|}
\hline & & Frequency & Percent & Valid Percent & $\begin{array}{l}\text { Cumulative } \\
\text { Percent }\end{array}$ \\
\hline \multirow[t]{7}{*}{ Valid } & $\begin{array}{l}\text { African } \\
\text { American }\end{array}$ & 4 & 1.3 & 1.3 & 1.3 \\
\hline & Asian & 16 & 5.4 & 5.4 & 6.7 \\
\hline & White & 239 & 80.2 & 80.2 & 86.9 \\
\hline & Hispanic & 11 & 3.7 & 3.7 & 90.6 \\
\hline & Native & 6 & 2.0 & 2.0 & 92.6 \\
\hline & Other & 22 & 7.4 & 7.4 & 100.0 \\
\hline & Total & 298 & 100.0 & 100.0 & \\
\hline
\end{tabular}

Table 5.12: CPO Race/Ethnicity Totals

\begin{tabular}{|c|c|c|c|c|c|}
\hline & & Frequency & Percent & Valid Percent & $\begin{array}{c}\text { Cumulative } \\
\text { Percent }\end{array}$ \\
\hline \multirow[t]{7}{*}{ Valid } & $\begin{array}{l}\text { African } \\
\text { American }\end{array}$ & 7 & 2.4 & 2.4 & 2.4 \\
\hline & Asian & 15 & 5.1 & 5.1 & 7.5 \\
\hline & White & 240 & 81.4 & 81.6 & 89.1 \\
\hline & Hispanic & 6 & 2.0 & 2.0 & 91.2 \\
\hline & Native & 4 & 1.4 & 1.4 & 92.5 \\
\hline & Other & 22 & 7.5 & 7.5 & 100.0 \\
\hline & Total & 294 & 99.7 & 100.0 & \\
\hline Missing & System & 1 & .3 & & \\
\hline Total & & 295 & 100.0 & & \\
\hline
\end{tabular}

The survey respondents were fairly representative of all class standings. Overall, juniors accounted for the majority of the respondents or 32.9\%, while sophomores accounted for the minority of the survey respondents or $19.1 \%$ (see table 5.13 ). Class standing for both the PPO survey (see table 5.14) and the CPO survey (see table 5.15) were fairly representative of all class ranges. Juniors and freshmen 
Table 5.13: Total Class Standing

\begin{tabular}{|ll|r|r|r|r|}
\hline & Frequency & Percent & Valid Percent & $\begin{array}{c}\text { Cumulative } \\
\text { Percent }\end{array}$ \\
\hline Valid & Freshman & 159 & 26.8 & 26.8 & 26.8 \\
& Sophomore & 113 & 19.1 & 19.1 & 45.9 \\
& Junior & 195 & 32.9 & 32.9 & 78.8 \\
& Senior & 126 & 21.2 & 21.2 & 100.0 \\
& Total & 593 & 100.0 & 100.0 & \\
\hline
\end{tabular}

appeared to have the highest percentage total in both surveys, while sophomores and juniors had the lowest total percentage rates.

Table 5.14: PPO Class Standing Totals

\begin{tabular}{|ll|r|r|r|r|}
\hline & Frequency & Percent & Valid Percent & $\begin{array}{c}\text { Cumulative } \\
\text { Percent }\end{array}$ \\
\hline Valid & Freshman & 84 & 28.2 & 28.2 & 28.2 \\
& Sophomore & 60 & 20.1 & 20.1 & 48.3 \\
& Junior & 97 & 32.6 & 32.6 & 80.9 \\
& Senior & 57 & 19.1 & 19.1 & 100.0 \\
& Total & 298 & 100.0 & 100.0 & \\
\hline
\end{tabular}

Table 5.15: CPO Class Standing Totals

\begin{tabular}{|ll|r|r|r|r|}
\hline & & & & \multicolumn{2}{c|}{$\begin{array}{c}\text { Cumulative } \\
\text { Percent }\end{array}$} \\
\hline Valid & Freshman & 75 & 25.4 & 25.4 & 25.4 \\
& Sophomore & 53 & 18.0 & 18.0 & 43.4 \\
& Junior & 98 & 33.2 & 33.2 & 76.6 \\
& Senior & 69 & 23.4 & 23.4 & 100.0 \\
& Total & 295 & 100.0 & 100.0 & \\
\hline
\end{tabular}

Lastly, it should be noted that out of the 593 total survey respondents 59 majors were represented (see Appendix H). The majors were re-coded into each college. Thus, an accurate representation of the colleges in the survey could be identified. WSU houses 12 colleges $^{6}$ : Agriculture, Human, and Natural Resources, Business and Economics,

\footnotetext{
${ }^{6}$ Although the university houses 12 colleges only 9 were included in the survey. The Honors College, the Graduate School and the Distance Degree Program were out of the purview of this study.
} 
Education, Engineering and Architecture, Liberal Arts, Nursing, Pharmacy, Sciences, and Veterinary Medicine (Current Students, n.d.).

What can be identified is that students from all colleges were represented in the surveys (see Table 5.16). However, the distribution was highly skewed. The majority of students that participated in the survey were from the College of Liberal arts, Education, and Business. It should also be noted that 3.4\% of the sample were double majors and $3.4 \%$ of the sample were undecided. However, between the two surveys (PPO and CPO), although the college distributions were highly skewed, the frequencies of the colleges represented between surveys were very comparable (see Tables 5.17 and 5.18).

Table 5.16: Total Colleges Represented

\begin{tabular}{|ll|r|r|r|r|}
\hline & & & & \multicolumn{2}{c|}{$\begin{array}{c}\text { Cumulative } \\
\text { Percent }\end{array}$} \\
\hline Valid & Frequency & Percent & Valid Percent & .3 \\
& Busiculture & 2 & .3 & .3 & 15.8 \\
& 90 & 15.2 & 15.4 & 44.9 \\
& Education & 170 & 28.7 & 29.1 & 46.9 \\
& Engineering & & & \\
and & 12 & 2.0 & 2.1 & 83.9 \\
& Architecture & & & 86.5 \\
& Liberal Arts & 216 & 36.4 & 37.0 & 87.7 \\
& Nursing & 15 & 2.5 & 2.6 & 91.4 \\
& Pharmacy & 7 & 1.2 & 1.2 & 93.0 \\
& Sciences & 22 & 3.7 & 3.8 & 96.6 \\
& Veterinary & 9 & 1.5 & 1.5 & 100.0 \\
& Medicine & 21 & 3.5 & 3.6 & \\
& Double & 20 & 3.4 & 3.4 & \\
& Majors & 584 & 98.5 & 100.0 & \\
Missing & Undecided & 9 & 1.5 & & \\
Total & Sotal & 593 & 100.0 & & \\
& System & & &
\end{tabular}


Table 5.17: PPO Colleges Represented Totals

\begin{tabular}{|ll|r|r|r|r|}
\hline & & & & Cumulative \\
& & Frequency & Percent & Valid Percent & \multicolumn{2}{c|}{ Percent } \\
\hline Valid & Business & 46 & 15.4 & 15.6 & 15.6 \\
& Education & 79 & 26.5 & 26.9 & 42.5 \\
& Engineering & & & \\
and & 6 & 2.0 & 2.0 & 44.6 \\
& Architecture & & 37.8 & 82.3 \\
& Liberal Arts & 111 & 37.2 & 2.4 & 84.7 \\
& Nursing & 7 & 2.3 & 1.7 & 86.4 \\
& Pharmacy & 5 & 1.7 & 4.8 & 91.2 \\
& Sciences & 14 & 4.7 & 1.4 & 92.5 \\
& Veterinary & 4 & 1.3 & 4.4 & 96.9 \\
& Medicine & 13 & 4.4 & 3.1 & 100.0 \\
& Double & 9 & 3.0 & 100.0 & \\
& Majors & 294 & 98.7 & & \\
Missing & Undecided & 4 & 1.3 & & \\
Total & Sotal & 298 & 100.0 & & \\
& System & & &
\end{tabular}

Table 5.18: CPO Colleges Represented Totals

\begin{tabular}{|c|c|c|c|c|c|}
\hline & & Frequency & Percent & Valid Percent & $\begin{array}{c}\text { Cumulative } \\
\text { Percent }\end{array}$ \\
\hline \multirow[t]{12}{*}{ Valid } & Agriculture & 2 & .7 & .7 & .7 \\
\hline & Business & 44 & 14.9 & 15.2 & 15.9 \\
\hline & Education & 91 & 30.8 & 31.4 & 47.2 \\
\hline & $\begin{array}{l}\text { Engineering } \\
\text { and } \\
\text { Architecture }\end{array}$ & 6 & 2.0 & 2.1 & 49.3 \\
\hline & Liberal Arts & 105 & 35.6 & 36.2 & 85.5 \\
\hline & Nursing & 8 & 2.7 & 2.8 & 88.3 \\
\hline & Pharmacy & 2 & .7 & .7 & 89.0 \\
\hline & Sciences & 8 & 2.7 & 2.8 & 91.7 \\
\hline & $\begin{array}{l}\text { Veterinary } \\
\text { Medicine }\end{array}$ & 5 & 1.7 & 1.7 & 93.4 \\
\hline & $\begin{array}{l}\text { Double } \\
\text { Majors }\end{array}$ & 8 & 2.7 & 2.8 & 96.2 \\
\hline & Undecided & 11 & 3.7 & 3.8 & 100.0 \\
\hline & Total & 290 & 98.3 & 100.0 & \\
\hline Missing & System & 5 & 1.7 & & \\
\hline Total & & 295 & 100.0 & & \\
\hline
\end{tabular}




\section{Conclusion}

In the second phase of this study, two surveys were administered in selected undergraduate classes at WSU. The surveys were developed in order to identify students’ perceptions of PP or CP. The surveys also identified demographic characteristics of the respondents.

Once the surveys were returned and evaluated, the demographic responses of the respondents were identified. Consequently, the purpose of Chapter Four was to describe the sample characteristics of each survey group. Although, the samples were selected using a non-parametric sampling technique, the hope was that the undergraduate classes chosen would still be representative of the overall population at WSU.

Respondents were disaggregated by gender, age, in-state/out of state, ethnicity, class standing, and colleges represented between surveys and the overall WSU population. In terms of gender, males account for $48 \%$ of the total WSU population. Males accounted for $46 \%$ of the total sample population for the PPO survey, while males accounted for $48 \%$ of the total sample for the CPO survey. The average age for WSU undergraduate student population was 23. The PPO survey respondents' mean age was 20.31, with a range between 18 and 51, while the PPO survey respondents' mean age of 20.37 with a range between 18 and 46 . Approximately $16 \%$ of the WSU undergraduate population is from out of state. Fifteen percent of the PPO survey respondents indicated that they were from out of state, while approximately $12 \%$ of the CPO respondents indicated they were from out of state. Approximately $14 \%$ of undergraduate students at WSU report having membership in a minority group. Both PPO and CPO surveys respondents reported a slightly higher multicultural background with a 19.8\% and 18.6\% 
respectively. Although all colleges were represented in the sample surveys, the colleges in terms of raw number were highly skewed. However, for both the PPO and CPO surveys, Liberal Arts, Education and Business were the most represented colleges. In general, the survey samples are fairly representative of the overall WSU population. Furthermore, the surveys samples are extremely similar to one another. Consequently, it appears possible to make comparison between samples as well as make inferences on the overall WSU population. 


\title{
CHAPTER SIX
}

\section{SCALE DEVELOPMENT AND BI-VARIATE FINDINGS}

\author{
Introduction
}

One of the primary research questions was to determine the extent of the perceived difference in the legitimacy between CP officers and "mainstream" officers.

As discussed earlier, CP from WSU perceived legitimacy levels were being compared to PP perceived legitimacy levels. To determine the extent of the perceived legitimacy levels, a legitimacy scale needed to be developed. The researcher incorporated a modified Sunshine and Tyler (2003) scale, which was initially used for measuring legitimacy. However, after analyzing the completed surveys, specifically the modified Sunshine and Tyler (2003) legitimacy scale, it became apparent that the scale had to be further refined. Once the refinement took place, a measurement of legitimacy for both department and officer appeared.

Consequently, legitimacy could be measured and compared between PP (department and officer) and CP (department and officer). By comparing both department and officer between PP and CP appeared to add a richer understanding of legitimacy between campus and municipal police.

Once an accurate measurement of legitimacy was identified, comparison could be made between PP (department and officer) and CP (department and officer). The test used to determine perceived legitimacy differences between PP (department and officer) and CP (department and officer) were independent sample t-tests. Independent sample are groups that have no observational relationship to one another (Coladarci et al., 2001). In other words, an individual is limited to one group; therefore, one group's observations 
are in no way related to the other group. An independent sample t-test is used to compare two samples that are independent from one another (i.e. PP and CP). Once the $t$-tests were performed an eta squared was calculated on each model to determine the magnitude of the difference. Consequently, a $t$-test was performed to measure if there was, indeed, a difference between perceived legitimacy levels between PP (department and officer) and $\mathrm{CP}$ (department and officer), while the eta squared was performed to determine (if there was a difference) how much difference was there?

\section{Legitimacy Scale Development}

Two surveys were equally distributed to undergraduate students in selected classes at WSU. One survey measured the perceived legitimacy of PP officers and the alternate survey measured the perceived legitimacy of CP officers. The legitimacy measure was a scale that was developed by Sunshine and Tyler (2003). The Sunshine and Tyler (2003) scale used 19 items on a Likert scale to identify levels of perceived legitimacy. Legitimacy was operationalized as the obligation to obey directives of a legal authority and trust both in the individual police officer and the institution of policing itself. Sunshine and Tyler indicated the overall scale had an alpha reliability of 0.84 , a mean of 2.36, and an S.D. of 0.53 (p. 543) ${ }^{7}$.

A modified Sunshine and Tyler (2003) legitimacy scale was used for the current project. Once the surveys were returned, they were screened for errors. All found errors were corrected in the data file. Many of the items in "Section 3" (legitimacy scale) were reversed coded. As discussed earlier, reverse coding was used to control for response bias. Consequently, the reverse coded items responses were reversed into positive form

\footnotetext{
${ }^{7}$ In the overall scale, a lower score was an indication of higher legitimacy
} 
and put back into the data set. Once the reverse coded items responses were changed into a positive form and put back into the data set, the individual items were added together in both the PP and CP legitimacy scales and a new variable was created. The new variable was identified as “scale 1.”

\section{Assumption Testing of the Dependant Variable}

Before doing any statistical analysis it is important that a violation of the assumptions of the particular statistical test is not violated (Tabachnick \& Fidell, 2001). Multiple tests were conducted to check for violations of the assumptions of the statistical techniques used to address the researcher's research question: What is the extent of the perceived difference in the legitimacy between CP officer and "mainstream" officers (PP officer). First , a Kolmogorov-Smirnov test was conducted to determine if the new dependant variable (Scale 1) was normally distributed. The Kolmogorov-Smirnov test identified a Significance Value for the PP scale of .092 and a Significance Value .069 for the CP scale (see table 6.1). Both significance levels were non significant at the .05 level, indicating that assumption of normality was not violated. Secondly, statistical techniques that the research used to answer the research questions are sensitive to outliers. Outliers

Table 6.1: PP Scale and CP Scale Tests of Normality

\begin{tabular}{|r|r|r|r|r|r|r|r|}
\hline & Survey & \multicolumn{3}{|c|}{ Kolmogorov-Smirnov(a) } & \multicolumn{3}{|c|}{ Shapiro-Wilk } \\
& & Statistic & \multicolumn{1}{|c|}{$\mathrm{df}$} & \multicolumn{1}{c|}{ Sig. } & Statistic & \multicolumn{1}{c|}{$\mathrm{df}$} & Sig. \\
\hline Scale 1 & PPO Scale & .092 & 298 & .000 & .974 & 298 & .000 \\
& CPO Scale & .069 & 295 & .002 & .982 & 295 & .001 \\
\hline
\end{tabular}

a Lilliefors Significance Correction

are extreme low and high cases in a data set. According to Pallant (2001), outliers have the potential to distort the $r$ value/correlation co-efficient. Outliers were identified using 
the Boxplot. The Boxplot for the PP scale identified seven outliers, while the Boxplot for CP identified six outliers. The outliers were inspected for their authenticity in terms of the range of possible scores, input mistakes, etc. All of the identified outliers were true outliers and subsequently were removed from the data set.

\section{Factor Analysis on the Legitimacy Scale}

Factor analysis was conducted to determine what, if any, underling constructs(s) existed for measures of the 19 items in the modified Sunshine and Tyler (2003) legitimacy scale for the PP (see appendix I). Principle component analysis was conducted utilizing a Varimax Rotation (see table 6.2). The analysis produced a 4 component solution, which was evaluated with the following criteria: eigenvalue, variance, scree plot, and residuals.

\section{Table 6.2: PP Rotated Component Matrix(a)}

\begin{tabular}{|l|l|l|l|l|}
\hline & \multicolumn{5}{|c|}{ Component } \\
\cline { 2 - 5 } & 1 & 2 & 3 & 4 \\
\hline S3Q1 & & & & \\
S3Q2 & & .760 & & \\
S3Q3 & & .837 & & \\
S3Q4 & & .772 & & .838 \\
S3Q5 & & & & .678 \\
S3Q6 & & & .758 & \\
S3Q7 & & & .781 & \\
S3Q8 & & & .609 & \\
S3Q9 & & & & \\
S3Q10 & & & & \\
S3Q11 & .836 & & & \\
S3Q12 & .825 & & & \\
S3Q13 & .781 & & & \\
S3Q14 & .759 & & & \\
S3Q15 & .832 & & & \\
S3Q16 & .743 & & & \\
S3Q17 & & & & \\
S3Q18 & & & & \\
S3Q19 & & & & \\
\hline
\end{tabular}

a Rotation converged in 5 iterations. 
However, 2 of the 4 components did not appear to be a measurement of legitimacy of the institution or the individual police officer. Components 3 and 4 appeared to measure perceptions in the legitimacy of the law. Consequently, only components 1 and 2 were used for PP scale development. Component 1 appeared to measure perception of legitimacy with the PP department using items 11, 12, 13, 14, 15, and 16, while component 2 appeared to measure perceptions in the legitimacy of the individual PP officer using items two, three, and four.

A factor analysis was conducted again to determine what, if any, underling constructs(s) existed for measures of the 19 items in the modified Sunshine and Tyler (2003) legitimacy scale for the CP (see appendix J). Principle component analysis was conducted utilizing a Varimax Rotation (see table 6.3). The analysis produced a 4 component solution, which was again evaluated with the following criteria: eigenvalue, variance, scree plot, and residuals. 


\section{Table 6.3: CP Rotated Component Matrix(a)}

\begin{tabular}{|l|l|l|l|l|}
\hline & \multicolumn{4}{|c|}{ Compont } \\
\cline { 2 - 5 } & 1 & 2 & 3 & 4 \\
\hline S3Q1 & & & & \\
S3Q2 & & .761 & & \\
S3Q3 & & .854 & & \\
S3Q4 & & .762 & & \\
S3Q5 & & & & .761 \\
S3Q6 & & & & \\
S3Q7 & & & & \\
S3Q8 & & & & \\
S3Q9 & & & & \\
S3Q10 & & & & \\
S3Q11 & .825 & & & \\
S3Q12 & .834 & & & \\
S3Q13 & .731 & & & \\
S3Q14 & .706 & & & \\
S3Q15 & .772 & & & \\
S3Q16 & .609 & & & \\
S3Q17 & & & & \\
S3Q18 & & & & \\
S3Q19 & & & & \\
\hline
\end{tabular}

Extraction Method: Principal Component Analysis. Rotation Method: Varimax with Kaiser Normalization. a Rotation converged in 6 iterations.

However, like the PP component solution, 2 of the 4 components did not appear to measure legitimacy perceptions of the institution or the individual police officer.

Components 3 and 4 appeared to measure perceptions in the legitimacy of the law and policies. Consequently, only components 1 and 2 were used for CP scale development. Similarly, component 1 appeared to measure perception of legitimacy with the CP department using items 11, 12,13,14,15, and 16, while component 2 appeared to measure perceptions in the legitimacy of the individual campus police officer using items two, three, and four. ${ }^{8}$

\footnotetext{
${ }^{8}$ There was a loading on item 1 for component 2. The loading was significant, but small. Consequently, the item 1 loading was left out in order to make more accurate comparison between CP and PP officer legitimacy scales.
} 


\section{Internal Consistency Checks}

After developing the scales, a Cronbach’s alpha coefficient was conducted in order to determine the scales’ internal consistency. Internal consistency is used to determine if the items in the scale are actually measuring the same underlying construct (Mertler \& Vannatta, 2001). As discussed earlier, Sunshine and Tyler (2003) reported their legitimacy scale had good internal consistency with a Cronbach’s alpha coefficient of .84 .

A Cronbach's alpha coefficient is a measure that determines how well the items from the scale are measuring the same underlying construct. The alpha coefficient value ranges from 0 to 1 . The stronger the correlations between items, in a scale, will result in a higher alpha coefficient value (Pallant, 2001). In other words, the Cronbach's alpha measures how well the items in the scale "hang together" (p. 6). A minimally acceptable Cronbach’s alpha is .70 (Devellis, 2003; Pallant, 2001; Spicer, 2005); between .70 and .80 is considered respectable; and between .80 and .90 is considered very good (Devellis, 2003, p. 95-96).

After conducting the factor analysis on the modified scales, two separate components emerged. Furthermore, 2 separate components emerged on the PPO and CPO surveys. Consequently, a Cronbach's alpha coefficient was calculated for PP and CP scales as well as the two components identified with the factor analysis. In other words, four separate Cronbach’s alpha coefficients were calculated. The Cronbach’s alpha coefficients for the developed PP department and officer legitimacy scales were .763 and .905 respectively. The Cronbach’s alpha coefficients for the developed CP department and officer legitimacy scales were .783 and .893. Consequently, the four 
scales (PPO and CPO: department legitimacy and officer legitimacy) appeared to be measuring their intended purpose. Or, put another way, the scales appeared to be sound instruments that measured the department and officer perceived legitimacy levels.

\section{Means Comparison Between PP and CP: Department and Officer}

The legitimacy scales were compared against each other in terms of CP and PP: department and officer. The researcher's interest was to determine the extent of the perceived legitimacy differences. Initially, independent $t$-tests were conducted between the PP department/officer legitimacy perceptions and the CP department/officer legitimacy perception to determine the differences. After differences were identified, an eta squared was calculated in order to determine the extent or the magnitude of those differences. SPSS does not provide an eta squared function for an independent $t$-test (Pallant, 2001). Consequently, an eta squared was hand calculated using the formula (Walsh \& Ollenburger, 2001, p.115):

$$
\text { Eta squared }=\frac{t \text { squared }}{t \text { squared }+(\mathrm{N} 1+\mathrm{N} 2-2)}
$$

According to Pallant (2001, p. 175), a .01 eta is a small effect, a .06 is a moderate effect, and a .14 is a large effect. Once the eta squared was calculated it could be multiplied by 100, which would indicate the percentage of variance explained in the model.

\section{$\underline{\text { PP/CP Department Means Comparison }}$}

The first independent-samples $t$-test was conducted to compare the legitimacy perception scores between PP and CP departments. There was a significant difference in 
scores for the PP department $(\underline{\mathrm{M}}=13.43, \underline{\mathrm{SD}}=5.21)$, and the CP department $[\underline{\mathrm{M}}=14.3$, $\underline{\mathrm{SD}}=5.18 ; \underline{t}(578)=-2.021, \underline{p}=.044]$ (see appendix K). The magnitude of the difference of the means was small (eta squared=.007) .

\section{$\underline{\text { PP/CP Officer Means Comparison }}$}

The second independent-samples t-test was conducted to compare the legitimacy perception scores between PP and CP officers. There was a significant different in scores for PP officers ( $\underline{\mathrm{M}}=6.97, \underline{\mathrm{SD}}=2.95)$, and CP officers $[\underline{\mathrm{M}}=7.73, \underline{\mathrm{SD}}=3.0 ; \underline{t}(578)=-3.088$, $\underline{p=.002)] ~(s e e ~ a p p e n d i x ~ L) . ~ T h e ~ m a g n i t u d e ~ o f ~ t h e ~ d i f f e r e n c e ~ o f ~ t h e ~ m e a n s ~ w a s ~ s m a l l ~(e t a ~}$ squared $=.016)$.

\section{Conclusion}

Factor analysis and alpha reliability tests were conducted in order to develop an accurate scale for measuring perceived legitimacy. The final scale developed appeared to measure two forms of perceived legitimacy: department and officer. Consequently both department and officer were measured between PP and CP.

Two t-tests were conducted to test legitimacy differences between PP/CP department and PP/CP officer. The two models identified significant differences. In other words, perceptions of legitimacy were different between the PP and the CP department and individual officers. The direction of the coefficients indicated that PP, both department and officer, had higher perceived legitimacy perceptions than the CP department and officers. However, the magnitude was very small in both models, which suggests that perceived legitimacy only accounts for a small percentage of the variation. 
In other words, there was a statistical significant difference in perceived legitimacy, but it is difficult to determine if there was a substantive one. 


\section{CHAPTER SEVEN \\ MULTIVARIATE FINDINGS}

Introduction

The final research question was to determine the selected independent variables that returned significant perceived legitimacy levels. Based on the two scales (department and officer) and the PPO and the CPO surveys, four multiple regression models were constructed. The multiple regression models were developed in order to determine which selected set of independent variables significantly contributed to each model.

Furthermore, each model identified the variance in the dependant variable (legitimacy perceptions) as explained by each predictor variable. Finally, the significant predictor variables were then tested between the models to determine the significance of the regression coefficients.

\section{Legitimacy Predictor Variables}

The researcher utilized 11 independent variables or predictor variables in the regression models. Again, these predictor variables were chosen based on prior literature from municipal/state police, campus police, as well as CP interviews in order to predict significant perceived legitimacy levels (Bordner \& Peterson, 1983; Garcia \& Cao, 2005; Griffith et al., 2004; Hopkins et al., 1992; Hurst, Browning, \& Browning, 2000; Miller \& Pan, 1987; Murphy \& Worrall, 1999; Reisig and Giacomazzi, 1999; Reisig \& Parks, 2000; Sloan, 1992; Weitzer \& Tuch, 1997; White and Menke, 1982; Worrall, 1999; Zamble \& Annesley, 1987). These independent variables were: 1) Does the respondent live on campus; 2) Is the respondent a fraternity or sorority member; 3) Is a member of 
the respondent's family a police officer; 4) Respondent’s home city (urban/rural); 5) Respondent's race/ethnicity; 6) If the respondent had contact with a by a police officer (campus or municipal) was the contact negative (perceived as treated unfairly); 7) If the respondent new someone who had contact with the police (campus or municipal) was the contact negative positive (perceived as treated unfairly); 8) respondent’s gender; 9) Respondent's class standing in college; 10) Respondent's age; 11) And a positive stereotype scale.

Independent variables 1 through 3 were “yes”- “no” questions coded as 0-NO and 1-YES. Independent variable 4 was the respondent's hometown. ${ }^{9}$ The hometown was identified by city and state on the survey. The city and state were re-coded into urban and rural cities as defined by the U.S. Census Bureau for the 2000 census. Consequently, independent variable 4 was re-coded as 0-RURAL and 1-URBAN. Independent variable 5 was respondent's race/ethnicity. Race and ethnicity was originally coded: 1-African American, 2-Asian American, 3-Caucasian, 4-Hispanic, 5-Native American, and 6-Other. Since one racial/ethnic group did not account for more than $7 \%$ of the total sample, all racial/ethnic groups were combined. Consequently, race/ethnicity was re-coded into 0WHITE and 1-NON-WHITE. Independent variable 6 was if a respondent's contact with a police officer (campus or municipal) was negative. Independent variable 6 was coded as 0-ABSENCE OF A NEGATIVE CONTACT and 1-NEGATIVE CONTACT. Independent variable 7 was if respondent had a friend whose contact with a police officer (campus or municipal) was negative. Independent variable 7 was coded as 0-ABSENCE OF NEGATIVE CONTACT and 1-NEGATIVE CONTACT. Independent variable 8

\footnotetext{
${ }^{9}$ A home city was operationalized as where the respondent felt he or she grew up (i.e. hometown). If the respondent grew up in multiple cities, the respondent was to identify a single city that he or she considered his or her hometown.
} 
was respondent's gender coded as 1-MALE and 2-FEMALE. Independent variable 9 was respondent's class standing coded as 1-FRESHMAN, 2-SOPHOMORE, 3-JUNIOR, and 4 SENIOR. Independent variable 10 was the respondent's age. The respondent's age was coded with his or her identified age.

Lastly, an adjective scale was included in the regression model. The original scale was developed by Hewston et al. (1992) and used to identify student stereotype perceptions of School Liaison Officers (SLO). As discussed in the methods section of this project, the adjective scale was based on four positive and four negative adjectives and respondents were asked to identify his or her levels (seven point Likert scale) of each adjective based on his or her perception of SLOs.

After analyzing the completed surveys of this project, a factor analysis was conducted on the "Adjective Scale.” The factor analysis was conducted to determine if there were two underlying constructs (positive and negative) in the "Adjective Scale.” Principal component analysis was conducted utilizing a Varimax Rotation (see table 7.1). The analysis produced a two-component solution, which was evaluated with eignevalue, variance, scree plot, and residuals. 


\section{Table 7.1: Adjective Scale Rotated Component Matrix(a)}

\begin{tabular}{|l|r|r|}
\hline \multirow{2}{*}{} & \multicolumn{2}{|c|}{ Component } \\
\cline { 2 - 3 } & 1 & \multicolumn{1}{|c|}{2} \\
\hline S4Q1 & .796 & -.019 \\
S4Q2 & -.098 & .724 \\
S4Q3 & .847 & -.024 \\
S4Q4 & .397 & .563 \\
S4Q5 & .830 & -.083 \\
S4Q6 & .115 & .737 \\
S4Q7 & .806 & .102 \\
S4Q8 & -.178 & .620 \\
\hline
\end{tabular}

Extraction Method: Principal Component Analysis.

Rotation Method: Varimax with Kaiser Normalization.

a Rotation converged in 3 iterations.

A Cronbach’s alpha coefficient was performed in order to determine the scale's internal consistency. The alpha coefficient for the overall model was low indicating a weak internal consistency. Based on the weak internal consistency, a Cronbach’s alpha coefficient was conducted for each component that was identified in the factor analysis. The two components identified were based on the two adjective types (positive and negative). The positive adjectives (component one) had good internal consistency with a .85. The negative adjectives produced a Cronbach’s alpha of .57, which identified an unacceptable internal consistency (Pallant, 2001). Based on the unacceptable alpha coefficient, the negative adjectives (component two) were removed from the scale and only the positive adjectives were kept. Consequently, the new adjective scale only incorporated levels of positive stereotypes and was coded from a 1 to $7 .^{10}$

\footnotetext{
107 being "very much” with a 1 indicating "not at all.”
} 
All of the 11 independent variables were assessed for accuracy and manipulated into a form that could be used for the multiple regression models. Once the independent variables were assessed for accuracy, manipulated into a useable form, and applied to the dependent variable (legitimacy scales), testing the assumptions of the multiple regressions could be conducted.

\section{Assumptions of Multiple Regression}

Multiple regression is a statistical technique that allows a researcher to identify patterns between multiple independent variables (predictor variables) on a single dependant variable (Tabachnick \& Fidell, 2001). Multiple regression can address how well a set of variables is able to predict an outcome as well as which variable is the best predictor of the outcome (Pallant, 2001).

Initially, before a multiple regression can be conducted, the data must meet specific assumptions (Mertler \& Vannatta, 2005). If the data do not meet the specific assumption, the results would be consider untrustworthy (Spicer, 2005). In other words, a multiple regression analysis is only legitimate when the assumptions of a multiple regression are met. These assumptions are normality, linearity, and homoskedasticity, (Pallant, 2001; Spicer, 2005; Tabachnick \& Fidell, 2001).

\section{Practical Issues with the PP and CP Data}

Before assumption of normality, linearity, and homoskedasticity can be tested, practical matters of the data must be assessed (Tabachnick \& Fidell, 2001). These practical matters are sample size, outliers, and absence of multicollinearity. 
The characteristics of the sample of students were used in order to make conclusions about the entire WSU undergraduate population's PP and CP legitimacy perception levels. Consequently, how generalizable the samples are to the population becomes paramount.

Tabachnick and Fidell (2001, p.117) suggest that a minimum sample size, for regression analysis, should be: $N \geq 104+8 m$. In other words, the $N$ must be equal to or larger than 104 cases +8 times the number of independent variables used in the regression equation. An N larger or equal to $104+8 m$ increases the likelihood of generalizability.

After, outliers were accounted for (which will be discussed later in the work) the PPO survey comprised an N=270 and the CPO survey obtained an N=272. The PP and $\mathrm{CP}$ regression equations incorporated 11 independent variables in the analysis $(m=11)$. Consequently, both surveys needed a sample size equal to or over $\mathrm{N}=104+8(11)$ or $\mathrm{N}=192$. Since both surveys had sample sizes of $\mathrm{N}=270$ and $\mathrm{N}=272$ respectively, the minimum sample size requirement, as identified by Tabachnick and Fidell (2001), were fulfilled.

Although outliers and multicollinearity are not assumption testing issues, they will be addressed in the "Assumptions Testing" section of this work. Both, outliers and multicollinearity issues were addressed while testing for normality, linearity, and homoskedasticity. Consequently, it would be more appropriate to discuss these issues and assumption tests simultaneously. 


\section{Assumption Testing of the PP and CP Data}

As addressed earlier, assumptions of normality, linearity and homoskedasticity had to be addressed for multivariate statistical testing. Normality suggests that all observations in a sample are normally distributed. Linearity refers to a straight-line relationship between two variables. Homoskedasticity identifies that scores in one continuous variable are similar to scores in another continuous variable.

Homoskedasticity is related to normality in that if normality is met, then so must homoskedasticity (Mertler \& Vanatta, 2005).

Assumptions of normality, linearity, and homoskedasticity were assessed using residuals scatterplots and normality probability plots. In normality probability plots, the straighter a diagonal line from bottom left to top right is an indication of higher levels of normality (Mertler \& Vannatta, 2005). Based on the normality probability plots (see Appendices N, O, P, and Q), assumptions of normality were not violated. Residuals scatterplots can indicate matters of linearity and homoskedasticity. The more a scatterplot is rectangular with centralized scores around the zero point is an indication of higher levels of linearity and homoskedasticity (Mertler \& Vannatta, 2005). Based on the residuals scatterplots (see Appendix N, O, P and Q), it also did not appear that the assumptions of linearity and homoskedasticity were violated. Consequently, the assumptions of multivariate statistical procedures were met and multiple regression tests could be conducted. However, as discussed earlier in this chapter, two more practical issues with the data needed to be assessed: multicollinearity and outliers.

Multicollinearity becomes a problem when the independent variables are highly correlated (Pallant, 2001). If the independent variables are highly correlated rejecting the 
null hypothesis becomes more difficult (Spicer, 2005). Consequently, a Collinearity Diagnostics was conducted on each regression equations (see appendix M). The Tolerance section of the Collinearity Diagnostics indicated coefficients for each independent variable. The closer the coefficient was to zero indicated multicollinearity (Pallant, 2001). After reviewing each Tolerance item, it did not appear that multicollinearity was a concern in any of the regression models.

As discussed earlier in the project, outliers are extreme low and high cases in a data set. According to Pallant (2001), outliers have the potential to distort statistical tests. Consequently, outliers had to be identified and appropriately managed in the data set. In the current project, outliers in the models were identified with Mahalanobis distances and the critical chi-square values. ${ }^{11}$ For the PP department and officer models, Mahalanobis distances were identified (see table 7.2).

\section{Table 7.2: Mahalanobis Distances for PP Department and Officer Models}

\begin{tabular}{|l|l|l|r|r|}
\hline & & & Case Number & \multicolumn{1}{c|}{ Value } \\
\hline Mahalanobis & Highest & 1 & 56 & 160.54795 \\
Distance & 2 & 125 & 42.56048 \\
& 3 & 109 & 26.02284 \\
& 4 & 267 & 25.18148 \\
& 5 & 269 & 24.70242 \\
& & 251 & 4.27700 \\
& & 2 & 168 & 4.29606 \\
& & 3 & 154 & 4.43558 \\
& 4 & 11 & 4.43558 \\
& 5 & 206 & 4.45367 \\
\hline
\end{tabular}

The critical chi-square values were identified using a "Critical Values of Chi Square” table (see Tabachnick \& Fidell, 2001, Table C.4). Using an alpha level of .001 with 11 degrees of freedom, the critical chi-square value was 31.264. Cases 56 and 125

\footnotetext{
${ }^{11}$ The number of independent variables was used to determine degree of freedom. Consequently, for each regression model degrees of freedom equaled 11.
} 
exceeded the critical chi-square value indicating extreme cases. Consequently, cases 56 and 125 were deleted from the data set.

For the CP department and officer models, Mahalanobis distances were again identified (see table 7.3). The critical chi-square values were identified using an alpha level of .001 with 11 degrees of freedom. The critical chi-square value was again 31.264. Cases 550 and 580 exceeded the critical chi-square value and were subsequently removed from the data set.

Once all the outliers were removed, the data was finally complete in assessing practical matters as well as meeting the assumptions of multivariate statistical testing. Consequently, the regression models, in this project could be conducted.

\section{Table 7.3: Mahalanobis Distances for CP Department and Officer Models}

\begin{tabular}{|l|l|l|r|r|}
\hline & & & Case Number & \multicolumn{1}{c|}{ Value } \\
\hline Mahalanobis & Highest & 1 & 550 & 130.23789 \\
Distance & 2 & 580 & 35.82044 \\
& 3 & 445 & 29.00507 \\
& 4 & 364 & 25.08561 \\
& & 5 & 575 & 20.85787 \\
& & & 461 & 4.20104 \\
& & 2 & 460 & 4.35648 \\
& & 3 & 466 & 4.62132 \\
& 4 & 531 & 4.62206 \\
& 5 & 473 & 4.63048 \\
\hline
\end{tabular}

\section{Regression Models}

\section{$\underline{\text { PP Department Legitimacy Multiple Regression Analysis }}$}

A standard multiple regression was conducted to determine the accuracy of the independent variables (Live on campus [S6Q3], Greek affiliated [S6Q4], Family member a police officer [S6Q5], Hometown [UrbanRural], Race [Race], Negative contact with PPO [Negative_Contact], Friend had negative contact with PPO [Friend_Neg_Contact], 
Gender [Gender], Class standing [Year], Age [Age], Adjective Scale [PosScale]) predicting student legitimacy perception levels of the PP department (see appendix R). Regression results indicated that the overall model significantly predicted student legitimacy perceptions of the PP department, R2=.537, R2adj=.517, $F(11,256$, $)=26.974$, $p<.001$. This model accounted for $54 \%$ of the variance in student legitimacy perceptions of the PP department. A summary of regression coefficients is presented in Table 7.4 and indicated that three variables (Hometown, Negative contact with a PPO, and Adjective scale) contributed to the model. 


\begin{tabular}{|c|c|c|c|c|c|c|}
\hline & B & $B$ & $\mathrm{t}$ & p & Bivariate $r$ & Partial r \\
\hline $\begin{array}{l}\text { Live on } \\
\text { campus }\end{array}$ & -.829 & -.078 & -1.58 & .115 & -.090 & -.098 \\
\hline $\begin{array}{l}\text { Greek } \\
\text { affiliated }\end{array}$ & .083 & .006 & .142 & .887 & .024 & .009 \\
\hline $\begin{array}{l}\text { Family } \\
\text { member a } \\
\text { police } \\
\text { officer }\end{array}$ & -.218 & -.015 & -.335 & 738 & -.042 & -.021 \\
\hline Hometown & -1.020 & -.097 & -2.21 & $.028 *$ & -.076 & -.137 \\
\hline Race & .452 & .033 & .760 & .448 & .014 & .047 \\
\hline $\begin{array}{l}\text { Negative } \\
\text { contact } \\
\text { w/PPO }\end{array}$ & 2.89 & .178 & 3.64 & $.001^{\wedge}$ & 455 & 222 \\
\hline $\begin{array}{l}\text { Friend } \\
\text { negative } \\
\text { contact } \\
\text { w/PPO }\end{array}$ & .634 & .061 & 1.327 & .186 & 290 & .083. \\
\hline Gender & .165 & .016 & .362 & .718 & -.018 & .023 \\
\hline $\begin{array}{l}\text { Class } \\
\text { standing }\end{array}$ & .244 & .052 & .860 & .391 & .069 & .054. \\
\hline Age & -.134 & -.049 & -.813 & .417 & -.012 & -.051 \\
\hline $\begin{array}{l}\text { Adjective } \\
\text { scale }\end{array}$ & -.731 & -.602 & -12.206 & $.001^{\wedge}$ & -.696 & -.519 \\
\hline
\end{tabular}

\section{$\underline{\text { PP Officer Legitimacy Multiple Regression Analysis }}$}

A standard multiple regression was also conducted to determine the accuracy of the independent variables (Live on campus [S6Q3], Greek affiliated [S6Q4], Family member a police officer [S6Q5], Hometown [UrbanRural], Race [Race], Negative contact with PPO [Negative_Contact], Friend had negative contact with PPO [Friend_Neg_Contact], Gender [Gender], Class standing [Year], Age [Age], Adjective 
Scale [PosScale]) predicting student legitimacy perception levels of the PP officers (see appendix S). Regression results indicated that the overall model significantly predicted student legitimacy perceptions of the PP officers, R2=.167, R2adj=.131, $F(11$, 256 ,) $=4.66, p<.001$. This model accounted for $17 \%$ of the variance in student legitimacy perceptions of the PP officers. A summary of regression coefficients is presented in Table 7.5 and indicated that four variables (Race, Negative contact with a PPO, Gender, and Adjective scale) contributed to the model. 
Table 7.5: Coefficients for Model Variables PP Officer

\begin{tabular}{|c|c|c|c|c|c|c|}
\hline & $\mathrm{B}$ & $B$ & $\mathrm{t}$ & $\mathrm{p}$ & Bivariate $\mathrm{r}$ & Partial $\mathrm{r}$ \\
\hline $\begin{array}{l}\text { Live on } \\
\text { campus }\end{array}$ & .572 & .094 & 1.432 & .153 & .078 & .089 \\
\hline $\begin{array}{l}\text { Greek } \\
\text { affiliated }\end{array}$ & -.317 & -.042 & -.712 & .477 & -.026 & -.044 \\
\hline $\begin{array}{l}\text { Family } \\
\text { member a } \\
\text { police } \\
\text { officer }\end{array}$ & -.014 & -.002 & -.028 & .978 & .003 & -.002 \\
\hline Hometown & -.274 & -.046 & -.779 & .437 & -.020 & -.049 \\
\hline Race & 1.086 & .138 & 2.392 & $.017^{*}$ & .143 & 178 \\
\hline $\begin{array}{l}\text { Negative } \\
\text { contact } \\
\text { w/PPO }\end{array}$ & 1.096 & .118 & 1.087 & $.072+$ & .191 & .112 \\
\hline $\begin{array}{l}\text { Friend } \\
\text { negative } \\
\text { contact } \\
\text { w/PPO }\end{array}$ & .052 & .009 & .143 & .886 & .118 & .009 \\
\hline Gender & 1.536 & .258 & 4.401 & $.001^{\wedge}$ & .235 & .265 \\
\hline $\begin{array}{l}\text { Class } \\
\text { standing }\end{array}$ & -.114 & -.042 & -.525 & .600 & -.015 & -.033 \\
\hline Age & .116 & .074 & .927 & .355 & -.011 & .058 \\
\hline $\begin{array}{l}\text { Adjective } \\
\text { scale }\end{array}$ & -.149 & -.216 & -3.267 & $.001^{\wedge}$ & -.248 & -.200 \\
\hline
\end{tabular}

\section{CP Department Legitimacy Multiple Regression Analysis}

A standard multiple regression was conducted to determine the accuracy of the independent variables (Live on campus [S6Q3], Greek affiliated [S6Q4], Family member a police officer [S6Q5], Hometown [UrbanRural], Race [Race], Negative contact with СPO [Negative_Contact], Friend had negative contact with CPO [Friend_Neg_Contact], Gender [Gender], Class standing [Year], Age [Age], Adjective Scale [PosScale]) 
predicting student legitimacy perception levels of the CP department (see appendix T). Regression results indicated that the overall model significantly predicted student legitimacy perceptions of the CP department, R2=.503, R2adj=.482, $F(11,258)=$,23.723 , $p<.001$. This model accounted for $50 \%$ of the variance in student legitimacy perceptions of the CP department. A summary of regression coefficients is presented in Table 7.6 and indicated that four variables (Gender, Class, Age, and Adjective scale) contributed to the model. 


\begin{tabular}{|c|c|c|c|c|c|c|}
\hline & B & $\bar{B}$ & $\mathrm{t}$ & $\bar{p}$ & Bivariate $r$ & Partial r \\
\hline $\begin{array}{l}\text { Live on } \\
\text { campus }\end{array}$ & .378 & .036 & .734 & .482 & -.080 & .044 \\
\hline $\begin{array}{l}\text { Greek } \\
\text { affiliated }\end{array}$ & -.611 & -.045 & -.979 & .329 & -.046 & -.061 \\
\hline $\begin{array}{l}\text { Family } \\
\text { member a } \\
\text { police } \\
\text { officer }\end{array}$ & -1.004 & -.063 & -1.409 & .160 & -.092 & -.087 \\
\hline Hometown & -.285 & -.027 & -.615 & .539 & -.002 & -.038 \\
\hline Race & -.117 & -.008 & -.179 & .858 & .008 & -.011 \\
\hline $\begin{array}{l}\text { Negative } \\
\text { contact } \\
\text { w/PPO } \\
\text { Friend } \\
\text { negative } \\
\text { contact } \\
\text { w/PPO }\end{array}$ & .123 & .041 & .841 & .401 & .274 & .001 \\
\hline Gender & -.998 & -.096 & -2.095 & $.037^{*}$ & -.223 & -.129 \\
\hline $\begin{array}{l}\text { Class } \\
\text { standing }\end{array}$ & .704 & .150 & 2.407 & $.017^{*}$ & .153 & . 148. \\
\hline Age & -.270 & -.103 & -1.657 & $.099+$ & .049 & -.103 \\
\hline $\begin{array}{l}\text { Adjective } \\
\text { scale }\end{array}$ & -.761 & -.644 & -12.191 & $.001^{\wedge}$ & -.690 & -.605 \\
\hline
\end{tabular}

\section{CP Officer Legitimacy Multiple Regression Analysis}

A standard multiple regression was also conducted to determine the accuracy of the independent variables (Live on campus [S6Q3], Greek affiliated [S6Q4], Family member a police officer [S6Q5], Hometown [UrbanRural], Race [Race], Negative contact with CPO [Negative_Contact], Friend had negative contact with CPO [Friend_Neg_Contact], Gender [Gender], Class standing [Year], Age [Age], Adjective 
Scale [PosScale]) predicting student legitimacy perception levels of the CP officers (see appendix U). Regression results indicated that the overall model significantly predicted student legitimacy perceptions of the CP officers, R2=.173, R2adj=137, $F(11$, 258, ) $=4.89, p<.001$. This model accounted for $17 \%$ of the variance in student legitimacy perceptions of the CP officers. A summary of regression coefficients is presented in Table 7.7 and indicates that four variables (Live on campus, Family member a police officer, Race, and Adjective scale) contributed to the model.

Table 7.7 Coefficients for Model Variables CP Officer

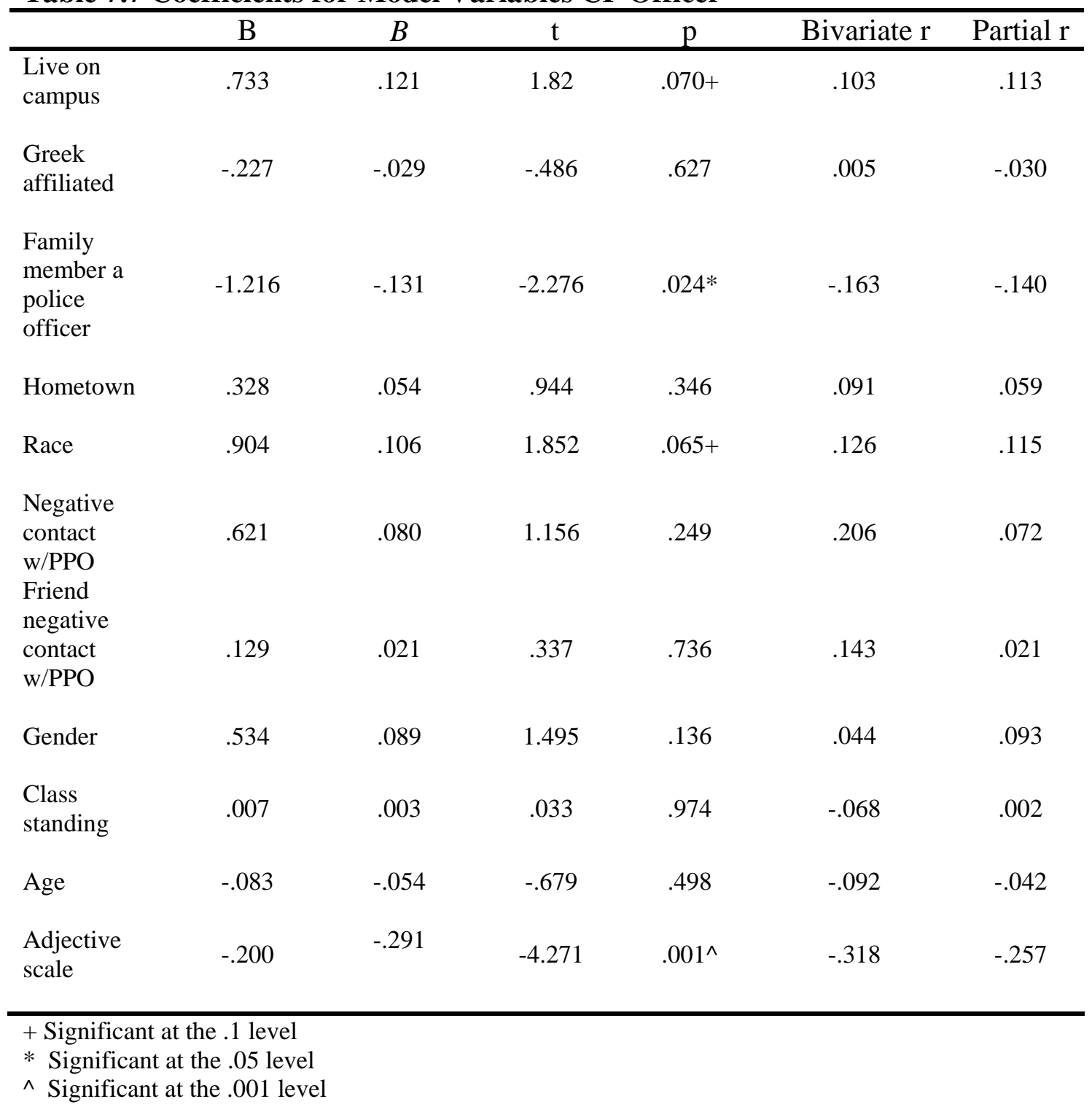




\section{Equality of Regression Coefficient Tests}

A $z$-test was conducted to determine whether the empirical relationships that were estimated with two independent samples were significant. According to Paternoster, Brame, Mazerolle and Piquero (1998), the z-test is the most appropriate test for determining the equality of regression coefficients between independent models.

Paternoster et al. (1998, p. 862) recommend the following equation to be used when testing the null hypothesis between two independent sample regression coefficients:

$\mathrm{Z}=\frac{b 1-b 2}{2}$

The square root of: (SEb1 Squared + SEb2 Squared)

Since SPSS does not have functions concerning Regression Coefficient Testing, all significant coefficients between PP and CP multiple regression models were hand calculated using the formula recommended by Paternoster et al. (1988).

PP and CP Predictor Comparisons and Coefficient Testing

\section{$\underline{P P}$ and CP Department}

It appears that, for the most part, different predictor variables were driving the perceived legitimacy models for the PP and the CP department. As identified in Table 7.8, PP department perceived legitimacy was driven by the respondents' hometown, negative contact with a PP and stereotyping the officer, while perceived legitimacy for the CP department is driven by gender, class standing, age and stereotyping the officer. 
Both models indicated that stereotyping was a significant predictor of each model. Because the adjective scale was a significant predictor in both models, a z-test was performed in order to determine if the stereotyping effect was similar for both the PP and the CP department perceived legitimacy levels. The null hypothesis for the equation would be $b$ PP department $=b C P$ department $(\underline{t}=1.98 . \underline{p}<.05)$. The results indicated $z<$ 1.98 (see table 7.8). Consequently the null hypothesis failed to be rejected. In other words, the effect of stereotyping on perceived legitimacy was similar for both the PP department and the CP department.

\section{Table 7.8: Significant Coefficients for Model Variables and Z-Test PP/CP} Department

\begin{tabular}{|c|c|c|c|}
\hline & $\begin{array}{c}\text { PP } \\
\text { Department } \\
b(\mathrm{SE}) \\
\end{array}$ & $\begin{array}{c}\text { CP } \\
\text { Department } \\
b(\mathrm{SE}) \\
\end{array}$ & z-test \\
\hline Hometown & $\begin{array}{l}-.097 * \\
(.461)\end{array}$ & & \\
\hline $\begin{array}{l}\text { Negative } \\
\text { contact } \\
\text { w/PPO }\end{array}$ & $\begin{array}{l}.178^{\wedge} \\
(.794)\end{array}$ & & \\
\hline Gender & & $\begin{array}{l}-.096 * \\
(.477)\end{array}$ & \\
\hline $\begin{array}{l}\text { Class } \\
\text { standing }\end{array}$ & & $\begin{array}{l}.150 * \\
(.292)\end{array}$ & \\
\hline Age & & $\begin{array}{l}-.103+ \\
(.163)\end{array}$ & \\
\hline $\begin{array}{l}\text { Adjective } \\
\text { scale }\end{array}$ & $\begin{array}{l}-.602^{\wedge} \\
(.060) \\
\end{array}$ & $\begin{array}{l}-.644 \wedge \\
(.062) \\
\end{array}$ & .348 \\
\hline \multicolumn{4}{|c|}{$\begin{array}{l}+ \text { Significant at the } .1 \text { level } \\
* \text { Significant at the } .05 \text { level } \\
\wedge \text { Significant at the } .001 \text { level }\end{array}$} \\
\hline
\end{tabular}

As with the PP department and the CP department, different predictor variables were driving the perceived legitimacy models for PP and CP officer. As identified in 
Table 7.9, PP officer perceived legitimacy was driven by the respondents' race, negative contact with a CP, gender and stereotyping of the officer, while perceived legitimacy for the CP officer was based on, living on campus, family member is a police officer, race, and stereotyping of the officer.

Both models indicated that race and stereotyping were significant predictors of each model. Because race and stereotyping were significant predictors in both models, ztests were performed in order to determine if the stereotyping effect was similar for both PP and CP officer perceived legitimacy levels as well as if race effect is similar for both PP and CP officer perceived legitimacy levels. The null hypothesis for both equations would be $b$ PP officer $=b$ CP officer $(\underline{t}=1.98 . \underline{p}<.05)$. The results indicated $z<1.98$ in both instances (see table 7.10). Consequently, the null hypothesis failed to be rejected in both cases. In other words, the effect of stereotyping and race on perceived legitimacy was similar for both PP officer and CP officer. 
Table 7.9 Significant Coefficients for Model Variables and Z-Test PP/CP Officer

\begin{tabular}{|c|c|c|c|}
\hline & $\begin{array}{c}\text { PP } \\
\text { Officer } \\
b(\mathrm{SE})\end{array}$ & $\begin{array}{c}\text { CP } \\
\text { Officer } \\
b(\mathrm{SE}) \\
\end{array}$ & z-test \\
\hline $\begin{array}{l}\text { Live on } \\
\text { campus }\end{array}$ & & $\begin{array}{l}.121+ \\
(.403)\end{array}$ & \\
\hline $\begin{array}{l}\text { Family } \\
\text { member a } \\
\text { police } \\
\text { officer }\end{array}$ & & $\begin{array}{l}-.131 * \\
(534)\end{array}$ & \\
\hline Race & $\begin{array}{l}.138 * \\
(.454)\end{array}$ & $\begin{array}{l}.106+ \\
(.488)\end{array}$ & .273 \\
\hline $\begin{array}{l}\text { Negative } \\
\text { contact } \\
\text { w/PPO }\end{array}$ & $\begin{array}{l}.118+ \\
(.606)\end{array}$ & & \\
\hline Gender & $\begin{array}{l}.258^{\wedge} \\
(.349)\end{array}$ & & \\
\hline $\begin{array}{l}\text { Adjective } \\
\text { scale }\end{array}$ & $\begin{array}{l}-.216^{\wedge} \\
(.046)\end{array}$ & $\begin{array}{l}-.291 \wedge \\
(.047)\end{array}$ & .809 \\
\hline
\end{tabular}

+ Significant at the 1 level

* Significant at the .05 level

$\wedge$ Significant at the .001 level

Conclusion

The purpose of Chapter Seven was to determine the selected independent variable that returned significant perceived legitimacy levels. Eleven independent variables were selected as predictor variables. The 11 predictor variables were assessed for accuracy and manipulated into a form that could be used with multiple regression.

Four multiple regression models were constructed. The models were developed in order to determine which predictor variables significantly contributed to each model. It appears that a respondent's hometown, if they had negative contact with a PP, and the adjective scale were the independent variables that significantly contributed to the 
perceived legitimacy of the PP department, while gender, age, class standing, and stereotyping explained the variation in the CP department perceived legitimacy levels. Coefficient testing determined the effect of stereotyping on perceived legitimacy was the same for both the PP and the CP department.

In terms of individual officers, race, gender, negative contact with a PP, and stereotyping were the independent variables that significantly contributed to the perceived PP officer legitimacy model. Alternately, living on campus, family member a police officer, race, and stereotyping were the independent variables that significantly contributed to perceived CP officer legitimacy levels. Coefficient testing was conducted on both race and stereotyping in each model. The coefficient tests indicated that the effect of race and stereotyping on perceived legitimacy was the same for both PP and CP officers. 


\title{
CHAPTER EIGHT \\ DISCUSSION
}

\author{
Introduction
}

Scholars have argued that universities are nothing more than small cities in many respects (Griffith et al., 2004; Michals \& Higgins, 1997). In fact, the university campus is just a microcosm of the outside world (Bennett-Johnson, 1997). Therefore, crime is not only endemic outside the walls of the university, it is also present within the walls of higher education. In fact, universities have been described, in many instances, as “dangerous places” (Smith \& Fossey, 1995). Recent examples that illustrate the dangerous nature of universities are: the Virginia Tech shooting where 32 people were killed by lone gunman, Seung Hui Cho (Johnson, 1997); Rebecca Griego, who was shot and killed in her office at the University of Washington by her estranged boyfriend Jonathan Rowan in April of 2007 (MSNBC, n.d.); Douglas Pennington, who killed his two sons and himself at Shepherd University in September of 2006; Robert Flores, who in October of 2002, shot and killed 3 of his instructors at the University of Arizona (MSNBC, n.d); Peter Odiguhizuwa, who shot and killed a dean, a professor, and a student at Virginia’s Appalachian School of Law in January of 2002; And in August of 2000, James Kelly killed his chair and himself at the University of Arkansas (MSNBC, n.d.). It is from tragic incidents like these that illustrate the dangerous nature of universities. It is also from tragic incidents that changes in campus policing have occurred. As discussed earlier, tragic incidents at Kent State, the University of Texas, and Jackson State, in the 1970s, led university administrators to rethink the role of campus security and conceptualize modern campus policing (Esposito \& Stormer, 1989). 
Consequently, campus police officers are much different from the antiquated campus security of the mid $20^{\text {th }}$ century. Primarily, campus police officers differ from campus security in that they were granted full police powers. In other words, campus police were given the power of arrest (Paoline \& Sloan, 2003). With the power of arrest, campus police became similar to "mainstream" police.

The conundrum of CP is that they are trained as "mainstream" police, where control and arrest have been historically considered their primary law enforcement function, however, because of the nature of the university, ideologically, CP are based on prevention and service (Esposito \& Stormer, 1989). The disparate ideological foci have placed CP in an awkward position. First, universities do not recognize them as part of the university system because they are "cops” and not part of academia (Smith, 1988). Conversely, and maybe more importantly, campus policing scholars have indicated that, in many instances, campus police are not perceived by the public as "real" cops, because they are based in university system (Bordner \& Peterson, 1983; Hinkle \& Jones, 1991; Heinsler et al., 1990; Nichols, 1987; Smith, 1988; Wensyel, 1987). However, these indications of campus police marginalization have been intuitive, anecdotal, or from the perception of campus police themselves. It does not appear that perceptions of campus police, in terms of being identified as "real" police from the community, have ever been empirically tested. Consequently, the main purpose of this project was to identify community perceived legitimacy perception of $\mathrm{CP}$ officers in relationship to “mainstream” or municipal police officers.

The theory hypothesized that would account for campus police marginalization, as a sworn law enforcement agent, was liminality. Liminality has been described as a 
transitional period between two social standing (Turner, 1987). The liminal period is where a person is stripped of their "old” self and through ritual and ceremony and is transformed into something new (Turner, 1974). A person who exists in the transitional state is considered a liminal "passenger” (Turner, 1974). The goal of the liminal "passenger" is to be transformed into something new. However, in some instances, liminal "passengers” may become permanently trapped in the liminal stage. Or, put another way, sometimes a liminal "passenger” may never move onto his or her new desired social standing. These unfortunate few are considered "permanently" liminal. The "permanently" liminal exist somewhere "betwixt and between."

\section{CP Officers’ Perceptions}

Two-phases were developed in this mixed-method project. The first phase consisted of CP interviews. The first-phase had a two-pronged purpose. First, the interviews were used to develop a hypothesis for the study. Secondly, the interviews were used to gather the information necessary to answer the first research question:

To what extent do CP officers' feel that they are not perceived as "real” police?

As discussed in the Chapter Four, the campus police officers interviewed had varying levels of feelings that they were not perceived as "real” police. In general, all of the CP officers interviewed indicated a feeling of marginalization by the public. However, in most instances, it was dependent on the public that they were serving. For example, one CP officer stated that the established community that "knows" them, "We are viewed as a 'real’ police force” (CPO B, 2006). However, the people that they encounter from other 
jurisdictions, other communities, and new students, often are unaware of their policing powers. However, it was clear that $\mathrm{CP}$ officers had to sell their profession. In other words, in most instances, $\mathrm{CP}$ officers have to identify themselves and explain their functions, duties, roles, police powers, etc. whereas, a municipal police officer does not. In many of the conversations with CP officers, they were specific in letting the public and in some instances fellow police brethren know that they attended the same police academy and/or training as “mainstream” police. One survey question in this project was used to identify the public's knowledge of a CP officers' training (in terms of police academy training). Question 5-1 in both surveys asked students if they believe CP officers and PP officers attend the same academy. It appears that a little over $56 \%$ of the respondents were aware that $\mathrm{CP}$ officers attend the same police academy as PP officers (see Table 8.1). Conversely, over $41 \%$ of the survey respondents were not aware that a $\mathrm{CP}$ officer's training is the same as a PP officer's, which somewhat identifies why CP appear to have to "sell" or justify their policing powers to the public.

Table 8.1: Do CP and PP attend the same police academy?

\begin{tabular}{|c|c|c|c|c|c|}
\hline & & Frequency & Percent & Valid Percent & $\begin{array}{l}\text { Cumulative } \\
\text { Percent }\end{array}$ \\
\hline \multirow[t]{3}{*}{ Valid } & Yes & 328 & 56.6 & 57.7 & 57.7 \\
\hline & No & 240 & 41.4 & 42.3 & 100.0 \\
\hline & Total & 568 & 97.9 & 100.0 & \\
\hline Missing & System & 12 & 2.1 & & \\
\hline Total & & 580 & 100.0 & & \\
\hline
\end{tabular}

In fact, many of the CP officers argued that the public, in most instances, identifies them as the antiquated security guards of the middle $20^{\text {th }}$ century. Therefore, as the CP officers indicated, the public identifies them as something "less than" a sworn law enforcement agent. Although, $5 \mathrm{CP}$ officer interviews may make it difficult to generalize 
to the entire CP department, it appears that, in general, CP officers feel, to varying degrees, that they are not recognized as "real” police officers, at least in instances where the "contacted" had not been acculturated to a formalized campus police agency and/or officer.

Interestingly, the perceptions of CP officers were almost identical to the feelings of campus police officers in a study conducted by Bordner and Peterson (1983) over twenty years ago. This appears to indicate that the WSU CP officers' perceptions may be somewhat generalizable.

However, these feelings were based on the perceptions of campus police officers in terms of what they believe are the perceptions of the community. The actual legitimacy perception of the community is the question that has not been addressed in the literature. Consequently, the second purpose of this project was to identify the community’s legitimacy perceptions of CP.

\section{Community Legitimacy Perceptions of PP and CP}

As suggested earlier throughout this project, scholars (see Heinsler et al., 1990; Hinkle \& Jones, 1991; Smith, 1988; Nichols, 1987; Wensyel, 1987) have argued that the public does not perceive campus police "real” cops. This interpretation had been identified, primarily, intuitively. However, it does not appear that there have been any studies that actually empirically measure the public's perception of campus police in terms of, are they a "real” cop. In other words, does the public view campus police similarly, in terms of a legitimate law enforcement agent, as their "mainstream” counter parts (i.e. municipal police)? 
Consequently, the primary purpose of this project was to determine the public's legitimacy perceptions between CP and PP. It seemed that a perceived legitimacy comparison between a campus police department/officer and a municipal "mainstream" police department/officer would put these historical anecdotal annotations of legitimacy differences to "bed.” To identify legitimacy perceptions, two surveys were equally distributed in undergraduate classes at WSU. The undergraduate classes were chosen based on a convenience sample. Although, a convenience sample is less rigorous than a random sample, Goodwin (2002) has argued that perceptual studies are highly generalizable between undergraduate students. Furthermore, as discussed in chapter five, the respondent demographics were, in general, similar to the WSU population as well as extremely similar between groups. Consequently, the convenience samples should not be problematic, in terms of the reliability and validity, for this project.

The primary purpose of the surveys was to measure a student's legitimacy perception of either a PP or a CP, dependent on the survey the student received. A modified police legitimacy scale developed by Sunshine and Tyler (2003) was the instrument for measuring police legitimacy. Legitimacy was operationalized as the "perceived obligation to obey the directives of a legal authority, trusting in the institution of policing and in individual police officers in one's neighborhood, and affective feelings toward the police” (Sunshine \& Tyler, 2003, p. 539).

After analyzing the returned surveys from the current project, a factor analysis was run on the modified legitimacy scale. Two main factors were identified from the analysis. The two factors identified appeared to be legitimacy of an officer and legitimacy of the officer's department. Based on the factor analysis results, two 
legitimacy scales were constructed: legitimacy of the officer and legitimacy of the department. Consequently, two comparisons could be made between PP and CP. This appeared to add a more complex understanding of legitimacy between the two law enforcement agencies.

Based on the two legitimacy scales, two null hypotheses were constructed. First, the mean of legitimacy scores for the PP department would be equal to the mean legitimacy scores for the CP department or Ho1: mean of the PP department = mean of the CP department. Because, theoretically, it appears that CP are seen as not "real" police, it would also seem likely that the CP department is also not seen as "real" police department. Consequently, the alternative hypothesis formulated would be directional. In other words, it could be hypothesized that the PP department should have higher legitimacy levels than the CP department. Thus, the alternative hypothesis accounted for this directionality, H1: mean of the PP department legitimacy score < mean of the CP department legitimacy score ${ }^{12}$. Secondly, the mean of legitimacy scores for PP officers would be equal to the mean of legitimacy scores for $\mathrm{CP}$ officers or Ho2: mean of $\mathrm{PP}$ officers' legitimacy score = mean of CP officers' legitimacy score. The alternative hypothesis was based on the same rational as $H 1$ and formulated, $H 2$ : mean of $P P$ officers' legitimacy score < the mean of CP officers' legitimacy score.

The tests conducted for measuring legitimacy differences in PP and CP (department and officer) were independent sample t-tests. Independent sample t-tests "compare sample results with the conditions specified under the null hypothesis, dividing the difference by the standard error” (Coladarci, 2004, p. 290). Simply put, an independent sample t-test determines if there is a statistically significant means difference

${ }^{12}$ Lower scores on the legitimacy scale represented higher levels of legitimacy. 
between the two samples based on the sample results, conditions of the null hypothesis, and standard error. The formula for an independent sample $t$-test is as follows (Coladarci, 2004, p. 290):

$$
t=\frac{\text { mean of X1 }- \text { mean of X2 }}{\text { standard error of the mean of X1 - standard error of the mean of X2 }}
$$

As identified in Chapter Six, the first $t$-test was used to determine if no difference existed between the mean legitimacy scores of the PP department and the CP department

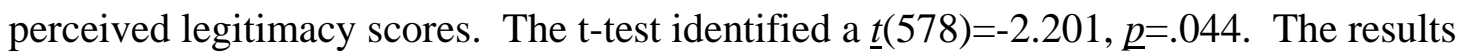
indicated that a statistically significant difference existed between the legitimacy scores of the PP department as compared with the CP department at the .05 level. As can also be identified, the $t$ value was -2.201 , which indicates, based on the legitimacy scale structure, that in fact, the PP department legitimacy, as perceived by the public, is higher than the CP department legitimacy as perceived by the public.

Similarly, the second $t$-test conducted between legitimacy perceptions of PP officer and legitimacy perceptions of CP officers also identified a statistically significant perceived legitimacy difference between the two types of law enforcement officers. The results of the $t$-test identified a $\underline{t}(578)=-3.088, \underline{p}=.002$. These results indicate a statistically significant difference of perceived legitimacy at the .001 level. Correspondingly, the $t$ value was negative, which indicates that PP officers have a higher legitimacy perceptions from the public than do CP officers.

However, as Walsh and Ollenburger (2001) point out, statistical significance only specifies how likely a measurable difference can be found between groups in a sample. Statistical significance does not necessarily identify substantive significance. In other 
words, a difference may be found between groups, but the difference may not have any practical importance.

To help identify the practical importance of a statistically significant test result, the effect size or the degree in which the variables are associated with one another can be calculated. The effect size indicates the amount of variance in the dependent variable based on the independent variable. The effect size, therefore, is an indicator of the magnitude of the difference between the means (Pallant, 2001). The magnitude of the difference helps explains, in general, the substantive importance of difference.

Looking at the first $t$-tests conducted in this project, the PP department and the CP department, a statistically significant result was returned. In other words, the PP department was perceived as more legitimate than the CP department as perceived by WSU undergraduate students. An eta squared was calculated to help understand the practicality of the result. The eta squared was calculated at a .007 . This means that the type of department (PP or CP) accounted for .7\% of the variance in perceived legitimacy in the sample. Conversely, .7\% of the variance means, $99.03 \%$ of the variance, in terms of department type and legitimacy perceptions, is accounted for by some other variable(s). In other words, the type of department plays almost no role in determining perceived legitimacy levels. Similarly, the $t$-test used to measure the difference between PP officer and CP officer returned a statistically significant result. Or more specific, PP officers were perceived as more legitimate than $\mathrm{CP}$ officers. An eta squared was calculated to determine the effect size. The magnitude of the difference was small at a.016. Thus, officer type (PP or $\mathrm{CP}$ ) accounted for $1.6 \%$ of the variance, indicating that 
98.4\% of the variance was accounted for by some other variable(s). In other words, officer type had a very small effect on perceived legitimacy levels.

The $t$-tests were used in order to answer the two proposed null hypotheses, Ho1 and Ho2. Secondly, eta squared was calculated for any significant results identified in either of the two $t$-tests and were used to, somewhat, determine the substantive value of the difference. As previously mentioned the first null hypothesis was Ho1: mean of the $P P$ department $=$ mean of the $C P$ department. As indicated by the $t$-test, the null hypothesis was rejected and the alternative hypothesis was supported, H1: mean of the PP department legitimacy score < mean of the CP department legitimacy score. The second null hypothesis was Ho2: mean of PP officers' legitimacy score = mean of CP officers' legitimacy score. Also, as indicated by a t-test, the null hypothesis was rejected and the alternative hypothesis was supported, $\mathrm{H2}$ : mean of PP officers' legitimacy score $<$ the mean of CP officers' legitimacy score. Simply put, both $t$-tests indicated that perceived legitimacy was higher for PP (department and officer) as compared to CP (department and officer). The calculated eta squared for both $t$-tests were very small. These findings indicated that, although there were significant differences, the differences may have little substantive or operational meaning.

\section{Predictors of PP and CP Legitimacy Perceptions}

The final research question was based on the selected independent variables that significantly predicted student legitimacy perceptions for each multiple regression model. As discussed earlier, multiple regression is a statistical technique that identifies patterns between multiple independent variable on a single dependent variable. Multiple 
regression also addresses how well two or more independent variables are able to predict an outcome of the dependent variable as well as indicate the relative strength of each independent variable in relationship to the dependent variable (Walsh \& Ollenburger, 2001). Simply put, the multiple regression models in this project identified the selected independent variables that were contributing to legitimacy perception. Furthermore, the multiple regression models indicated the strength of the effect of the independent variable(s) on legitimacy perceptions. Consequently, multiple regression models were used to answer the final research question: What selected independent variables returned significant perceived legitimacy results (for PP department/officer and CP department/officer)? Again, because the legitimacy scale developed in this project identified two components of legitimacy, department and officer, four null hypotheses were developed:

Ho3: the selected independent variables overall did not significantly predict student legitimacy perceptions of the PP department.

Ho5: the selected independent variables overall did not significantly predict student legitimacy perceptions of the CP department.

Ho4: the selected independent variables overall did not significantly predict student legitimacy perceptions of PP officers.

Ho6: the selected independent variables overall did not significantly predict student legitimacy perceptions of CP officers.

Consequently, what predictor variables contributed to the multiple regression models (PP and CP: department and officer) will be discussed first. Once all significant predictor variables are determined for all models, comparison between the models will be discussed. 


\section{Predictor Variables}

As discussed in Chapter Seven, 11 independent variables were used in the multiple regression models. Independent variables were chosen based on prior legitimacy literature for municipal/state police, $\mathrm{CP}$ literature, as well as $\mathrm{CP}$ interviews. These 11 independent variables were: 1) Does the respondent live on campus; 2) Is the respondent a fraternity or sorority member; 3) Is a member of the respondent's family a police officer; 4) Respondent’s home city (urban/rural); 5) Respondent's race/ethnicity; 6) If the respondent had contact with a by a police officer (campus or municipal) was the contact negative (perceived as treated unfairly); 7) If the respondent new someone who had contact with the police (campus or municipal) was the contact negative positive (perceived as treated unfairly); 8) Respondent's gender; 9) Respondent’s class standing in college; 10) Respondent’s age; 11) And a positive adjective scale.

\section{Predictors of Legitimacy}

According to Worrall (1999), public perceptions of the police have mostly focused on municipal police. Although, to date, no public legitimacy perceptions ${ }^{13}$ of campus police have been studied, scholars have argued that campus police have evolved similarly to municipal police (Bromley \& Reeves, 1998). Furthermore, comparative studies have indicated that municipal police and campus police, in general, are parallel in

\footnotetext{
${ }^{13}$ Miller and Pan (1987) studied community perceptions of campus police in terms of effectiveness as law enforcers and effective response. However, the dependant variable was not legitimacy per se. Miller and Pan's dependent variables were: effective at job, ability to handle all law enforcement problems, relationship with community, public respect. Therefore, it could be argued that there has been somewhat of a perceived legitimacy study of campus police. Similarly, Griffith et al. (2004) also conducted a study on perceptions of campus police. However, the perceptions were not based on legitimacy per se. One of the dependent variables was conceptualized as satisfaction with police services. Therefore, the Griffith et al. (2004) could also be argued to somewhat measure perceived legitimacy.
} 
organizational structure, (Paoline \& Sloan, 2003) operations, and practice (Bromely \& Reeves, 1998; Sloan, et al. 2000). Consequently, it was hypothesized that, in general, the CP understudy would have similar results in terms of the type of legitimacy predictors as PP.

The predictor variable(s), both individual and contextual, that significantly contributed to each of the models were identified. Once the significant predictor variable(s) were identified, a comparison between PP and CP could developed.

Furthermore, a z-test was calculated on significant predictor variable(s) between models (CP and PP). The z-tests were used to determine if the predictor variable(s) effect was the same for both PP and CP.

\section{$\underline{\text { PP Department Legitimacy Predictors }}$}

As identified in Chapter Seven, regression results for the overall model of the PP department was significant at the $p<.001$ (see Appendix R). Consequently, Ho3 must be rejected and the alternative hypothesis must be supported or the selected independent variables overall significantly predicted student legitimacy perceptions of the PP department. The selected independent variables accounted for $54 \%$ of the variance in student legitimacy perceptions of the PP department (see Appendix R). Three of the 11predictor variables returned significant results: hometown, negative contact with a PP officer and the adjective scale (see Table 8.2). 
Table 8.2: Significant Coefficients for Model Variables and Z-Test PP/CP

Department

\begin{tabular}{|c|c|c|c|}
\hline & $\begin{array}{c}\text { PP } \\
\text { Department } \\
b(\mathrm{SE}) \\
\end{array}$ & $\begin{array}{c}\text { CP } \\
\text { Department } \\
b(\mathrm{SE}) \\
\end{array}$ & $z$-test \\
\hline Hometown & $\begin{array}{l}-.097 * \\
(.461)\end{array}$ & & \\
\hline $\begin{array}{l}\text { Negative } \\
\text { contact } \\
\text { w/PPO or } \\
\text { CPO }\end{array}$ & $\begin{array}{l}.178 \wedge \\
(.794)\end{array}$ & & \\
\hline Gender & & $\begin{array}{l}-.096 * \\
(.477)\end{array}$ & \\
\hline $\begin{array}{l}\text { Class } \\
\text { standing }\end{array}$ & & $\begin{array}{l}.150^{*} \\
(.292)\end{array}$ & \\
\hline Age & & $\begin{array}{l}-.103+ \\
(.163)\end{array}$ & \\
\hline $\begin{array}{l}\text { Adjective } \\
\text { scale }\end{array}$ & $\begin{array}{l}-.602^{\wedge} \\
(.060)\end{array}$ & $\begin{array}{l}-.644 \wedge \\
(.062)\end{array}$ & .348 \\
\hline
\end{tabular}

Hometown was conceptualized in the survey as where the respondent grew up, if the respondent lived in multiple towns before college, where he or she felt was his or her place of greatest influence was recorded. Each respondent's recorded hometown was dichotomized into either urban or rural, based on the U.S. Census Department's 2000 classification of urban and rural areas by population.

During the CP interviews, officers indicated that perceptions of them not being identified as "real” police may be based on the size of the city and/or agency, not necessarily the institution of campus policing itself. For example, one CP officer indicated:

"A lot of these college students come from the big city and stuff like that, where there is a lot more violence might be going on. If they come from 
Sacramento, Seattle, or Bellevue, of course law enforcement challenges are a lot different over there than they are in Pullman. I think that if there is a college student that comes to Pullman, goes to WSU, and comes from a big city, I don't think that they will give the same amount of respect to WSU police or Pullman police. Because their impression of Pullman is college related. I think that may be another reason why the students may have maybe a different perceptions of police on campus and the city itself" (CPO A).

The impression (of environment) that the CP officers identified contradicted the "Hometown" finding in the regression model for the PP department. The regression result indicated that a respondent from an urban area had higher levels of perceived legitimacy for the PP department. The finding also contradicted the Zample and Annesley (1987) study in which a respondent's hometown population was a significant predictor of favorability for the police. As would be intuitively expected, the Zample and Annesley (1987) study indicated a respondent's hometown that was classified as rural had higher levels of favorability toward police. Consequently, a student's urban classification and higher levels of perceived legitimacy towards the PP department needs further investigation.

Second, a respondent's negative contact with PP was also a significant predictor of legitimacy levels. Or put another way, a negative contact with a PP officer led to lower levels of legitimacy. This finding was similar to the multiple police studies on citizen/police interactions and satisfaction levels (see Brandl, Frank, Worden, \& Bynum, 1994; Reisig \& Correia, 199; Sims et al., 2002).

Lastly, similar to the Hopkins et al. (1992) study, a respondent's preconceived stereotyping/perception of an officer, based on an adjective scale, was significant in predicting levels of perceived legitimacy. In other words, the more positive an 
individual's stereotyping/perception of the PP department increased the levels of perceived legitimacy.

\section{$\underline{\text { CP Department Legitimacy Predictors }}$}

Regression results for the overall model of the CP department was significant at the $p<.001$ (see appendix T). Consequently, Ho4 must be rejected and the alternative hypothesis must be supported or the selected independent variables overall significantly predicted student legitimacy perceptions of the CP department. The selected independent variables accounted for $17 \%$ of the variance in student legitimacy perceptions of the CP department (see appendix T). Moreover, four predictor variables returned significant results in the CP department multiple regression model: gender, class, age, and adjective scale (see table 8.2).

Gender of the respondent, in the current project, was a significant predictor of legitimacy of the CP department. It appears, in the current project, that females had higher perceived legitimacy levels for the CP department than did male respondents. The current finding was comparable to the multiple studies on gender and police favorability/satisfaction perceptions (see Griffith et al, 2004; Hopkins et al., 1992; Miller \& Pan, 1997; Reisig \& Giacomazzi, 1999).

The age of the respondent in the current study was also a significant predictor of legitimacy for the CP department. This finding was similar to multiple police studies that have identified younger persons as having lower levels of favorability toward the police than older persons (see Correia et al. 1996; Reisig \& Giacomazzi, 1998; Worrall, 1999). However, the current finding also contradicted the Miller and Pan (1997) study of 
campus police at Purdue University, as well as the Griffith et al. (2004) study that found age did not significantly predict favorability and satisfaction levels of campus police.

As discussed earlier, it does not appear that class standing has been studied, in terms of perceptions of police. Therefore, class standing was added as an independent variable (in this project) to determine if class standing would significantly predict student legitimacy perceptions. As indicated by the regression model, a significant relationship between class standing and legitimacy perceptions existed. However, the relationship was negative. In other words, the higher the class standing of a respondent led to lower levels of perceived legitimacy. It is unknown why class standing would result in lower levels of perceived legitimacy. This finding is something that will have to be looked at in future research.

Similar to the PP department, the more positive a respondent's stereotyping/perception of a CP department was also a significant predictor of increased legitimacy for the CP department. A z-test was conducted on the adjective scale for both the PP department and the CP department (see table 8.2) and returned a non-significant result. Therefore, it could be argued that the effects of stereotyping for both the PP department and the CP department were comparable.

\section{PP Officer Legitimacy Predictors}

As identified in Chapter Seven, regression results for the overall model of PP officer was significant at the $p<.001$ (see appendix S). Consequently, Ho5 must be rejected and the alternative hypothesis must be supported or the selected independent variables overall significantly predicted student legitimacy perceptions of PP officers. 
The selected independent variables accounted for $17 \%$ of the variance in student legitimacy perceptions of PP officers (see Appendix S). Four of the 11-predictor variables were significant predictors of legitimacy: race, negative contact with a PPO, gender, and the adjective scale (see Table 8.3).

Table 8.3: Significant Coefficients for Model Variables and Z-Test PP/CP Officer

\begin{tabular}{|c|c|c|c|}
\hline & $\begin{array}{c}\text { PP } \\
\text { Officer } \\
b(\mathrm{SE})\end{array}$ & $\begin{array}{c}\text { CP } \\
\text { Officer } \\
b(\mathrm{SE})\end{array}$ & $z$-test \\
\hline $\begin{array}{l}\text { Live on } \\
\text { campus }\end{array}$ & & $\begin{array}{l}.121+ \\
(.403)\end{array}$ & \\
\hline $\begin{array}{l}\text { Family } \\
\text { member a } \\
\text { police } \\
\text { officer }\end{array}$ & & $\begin{array}{l}-.131 * \\
(534)\end{array}$ & \\
\hline Race & $\begin{array}{l}.138 * \\
(.454)\end{array}$ & $\begin{array}{l}.106+ \\
(.488)\end{array}$ & .273 \\
\hline $\begin{array}{l}\text { Negative } \\
\text { contact } \\
\text { w/PPO or } \\
\text { CPO }\end{array}$ & $\begin{array}{l}.118+ \\
(.606)\end{array}$ & & \\
\hline Gender & $\begin{array}{l}.258^{\wedge} \\
(.349)\end{array}$ & & \\
\hline $\begin{array}{l}\text { Adjective } \\
\text { scale }\end{array}$ & $\begin{array}{l}-.216 \wedge \\
(.046)\end{array}$ & $\begin{array}{l}-.291 \wedge \\
(.047)\end{array}$ & .809 \\
\hline
\end{tabular}

Race was shown to be a significant predictor of legitimacy perceptions of PP officers. These results were similar to the multiple police studies that indicated race, blacks and Hispanics, in general, viewed the police with less favorability than whites (see Garcia \& Cao, 2005; Hurst et al., 2000; Murphy \& Worrall, 1999; Reisig \& Parks, 2000; Weitzer \& Tuch, 1997; Worrall, 1999). 
Negative contact with a PP officer was also shown to be a significant predictor of perceived legitimacy for PP officers. The results of the regression model indicated that as negative contact increases, lower levels of legitimacy perceptions toward PP officers followed. Again, the finding, in terms of negative contact with a PP officers and lower levels of legitimacy perceptions, was unsurprising. Based on satisfactions studies of police, negative contact with police (both campus and mainstream police) has shown to decrease levels of satisfaction toward police officers (see Brandl, et al., 1994; Reisig \& Correia, 1999; Sims et al., 2002; Sloan, 1992).

Gender of the respondent in the current project contradicted the multiple studies on gender and favorability/satisfaction perceptions of police (see Griffith et al, 2004; Hopkins et al.,1992; Miller \& Pan, 1997; Reisig \& Giacomazzi, 1999). The regression results indicated that females had lower perceived legitimacy perceptions for PP officers than did males. However, the current finding was similar to the Correia et al. (1996) study of the perceptions of Washington State Police (WSP), in that females had lower levels of favorability toward WSP officers. However, Correia et al (1996) only indicated that this finding was contradictory to policing literature and offered no theoretical rationale for the occurrence. Consequently, it appears that females' lower levels of perceived legitimacy towards PP officers needs further investigation.

Similar to the PP department, the more positive a respondent's stereotyping/perception was also a significant predictor of increased perceived legitimacy toward PP officers. This finding was not surprising. It seems intuitive that positive perceptions of an officer would also increase the levels of perceived legitimacy. 


\section{$\underline{\text { CP Officer Legitimacy Predictors }}$}

Regression results for the overall model of CP officer was significant at the $p<.001$ (see appendix J). Consequently, Ho6 must be rejected and the alternative hypothesis must be supported or the selected independent variables overall significantly predicted student legitimacy perceptions of CP officers. The selected independent variables accounted for $17 \%$ of the variance in student legitimacy perceptions of CP officers (see appendix J). Four of the 11-predictor variables were significant predictors of perceived legitimacy levels: live on campus, family member a police officer, race, and the adjective scale (see table 8.3).

Whether a respondent lived on or off-campus was a significant predictor of perceived legitimacy levels toward CP officers. As discussed earlier, since CP officers' primary jurisdiction is the university campus, live-on students should have more contact with CP. According to White and Menke (1982), citizens that had contact with the police appeared to inculcate less favorable views of them. The results of the current project confirmed the White and Menke (1982) study and identified that campus live-on students had lower levels of perceived legitimacy for CP.

Correia et al. (1996) indicated that citizen evaluations were more positive when an individual perceived that he or she was being treated fairly by the police officer. In the CP officer interviews, many officers indicated that, in general, CP officers are liked by the general public based on the time afforded to make individual positive contacts. For example:

"Because the environment we are in, we are afforded certain luxuries that a lot of other agencies are not, number one being time. We have the time 
to sit down and invest in a call, to talk to the reporting party or complainant” (CPO C).

"We are proactive. I think we make a lot of social contacts." (CPO E).

"I think we are respected, but beyond that I think we are liked" (CPO B).

Similar to the Correia et al. (1996) study, since CP officers are able to make positive individualized contacts, it seems citizen evaluations would be more favorable. Furthermore, many $\mathrm{CP}$ indicated that, in general, the public likes them. As with the Hopkins et al. (1992) study, the more positive perceptions of the police by the public indicated higher levels of favorability. Consequently, the lower levels of perceived legitimacy toward CP from live on campus respondents needs further investigation.

A family member being a police officer also significantly predicted perceptions of legitimacy. Although, there does not appear to be specific research indicating higher levels of favorability of policing based on a family member's occupation, generally, research has indicated that close proximity of acquaintances effect the values and attitudes of children (Goodman, 1957). Consequently, it seemed theoretically plausible that a respondent would have higher levels of legitimacy for police, if a family member was a police officer. The regression model confirmed the theoretical argument that a respondent whose family member was a police officer increased the levels of perceived legitimacy. However, it is uncertain why this variable only applied to CP and not for PP. Therefore, this variable may be a concern for future study.

As with PP officers, race also returned significant results for perceived legitimacy. Similarly, to the PP officer results, the perceived legitimacy of a CP officer was lower if the respondent was non-white. This finding was consistent with the multiple 
police studies that have identified non-whites having lower levels of favorability toward police (see Hurst, Browning, \& Browning, 2000; Murphy \& Worrall, 1999; Reisig \& Parks, 2000; Weitzer \& Tuch, 1997; Worrall, 1999). Although, one police study in particular, a study of citizen attitudes of Detroit police, by Frank, Brandl, Cullen, and Stichman (1996), found that blacks held more favorable views of police than do whites. However, the authors were quick to point out the context of the Detroit sample of respondents. The city of Detroit held a majority of black residents, had a long standing of retaining a black mayor, and over 50\% of the police department was black.

Consequently, Frank et al. (1996) argued that the context of the respondents was likely to be the influential component for the positive attitudes of black respondents toward police. Consequently, further study of race, legitimacy, and CP should be conducted at a university with a majority sample of minority students i.e. a historically black college or university (HBCU).

Lastly, similar to PP officer results, a significant finding between the adjective scale and levels of perceived legitimacy was identified. Higher levels of positive stereotyping, toward CP officers, led to higher levels of perceived legitimacy toward CP officers. The adjective/stereotype finding both for PP officer and CP officer were comparable to the Brandl et al. (1994) study that argued police evaluations were affected by stereotyping perceptions. Brandl et al. (1994) found that an individual who held favorable views of the police was more likely to perceive his or her contact with the police as positive. Therefore, a more positive stereotype and a more positive perception of legitimacy, in the current study, was not a surprising result. 
PP officer and CP officer regression models had two similar significant predictor variables. The significant predictor variables found in both models were race and the adjective scale (or stereotyping). A z-test was conducted on race and the adjective scale for both PP officer and CP officer (see table 8.3). The results of the z-tests returned a non-significant result for both race and the adjective scale. Therefore, it was argued that the effects of race and stereotyping perceptions (adjective scale) for both PP officer and CP officer were comparable.

\section{Conclusion}

When analyzing the campus police interviews, the levels of feeling marginalized by the public was varied between officers. However, it was clear that the marginalization, in terms of legitimacy or not being recognized as a "real” cop was present. These finding were similar to the conclusions of Bordner and Peterson (1983) almost 25 years earlier.

Based on the modified police legitimacy scale developed by Sunshine and Tyler (2003), two measurements of police legitimacy were identified, legitimacy of the department and legitimacy of the officer. The legitimacy scales were used to test the developed hypothesis derived from the CP interviews and historical campus police literature. In other words, are campus police not recognized as "real" cops by the public? However, since two legitimacy scales were developed from the original Sunshine and Tyler (2003) scale, two comparisons could be made between PP and CP, a department comparison and an officer comparison. 
Initially, independent sample t-tests were used to identify levels of legitimacy perceptions between PP and CP: department and officer. The results indicated that the feelings of CP were congruent with the public in that both PP: department and officer were identified with higher perceptions of legitimacy levels than CP: department and officer. However, these results should be noted with some skepticism. The eta squared or the measure that accounts for extent of the difference was very small. In other words, there were statistically significant differences, but the substantive differences were weak.

Nevertheless, based on the CP interviews and the statistical significance of the $t$ tests, it could be argued that $\mathrm{CP}$ are, in fact, permanently liminal. CP officers separate themselves from their community with an objective of progression into a new social group or social structure. Through the police academy or ceremony, CP are initiated with the ultimate purpose to transition him or her into a police officer. However, unlike "mainstream" police, it appears that CP are unable to leave that transitional state and become permanently liminal. CP appear to separate themselves from their original community, are initiated for a new social standing, but unlike their "mainstream" counterparts do not transition into their new or desired social standing. Or simply put, CP are not recognized as "real” cops.

In general, it appears that legitimacy predictors for PP were somewhat different for CP. In the current study PP: department and officer predictors of legitimacy were hometown, race, negative contact with a PP, gender, and the adjective scale, while the predictors of legitimacy for CP: department and officer were gender, class standing, age, living on campus, family member a police officer, race, and the adjective scale. However, race and the adjective scale were the two variables that significantly predicted perceived 
levels of legitimacy in both CP and PP models. Furthermore, the z-test indicated that effects of race and the adjective were the same for both CP and PP models.

Lastly, perceptions of legitimacy levels of PP and CP may be based on the size of the departments and/or the environment of the departments. Consequently, future studies of perceived legitimacy levels of CP should account for department size and the environment of the university. 


\section{CHAPTER NINE}

\section{CONCLUSION}

The current project yielded very few surprises. In fact, all research questions were confirmed by the data analysis. The primary objective of the project was to empirically discover if, indeed, campus police were not seen as "real” police by the public. The statistical evidence significantly indicated that campus police, both department and officers, were not seen as legitimate as compared to their "mainstream" counterparts. Again, the finding must be reviewed with caution. The percentage of variance explained by CP and PP were very small. These findings suggested that although there was a statistical significance in perceived legitimacy between PP and CP, the effect was weak. In other words, the substantive difference of perceived legitimacy between PP and CP was almost meaningless. However, albeit weak, there was a measurable difference.

Because of the measurable difference between perceived legitimacy of PP and $\mathrm{CP}$, it could be theorized that, indeed, campus police may be trapped in a liminal space, a space where CP are neither a civilian nor recognized as a "real” cop, someplace inbetween two worlds. Again, the findings must be reviewed with caution. Being a "real" cop was operationalized as being perceived as "legitimate” as conceptualized by Sunshine and Tyler (2003). However, the Sunshine and Tyler (2003) scale was used to measure legitimacy perceptions of already established “mainstream” police. What determines the legitimacy of campus police could, theoretically, be different from “mainstream” police. However, at the time of this project, no other measurements existed. 
Initially, the permanently liminal phenomenon of $\mathrm{CP}$ was considered a pessimistic attribute for a law enforcement agent. Not being identified as a "real" cop and being trapped in a liminal space seemed disconcerting, after all, $\mathrm{CP}$ go to the same police academy, attend similar training, and, in most instances, handle the same types of incidents as PP, their "mainstream” counterparts. It seemed unjust that the public would have a different perceptions or a different recognition of CP compared to their “mainstream” counterparts.

However, as Bordner and Peterson (1983), Nichols (1987) and Esposito and Stormer (1989) argued, the nature of campus police is different than "mainstream" police. Campus police are based on prevention and service rather than arrest and control. Moreover, campus police were developed to enhance the mission of a university by providing a safe atmosphere for scholarly learning. As one of the CP officers for the current project indicated:

"I really see myself as an extension of the educational portion of this university” (CPO E).

Thus, in a sense, campus police are supposed to be different than "mainstream" police. It is quite possible that campus police should not be seen as "real” cops. Campus police were created to be something in-between a cop and representative of the university. Consequently, the liminal space may be the appropriate gap that campus police should occupy.

Czarniawska and Mazza (2003) explain that an individual in a liminal space is undefined and beyond the normative structure. The liminal passenger, therefore, is also liberated from structural obligations. Czarniawska and Mazza (2003) argue that the liminal space can be considered a permanent place rather than a created space for 
transition. The liminal space can, thus, be beneficial. Bruce and Davies (2005), in their study of hospice care, argued that the liminal space is a place where solid binaries fade. Liminality, as explained by Bruce and Davies (2005), is also the hyphen between two dualities. It is a place where two multiple identities can exist at once.

It appears that campus police exist in the liminal space. Campus police appear to be the hyphen between the police and the university. It also appears that existing in the liminal space may be essential for campus police to negotiate their multiple roles. The liminal space allows campus police to exist both as a law enforcement officer as well as an extension of the educational mission of the university. 


\section{REFERENCES:}

About WSU. (n.d.). WSU history: Highlights by the decade. Retrieved May 13, 2007 From http://www.wsu.edu/WSU-history/.

About WSU. (n.d.a). WSU overview. Retrieved May 13, 2007. from http://www.wsu.edu/NIS/WSUOverview.html.

About WSU. (n.d.b). WSU statewide facts \& figures. Retrieved May 14, 2007. from http://www.wsu.edu/facts_figures_1106.pdf.

Alexander, B.C. (1991) Victor turner revisited. United States of America: American Academy of Religion.

Awerbuck, L. (1999). Tactical reality: An uncommon look at common sense firearms training and tactics. Boulder, Colorado: Paladin Press.

Babbie, E. (2001). The practice of social research. United Sates: Wadsworth, Thomas Learning.

Bachman, R., \& Paternoster, R. (1997). Statistical methods for criminology and criminal justice. New York: The McGraw-Hill Companies, Inc.

Barling, J., Kelloway, E.K., \& E.H. Bremermann. (1991). Preemployment predictors of union attitudes: The role of family socialization and work beliefs. Journal of Applied Psychology. 76. 725-731.

Beck, K., \& Wilson, C. (1998). Development of organisational: Pre-recruitment, training and probation. National Police Research Institute. Report Series No. 122.2

Bell, D.J. (1995) Police and public opinion. Journal of Police Science and Administration. 7. 196-205. 
Bennett-Johnson, E. (1997). The emergence of american crime and violence on the college and university. College Student Journal. 31. 129-136.

Bordner, D.C., \& Peterson, D.M. (1983). Campus policing: The nature of university police work. New York: University Press of America.

Bromley, M.L. (2000). A content review of campus police vehicle pursuits policies at large institutions of higher education. Policing: An International Journal of Police Strategies \& Management. 23. 492-505.

Borland, K.W. (2001). Qualitative and quantitative research: A complementary balance. Direction for Institutional Research: Balancing Qualitative and Quantitative Information for Effective Decision Support. 112. 5-13.

Brandl, S. G., Frank, J., R.E. Worden, \& T.S. Bynum. (1994). Global and specific attitudes toward the police: Disentangling the relationship. Justice Quarterly. 11. 119-134.

Brechi, M.G., \& Erickson, T.E. (1998). Community policing: The process of transitional change. The FBI Law Enforcement Bulletin. 67.16-21.

Bromley, M.L., \& Reaves, B.A. (1998). Comparing campus and city police operational practices. Journal of Security Administration. 21. 41-54.

Brown, B., \& Benedict, W.R. (2002). Perceptions of the police: Past findings, methodological issues, conceptual issues, and police implications. Policing: An International Journal of Police Strategies \& Management. 25. 543-580.

Bruce, A. \& Davies, B. (2005). Mindfulness in hospice care: Practicing meditationin-action. Qualitative Health Research. 15. 1329-1344. 
Center for Research on Criminal Justice. (1975). The iron fist and the velvet glove: An analysis of the u.s. police. Berkeley, California: Center for Research on Criminal Justice.

Coldarci, T., Cobb, C.D., Minium, E.D., \&. Clark, R.C. (2004). Fundamentals of statistical reasoning in education. United State of American: John Wiley \& Sons, Inc.

Coles, C.M., \& Kelling, G.L. (1999). Prevention through community prosecution: New approaches to fighting crime. Public Interest. 136. 69-84.

Correia, M.E., Reisig, M.D. \& Lovrich, N.P. (1996). Public perceptions of state police: An analysis of individual-level and contextual variables. Journal of Criminal Justice. 24. 17-28.

Cresswell, J. (1994). Research design: Qualitative and quantitative approaches. Thousand Oaks, CA: Sage Publications.

Cresswell, J.W. (2003). Research design: Qualitative, quantitative, and mixed methods approaches. Thousand Oaks, CA: Sage Publications.

Cresswell, J.W. (2005). Educational research: Planning, conducting, and evaluating quantitative and qualitative research. Upper Saddle River, New Jersey: Pearson Prentice Hall.

Current Students. (n.d.) Academics \& libraries. Retrieved May 15, 2007, from http://www.wsu.edu/current-students/academics-libraries.html.

Czarniawska, B., \& Mazza, C. (2003). Consulting as a liminal space. Human Relations. 56. 267-290. 
Davis, I.P. (1994). Integrating qualitative and quantitative methods in clinical research. In Sherman, E. and W.J. Reid (Eds.). Qualitative Research in Social Work. New York: Columbia University Press.

Department of Public Safety. (n.d.). A word of welcome. Retrieved April 23, 2006, from http://www.wsu.edu/police/welcome.html.

Department of Public Safety. (n.d.a). Comparative crime statistics. Retrieved May 13, 2007 from http://www.wsu.edu/safety/stats.html.

DeVellis, R.F. (2003). Scale development: Theory and application. Applied Social Research Methods Series. (Volume 26). Thousand Oaks: Sage Publications.

Esposito, D., \& Stormer, D. (1989). The multiple roles of campus law enforcement. Campus Law Enforcement Journal. 19. 26-32.

Evans, T. (2001). Campus security: facing new challenges. Campus Law Enforcement Journal. 31. 25-26.

Fielding, N.G. (1988). Joining forces: Police training socialization, \& occupational competence. New York: Routledge.

Fisher, B., \& Sloan, J.J..(1995). Campus crime: legal, social, and policy contexts. In Fisher, B and J.J. Sloan (eds.). Campus Crime: Legal, Social, and Policy Perspectives. Springfield, Illinois: Charles C. Thomas Publisher.

Fogelson, R.M. (1977). Big-city police. Cambridge: Harvard University Press.

Fosdick, R.B. (1921). American police systems. New York: The Century Co.

Frank, J., Brandl, S., Cullen, F.T. \& Stichman, A. (1996). Reassessing the impact of race on citizens' attitudes toward the police: A research note. Justice Quarterly. 13. 321-334. 
Franklin, E. (n.d). 2005 annual police report. University of Washington Police Department. Retrieved April 14, 2007 from http://www.washington.edu/admin/police/records/uwpdannualreport05.pdf

Future Students. (n.d.). Washington state university facts. Retrieved May 13, 2007 from http://www.wsu.edu/future-students/why-wsu/wsu-profile/profile.html.

Garcia, V. \& Cao, L. (2005). Race and satisfaction with the police in a small city. Journal of Criminal Justice. $\underline{33}$. 191-199.

Gehrand, K. (2000). University policing and the community. Law \& Order. $\underline{48}$. 111117.

Gelber, S. (1972). The role of campus security in the college setting. U.S. Department of Justice

Gennep, A.V. (1960). The rites of passage. Chicago: The University of Chicago Press.

Gillham, B. (2000). Case study research methods. New York: TJ International Ltd. Goldstein, H. (1990). Problem oriented policing. Philadelphia, PA: Temple University Press.

Goodman, M.E. (1957). Values, attitudes, and social concepts of japanese and american children. American Anthropologist. 59. 979-999.

Goodwin, C.J. (2002). Research in psychology: methods and design. New York: John Wiley.

Griffith, J.D., Hueston, H., Wilson, E., Moyer, C., \& Hart, C.L. (2004). Satisfaction with campus police services. College Student Journal. $\underline{38}$. 150-150. 
Harris, R.N. (1973). The police academy: An inside view. New York: John Wiley \& Sons, Inc.

Harrison, W.D. (1994). The inevitability of integrating methods. In Sherman, E. and W.J. Reid (Eds.). Qualitative Research in Social Work. New York: Columbia University Press.

Heinsler, J.M., Kleinman, S., \& Stenross, B. (1990). Making work matter: Satisfied detectives and dissatisfied campus police. Qualitative Sociology. 13. 235251.

Hennigan, K.M., Maxson, C.L., Sloane, D., \& Ranney, M. (2002). Community views on crime and policing: Survey mode effects on bias in community surveys. Justice Quarterly. 19. 565-587.

Hensen, V., \& Stone, W. (1999) Campus crime: A victimization study. Journal of Criminal Justice. 27. 295-307.

Hinkle, D.P., \&. Jones, T.S. (1991). Security guards or real cops: How some major universities are facing the nineties. Law and Order. $\underline{39}$. 141-146.

Ho, T., \& Brown, M.P. (2003). Jurisdiction considerations among campus police officers under the cleary act. Campus Law Enforcement Journal. September/October 23-26.

Hopper, M. (1977). Becoming a policeman: socialization of recruits in a police academy. Urban Life. $\underline{6}$. 149-171

Hummer, D., Austin, T.L., \& Bumphus, V.W. (1998). Arming the campus cops: A descriptive and multivariate assessment of support. Policing: An International Journal of Police Strategies \& Management. 21. 255-268. 
Hopkins, N., Hewston, N., \& Hantzi, A. (1992). Police-schools liaison and young people's image of the police: An intervention evaluation. The British Journal of Psychology. 83. 203-220.

Hurst, Y.G., Browning, J.F., \& Browning, S.L. (2000). The attitudes of juveniles toward the police: A comparison of black and white youth. Policing: A International Journal of Police Strategies \& Management. 23. 37-53.

IACLEA. (nod.). About IACLEA. International Association of Campus Law Enforcement Administrators. Retrieved May 30, 2007 from http://www.iaclea.org/visitors/about/.

Iannarelli, A.V. (1968). The campus police. California: Precision Photo-From Company.

Institutional Research. (n.d.). Enrollment and persistence. Retrieved May 13, 2007 from http://www.ir.wsu.edu/CommonDataSet/CDS2006_2007.xls.

Johnson, D.R. (1981). American law enforcement: A history. St. Louis, MO: Forum Press.

Johnson, K. (2007, June 12). Families skeptical of va. tech panel: Demand a role in the probe of shooting. USA Today, pp. A.1

Kaplin, W.A., \& Lee, B.A. (1995). The Law of higher education. San Francisco, CA: Jossey-Bass.

Keels, C.L. (2004). The best kept secret: Crime on campus. Black Issues in Higher Education. 21. 20-27.

Klockars, C.B. (1983). Thinking about police. New York: McGraw-Hill Inc. 
La Roche, C.R. (2005). Student's rights associated with disciplinary and academic hearings and sanctions. College Student Journal. 39. 149-155.

Lederman, L.C., Lederman, J.B., \& Kully, R.D. (2004). Believing is seeing: The coconstruction of everyday myths in the media about college drinking. The American Behavioral Scientist. 48. 130-136.

Louis, K.S. (1982). Multisite/multimethod studies: An introduction. The American. 26. 6-22.

Jackson, A. (2002). Police-schools resource officers' and students' perception of the police and offending. Policing: An International Journal of Police Strategies \& Management. 25. 631-650.

Janosik, S.M. (2001). The impact of the campus crime awareness act of 1998 on student decision-making. NAPSA Journal. 38. 348-360.

Manning, P.K. (1997). Police work: The social organization of policing. Long Grove, Illinois: Waveland Press.

Melear, K.B. (2003). From in loco parentis to consumerism: A legal analysis of the contractual relationship between institution and student. NAPSA. $\underline{40}$. 124-148.

Mertens, D.M. (1998). Research methods in education and psychology: Integrating diversity with quantitative and qualitative methods, Thousand Oaks, California: Sage.

Mertens, D.M., \& McLaughlin, J.A. (2004). Research and evaluation methods in special education. Thousand Oaks, California: Corwin Press, Inc. 
Mertler, C.A., \& Vannatta, R.A. (2005). Advanced and multivariate statistical methods: Practical applications and interpretations ( $3^{\text {rd }}$ Edition). Glendale, CA: Pyrczak Publishing.

Michals, J.E., \& Higgins, J.M. (1997). The relationship between education level and performance ratings of campus police officers. Journal of police and Criminal Psychology. 12. 15-18.

Miller, J.L., \& Pan, M.J. (1987). Student perceptions of campus police: The effects of personal characteristics and police contacts. American Journal of Police. 6. $27-44$.

MSNBC. (n.d.). Fact file: Deadly college shootings in u.s. Retrieved June 19, 2007 from http://www.msnbc.msn.com/id/18137414/.

Muller, E.N. (1970). Correlates and consequences of beliefs in the legitimacy of regime structures. Mid West Journal of Political Science. 14. 392-412.

Murphy, D.W., \& Worrall, J.L. (1999). Residency requirements and public perceptions of the police in large municipalities. Policing: An International Journal of Police Strategies \& Management. 22. 327-342.

NBC-2.com. (n.d.). The massacre at virginia tech. Retrieved June 19, 2007 from http://www.nbc-2.com/vatech/.

Neal, R.E. (1980). A history of campus security: early origins. Campus Law Enforcement Journal. 10. 28-30.

Nichols, D. (1979) Campus police: The new professionals. American School and University. 52. 70-77. 
Nichols, D. (1987). The administration of public safety in higher education. Springfield, Illinois: Charles C Thompson Publisher.

Office of Institutional Research at Washington State University (2007). Annual average headcount enrollment since 1987. Retrieved April 14, 2007 from http://www.ir.wsu.edu/db11.asp?tq=b0320\&st=Academic_Year\&flt=none

Pallant, J. (2001). SPSS survival manual. Philadelphia: Open University Press.

Paoline, E.A., \& Sloan, J.J. (2003). Variability in the organizational structure of contemporary campus law enforcement agencies. Policing: An International Journal of Police Strategies \& Management. 26. 612-639.

Parfitt, R. (2002). The special nature of campus policing. Campus Law Enforcement Journal. 32. 26-27.

Peak, K.J. (1993). Policing in american: Methods, issues, and challenges. Englewood Cliffs, NJ: Regents/Prentice Hall.

Peak, K.J. (1995). The professionalization of campus law enforcement: Comparing campus and municipal law enforcement agencies. In Fisher, B and J.J. Sloan (Eds.). Campus Crime: Legal, Social, and Policy Perspectives. Springfield, Illinois: Charles C. Thomas Publisher.

Powell, J.W. (1971). The history and proper role of campus security. Security World. $\underline{8}$. 18-22.

Powell, J.W. (1971a). The history and proper role of campus security (Part II). Security World. $\underline{8}$. 19-25.

Powell, J.W. (1994). The beginning -- yale campus police department, 1894. Campus Law Enforcement Journal. 24. 2-5 
Powell, J.W., Pander, M.S., \& Nielsen, R.C. (1994). Campus security and law enforcement. Newton, Massachusetts: Butterworth-Heinemann.

Price, B.F. (1977). Police professionalism. Lexington, MA: D.C. Heath and Company.

Prokos, A. \& Padavic, I.. (2002). 'There ougtta be a law against bitches:' masculinity lessons in police academy training. Gender, Work and Organization. ‥ 339- 459.

Pullman Police Department. (n.d.). Pullman police department patrol information. Retrieved April 23, 2006, from http://www.pullmanwa.gov/Departments/Police/DrawOnePage.aspx?PageID= 593.

Pullman Police Department. (n.d.a). 2005 annual statistics. Retrieved June 8, 2007 From http://www.pullmanwa.gov/Department/Police/DrawOnePage.aspx?PageID=3 34.

Reaves, B.A., \& Goldberg, A.L. (1996) Campus law enforcement agencies, 1995. U.S. Department of Justice: Bureau of Justice Statistics.

Reisig, M.D., \& Chandek, M.S. (2001). The effects of expectancy disconfirmation on outcome satisfaction in police citizen encounters. Policing: An International Journal of Police Strategies \& Management. 24. 88-99.

Reisig, M.D., \& Giacomazzi, A.L. (1998). Citizen perceptions of community policing: Are attitudes toward police important? Policing. 21. 547-561. 
Reppening, K., Powell, H., Doane, A., \& Dunkle. (2001). Demystifying school violence: A local state and national perspective on the phenomenon of school violence. Journal of Security Administration. 21. 45-64.

Rosenbaum, D.P., Schuck, A.M., Costello, S.K., Hawkins, D. F., \& Ring, M.K. (2005). Attitudes toward the police: The effects of direct and vicarious experience. Police Quarterly. ㅁ. 343-365.

Shadish, W.R., Cook, T.D., \& Campbell, D.T. (2002). Experimental and quasiexperimental designs for generalized casual inferences. Boston: Houghton Mifflin.

Sherman, L.W., \& Strang, H. (2004). Experimental ethnography: The marriage of qualitative and quantitative research. The Annals of American Academy of Political and Social Sciences. 595. 204-222.

Shipman, M. (1994). Perceptions of campus police: Newsgathering and access to public records. Newspaper Research Journal. 15. 2-13.

Sims, B., Hooper, M., \& Peterson, S.A. (2002). Determinants of citizens’ attitudes toward police: Results of the harrisburg citizen survey - 1999. Policing. $\underline{25}$. 457-471.

Skolnick, J.H., \& Bayley, D.H. (1986). The new blue line: Police innovation in six american cities. New York: The Free Press.

Sloan, J.J. (1992). The modern campus police: An analysis of their evolution, structure, and function. American Journal of Police. 11. 85-104. 
Sloan, J.J., Lanier, M.M. \& Beers, D.L. (2000). Policing the contemporary university campus: Challenging traditional organizational models. Journal of Security Administration. 23. 1-20.

Smith, B.W. (2005). Ethno-racial political transitions and satisfaction with police. Policing. 28. 242-254.

Smith, M.C. (1988). Coping with crime on campus. New York: Macmillan Publishing Company.

Smith, M.C., \& Fossey, R. (1995). Crime on campus: Legal issues and campus administration. West Port, Connecticut: Oryx Press.

Spicer, J. (2005). Making sense of multivariate data analysis. Thousand Oaks, California: Sage Publications, Inc.

Sunshine, J., \& Tyler, T.R. (2003). The role of procedural justice and legitimacy in shaping public support for policing. Law \& Society Review. 37. 513-548.

Tabachnick, B.G., \& Fidell, L.S. (2001). Using multivariate statistics. ( $4^{\text {th }}$ Ed.). Boston: Allyn and Bacon.

Toseland, R.W. (1994). Commentary: The Qualitative/quantitative debate: moving beyond acrimony to meaningful dialogue. In Sherman, E. and W.J. Reid (Eds.). Qualitative Research in Social Work. New York: Columbia University Press.

Turner, V. (1969). The ritual process: Structure and anti-structure. Chicago, Illinois: Aldine Publishing Company.

Turner, V. (1974). Dramas, fields, and metaphors: Symbolic actions in human society. Ithaca, New York: Cornell University Press. 
Turner, V. (1979). Frame, flow, and reflection: Ritual and drama as public liminality. Japanese Journal of Religious Studies. 6. 465-499.

Turner, V. (1988). The anthropology of performance. New York: PAJ Publications.

Tyler, T.R. (2004). Enhancing police legitimacy. The Annals of the American Academy. 593. 84-99.

U.S. Census Bureau. (n.d.). Urban, rural, classification \& data access. Retrieved April 14, 2007 from http://ask.census.gov/cgiin/askcensus.cfg/php/enduser/std_adp.php?p_faqid=661\&p_created=1094757 817\&p_sid=CUPmU7zi\&p_accessibility=0\&p_redirect $=\& p$ _lva $=\& p \_s p=c F 9$ zcmNoPTEmcF9zb3J0X2J5PSZwX2dyaWRzb3J0PSZwX3Jvd19jbnQ9MTY mcF9wcm9kcz0mcF9jYXRzPSZwX3B2PSZwX2N2PSZwX3BhZ2U9MSZw X3NIYXJjaF90ZXh0PXVyYmFuIGFuZCBydXJhbCBwb3B1bGF0aW9u\&p _li=\&p_topview=1

Van Maanen, J. (1975). Police socialization: A longitudinal examination of job attitudes in an urban police department. Administration Science Quarterly. 20. 207-228.

Vila, B., \& Morris, C. (1999). The role of police in america: A documentary history. Westport, CT: Greenwood Press.

Walker, S. (1977). A critical history of police reform. Lexington, Massachusetts: Lexington Books.

Walker, S. (1992). The police in america: An introduction. New York: McGrawHill. 
Walsh, A., \& Ollenburger, J.C. (2001). Essential statistics for the social and behavioral sciences: A conceptual approach. Upper Saddle River, New Jersey: Prentice Hall.

Weatherly, T. (2006). Personal communication, March 6, 2006

Weitzer, R., \& Tuch, S.A. (2005). Racially biased policing: Determinants of citizen perceptions. Social Forces. ⒊ 1009-1030.

Wensyel, J.W. (1987). Campus public safety and security: With guidance as well for high schools and private secondary schools. Springfield, Illinois: Charles C. Thomas.

White, M.F., \& Menke, B.A. (1982). On assessing the mood of the public toward the police: Some conceptual issues. Journal of Criminal Justice. 10. 211-230.

Wilson J. (1985). Thinking about crime. New York, New York: Vintage.

Wilson, J., \& Kelling, G.L. (1982). Broken windows: The police and neighborhood safety. The Atlantic Monthly. March. 29-38.

Wintre, M.G., North, C., \& Sugar, L.A. (2001). Psychologists’ response to criticism about research based on undergraduate participants: A

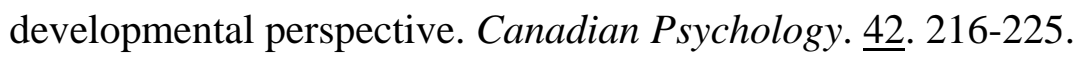

Worrall, J.L. (1999). Public perceptions of police efficacy and image. American Journal of Criminal Justice. 24. 47-66.

Zamble, E. and Annesley, P. (1987). Some determinants of public attitudes toward the police. Journal of Police Sciences and Administration, 15. 285-290. 


\section{Court Cases Cited:}

Dixon v. Alabama State Board of Education, 294 F.2d 150 (5 $5^{\text {th }}$ Cir 1961)

Gott v. Berea College, 161 S.W. 204, 206 (Ky. 1913). 


\title{
Appendix A
}

\author{
WASHINGTON STATE UNIVERSITY \\ INFORMED CONSENT Research Project -- Perceptual Studies of \\ Campus Police (Student Surveys)
}

\section{Researcher: James Wada, \\ Phone: 509 432-4281 \\ Email: jcwada@yahoo.com}

\section{Researchers' statement}

I am asking you to take part in a university-based research study. The purpose of this consent form is to give you the information you will need to help you decide whether to be in the study or not. Please read the form carefully. You may ask questions about the purpose of the research, what I would ask you to do, the possible risks and benefits, your rights as a volunteer, and anything else about the research or this form that is not clear to you. When I have answered all your questions, you can decide whether or not you want to be in the study. This process is called 'informed consent.' I will give you a copy of this form for your records.

\section{PURPOSE AND BENEFITS}

Scholars have argued that the public's opinion of police is the key factor in maintaining public support and cooperation. Without community support and/or community cooperation, a police officer's effort to combat crime and maintain order will be compromised. The purpose of the research is to identify the community perceptions of police based on university students' views.

\section{PROCEDURES}

I will ask you to answer a survey that will explore your views of police (either Washington State Campus Police or Pullman City Police). The survey will take about fifteen minutes to complete. Your participation is completely voluntary. You may refuse to answer any question, and you may stop taking the survey at any time.

\section{RISKS, STRESS, OR DISCOMFORT}

There should be no risks concerning stress, discomfort, embarrassment, legal risks, or invasion of privacy with the survey. This one-time, voluntary survey will be completely anonymous. There will be no recording of names. Only the researcher will have access to the survey data. The only possible concern may be a feeling of apprehension about completing a survey of policing openly.

If at any time, while filling out the survey, you feel apprehension or discomfort, you may stop at any time. If at a later date you are still feeling discomfort, you may contact the researcher listed above.

If you have general questions about the research, you can ask the researcher listed above. If you have questions regarding your rights as a participant, you can call the WSU Institutional Review Board at (509) 335-9661. This project has been reviewed and approved for human participation by the WSU IRB.

WSU Human Subjects Form 


\section{Appendix B}

\section{Perceptions of Washington State Campus Police}

In any society, people have different views of the police. This research is designed to determine what people think about the police. There are no right or wrong answers.

All of your responses will be kept confidential. Nobody, except the researcher will see your responses.

Please indicate with an " $X$ " if the following statements pertain to you.

1. I do not wish to participate in this survey.

2. I have already participated in this survey.

3. I am under 18 years of age.

If you placed an " $\mathrm{X}$ " to any of the above statements, you do not have to continue with this survey and you are free to leave.

If none of the above statements pertain to you, please continue with the survey.

Thank you for your time. 


\section{$\underline{\text { SECTION } 1}$}

Please check with an " $X$ " in the appropriate responses:

1. Gender:

Male
African American
Asian American
Caucasian (White)
Hispanic
Native American
Other

Female

2. Ethnicity:

Asian American

Caucasian (White)

Other

3. Year in School:

$\begin{array}{ll}\text { Freshman } \\ \text { Junior } & \text { Sophomore } \\ \text { Senior }\end{array}$

\section{SECTION 2}

Please write the appropriate response in the space provided:

1. Where did you grow up (City and State)?

* If you have lived in multiple places, where would you consider your hometown?

2. Major (i.e. criminal justice, education, etc.).

3. What is your age? Years

\section{SECTION 3}

DIRECTIONS: For each of the statements below, please indicate your level of agreement. If you agree with the statement please write " 1 " in the space provided to the left of the statement; if you disagree with the statement please write " 5 " in the space provided. And, of course, use the numbers in the middle if you fall between the two extremes.

\begin{tabular}{|ccccc|}
\hline $\mathbf{1}$ & $\mathbf{2}$ & $\mathbf{3}$ & $\mathbf{4}$ & $\mathbf{5}$ \\
Agree & $\begin{array}{c}\text { Somewhat } \\
\text { Agree }\end{array}$ & Uncertain & $\begin{array}{c}\text { Somewhat } \\
\text { Disagree }\end{array}$ & Disagree \\
& & & \\
\hline
\end{tabular}

1. You should accept the decisions made by a Washington State University campus police officer, even if you think he or she is wrong.

2. You should do what a Washington State University campus police officer tells you to do even when you do not understand the reasons for his or her decisions.

3. You should do what a Washington State University campus police officer tells you to do even when you disagree with his or her decisions.

4. You should do what a Washington State University campus police officer tells you to do even when you do not like the way he or she treats you. 


\begin{tabular}{|ccccc|}
\hline $\mathbf{1}$ & $\mathbf{2}$ & $\mathbf{3}$ & $\mathbf{4}$ & $\mathbf{5}$ \\
Agree & $\begin{array}{c}\text { Somewhat } \\
\text { Agree }\end{array}$ & Uncertain & $\begin{array}{c}\text { Somewhat } \\
\text { Disagree }\end{array}$ & Disagree \\
& & & \\
\hline
\end{tabular}

5. There are times when it is okay for you to ignore what a Washington State campus University Police Officer tells you.

6. Sometimes you have to bend the law for things to come out right.

7. The law represents the values of the people in power, rather than the values of people like you.

8. People in power use the law to try to control people like you.

9. The law does not protect your interests.

10. Overall the Washington State University campus police department is a legitimate authority and people should obey the decisions that a Washington State University Campus police officer makes.

11. I have confidence that the Washington State University Campus Police Department can do its job well.

12. I trust the leaders of the Washington State University Campus Police Department to make decisions that are good for everyone in the community.

13. People's basic rights are well protected by Washington State University campus police.

14. Washington State University Campus Police care about the well being of everyone they deal with.

15. I am proud of the work of the Washington State University Campus Police Department.

16. I agree with many of the values of the Washington State University Campus Police Department.

17. Washington State University campus police officers are often dishonest.

18. Some of the things Washington State University campus police officers do embarrass our community.

19. There are many things about the Washington State University Campus Police department and its policies that need to be changed. 


\section{SECTION 4}

For each word underlined, please indicate the number that you believe, in general, most represents a Washington State University campus police officer.

\begin{tabular}{|cccccccc|}
\hline $\mathbf{1}$ & 2 & 3 & 4 & 5 & 6 & 7 \\
Not at All & & & Uncertain & & & & Very Much \\
& & & & & & & \\
\hline
\end{tabular}

\section{Helpful}

\section{Aggressive}

3. Trustworthy

4. Racist

5. Friendly

6. $\underline{\text { Rude }}$

7. Fair

8. $\underline{\text { Strict }}$

\section{SECTION 5}

\section{Please indicate with an " $X$ " if you believe the following statement to be true or false.}

1. Washington State University campus police officers attend the same police academy as Pullman police officers.

true

false

2. Washington State University campus police officers have the same policing powers as Pullman police officers.

true false

3. Washington State University campus police officers have the power of arrest. true false

4. Washington State University campus police officers can use deadly force. true false

5. Washington State University campus police officers carry handguns. true false

6. Washington State University campus police officers' jurisdiction is limited to university property. true false

7. Washington State University campus police officers can only police Washington State University students. true false 


\section{SECTION 6}

\section{Please answer the following questions with an " $X$ " in the appropriate response}

1. Have you ever had contact with a Washington State University campus police officer (talked with, stopped, questioned, arrested, etc.)?

Yes No

1a. If you answered "yes" to question 1, was the contact positive (were you treated fairly). If you answered "no" to question 1, skip to question 2.
Yes
No

2. Has anyone you know had contact with a Washington State University campus police Officer?

Yes $\quad$ No

2a. If you answered "yes" to question 2, was the person's contact with the Washington State University campus police positive (was the person treated fairly)? If you answered 'no" to question 2, skip to question 3.
Yes
No
Don’t Know

3. Do you live on campus?

Yes

No

4. Are you a fraternity or sorority member?

Yes

No

5. Is any member of your family a police officer?

Yes

No 


\title{
Appendix C
}

\author{
WASHINGTON STATE UNIVERSITY \\ INFORMED CONSENT Research Project -- Perceptual Studies of \\ Pullman Police (Student Surveys)
}

\author{
Researcher: James Wada, \\ Phone: 509 432-4281 \\ Email: jcwada@yahoo.com
}

\section{$\underline{\text { Researchers' statement }}$}

I am asking you to take part in a university-based research study. The purpose of this consent form is to give you the information you will need to help you decide whether to be in the study or not. Please read the form carefully. You may ask questions about the purpose of the research, what I would ask you to do, the possible risks and benefits, your rights as a volunteer, and anything else about the research or this form that is not clear to you. When I have answered all your questions, you can decide whether or not you want to be in the study. This process is called 'informed consent.' I will give you a copy of this form for your records.

\section{PURPOSE AND BENEFITS}

Scholars have argued that the public's opinion of police is the key factor in maintaining public support and cooperation. Without community support and/or community cooperation, a police officer's effort to combat crime and maintain order will be compromised. The purpose of the research is to identify the community perceptions of police based on university students’ views.

\section{PROCEDURES}

I will ask you to answer a survey that will explore your views of police (either Washington State Campus Police or Pullman City Police). The survey will take about fifteen minutes to complete. Your participation is completely voluntary. You may refuse to answer any question, and you may stop taking the survey at any time.

\section{RISKS, STRESS, OR DISCOMFORT}

There should be no risks concerning stress, discomfort, embarrassment, legal risks, or invasion of privacy with the survey. This one-time, voluntary survey will be completely anonymous. There will be no recording of names. Only the researcher will have access to the survey data. The only possible concern may be a feeling of apprehension about completing a survey of policing openly.

If at any time, while filling out the survey, you feel apprehension or discomfort, you may stop at any time. If at a later date you are still feeling discomfort, you may contact the researcher listed above.

If you have general questions about the research, you can ask the researcher listed above. If you have questions regarding your rights as a participant, you can call the WSU Institutional Review Board at (509) 335-9661. This project has been reviewed and approved for human participation by the WSU IRB.

WSU Human Subjects Form 


\section{Appendix D}

\section{Perceptions of Pullman Police}

In any society, people have different views of the police. This research is designed to determine what people think about the police. There are no right or wrong answers.

All of your responses will be kept confidential. Nobody, except the researcher will see your responses.

Please indicate with an " $X$ " if the following statements pertain to you.

1. I do not wish to participate in this survey.

2. I have already participated in this survey.

3. I am under 18 years of age.

If you placed an " $X$ " to any of the above statements, you do not have to continue with this survey and you are free to leave.

If none of the above statements pertain to you, please continue with the survey.

Thank you for your time. 


\section{$\underline{\text { SECTION } 1}$}

Please check with an " $X$ " the appropriate responses:

1. Gender:

Male
African American
Asian American
Caucasian (White)
Hispanic
Native American
Other

Female

2. Ethnicity: Sophomore

Freshman Senior

\section{SECTION 2}

Please write the appropriate response in the space provided:

1. Where did you grow up (City and State)?

* If you have lived in multiple places, where would you consider your hometown?

2. Major (i.e. criminal justice, education, etc.).

3. What is your age? Years

\section{SECTION 3}

DIRECTIONS: For each of the statements below, please indicate your level of agreement. If you agree with the statement please write " 1 " in the space provided to the left of the statement; if you disagree with the statement please write " 5 " in the space provided. And, of course, use the numbers in the middle if you fall between the two extremes.

\begin{tabular}{|ccccc|}
\hline $\mathbf{1}$ & $\mathbf{2}$ & $\mathbf{3}$ & $\mathbf{4}$ & $\mathbf{5}$ \\
Agree & $\begin{array}{c}\text { Somewhat } \\
\text { Agree }\end{array}$ & Uncertain & $\begin{array}{c}\text { Somewhat } \\
\text { Disagree }\end{array}$ & Disagree \\
\hline
\end{tabular}

1. You should accept the decisions made by a Pullman police officer, even if you think he or she is wrong.

2. You should do what a Pullman police officer tells you to do even when you do not understand the reasons for his or her decisions.

3. You should do what a Pullman police officer tells you to do even when you disagree with his or her decisions.

4. You should do what a Pullman police officer tells you to do even when you do not like the way he or she treats you. 


\begin{tabular}{|ccccc|}
\hline $\mathbf{1}$ & $\mathbf{2}$ & $\mathbf{3}$ & $\mathbf{4}$ & $\mathbf{5}$ \\
Agree & $\begin{array}{c}\text { Somewhat } \\
\text { Agree }\end{array}$ & Uncertain & $\begin{array}{c}\text { Somewhat } \\
\text { Disagree }\end{array}$ & Disagree \\
\hline
\end{tabular}

5. There are times when it is okay for you to ignore what a Pullman police officer tells you.

6. Sometimes you have to bend the law for things to come out right.

7. The law represents the values of the people in power, rather than the values of people like you.

8. People in power use the law to try to control people like you.

9. The law does not protect your interests.

10. Overall the Pullman Police Department is a legitimate authority and people should obey the decisions that a Pullman Police Officer makes.

11. I have confidence that the Pullman Police Department can do its job well.

12. I trust the leaders of the Pullman Police Department to make decision that are good for everyone in the community.

13. People’s basic rights are well protected by Pullman Police Department.

14. Pullman police officers care about the well being of everyone they deal with.

15. I am proud of the work of the Pullman Police Department.

16. I agree with many of the values that define what the Pullman Police Department stand for.

17. Pullman police officers are often dishonest.

18. Some of the things Pullman police officers do embarrass our community.

19. There are many things about the Pullman Police Department and its policies that need to be changed. 


\section{SECTION 4}

For each word underlined, please indicate the number that you believe, in general, most represents a Pullman Police Officer.

\begin{tabular}{|ccccccc|}
\hline 1 & 2 & 3 & 4 & 5 & 6 & 7 \\
Not at All & & & Uncertain & & & \\
& & & & & & \\
\hline
\end{tabular}

\section{Helpful}

\section{2. $\underline{\text { Aggressive }}$}

3. Trustworthy

4. $\underline{\text { Racist }}$

5. Friendly

6. $\underline{\text { Rude }}$

7. $\underline{\text { Fair }}$

8. $\underline{\text { Strict }}$

\section{SECTION 5}

\section{Please indicate with an " $X$ " if you agree or disagree with the following statements.}

1. Pullman police officers attend the same police academy as Washington State University campus police. true false

2. Pullman police officers have the same policing powers as Washington State University campus police.

_true false

3. Pullman police officers have the power of arrest. true false

4. Pullman police officers can use deadly force. true false

5. Pullman police officers carry a handgun.

$$
\text { true }
$$
false

6. Pullman police officers' jurisdiction is limited to city property. true false

7. Pullman police officers can only police Pullman City residents. true false 


\section{$\underline{\text { SECTION } 6}$}

Please answer the following questions with an " $\mathrm{X}$ " in the appropriate response

1. Have you ever had contact with a Pullman police officer (talked with, stopped, questioned, arrested, etc.)?

Yes

No

1a. If you answered "Yes" to question 1, was the contact positive (were you treated fairly)? If you answered "No" to question 1, skip to question 2.
Yes
No

2. Has anyone you know had contact with a Pullman police officer?

Yes

No

2a. If you answered "Yes" to question 2, was the person's contact with the Pullman police officer positive (was the person treated fairly)? If you answered "No" to question 2, skip to question 3 .

Yes

No

Don’t Know

3. Do you live on campus?

Yes

No

4. Are you a fraternity or sorority member?

Yes No

5. Is any member of your family a police officer?

Yes No 


\title{
Appendix E
}

\author{
WASHINGTON STATE UNIVERSITY \\ CONSENT FORM Research Project -- Perceptual Studies of Campus Police (Campus Police Interviews)
}

\author{
Researcher: James Wada, \\ Phone: 509 432-4281 \\ Email: jcwada@yahoo.com
}

Researchers' statement

I am asking you to take part in a university-based research study. The purpose of this consent form is to give you the information you will need to help you decide whether to be in the study or not. Please read the form carefully. You may ask questions about the purpose of the research, what I would ask you to do, the possible risks and benefits, your rights as a volunteer, and anything else about the research or this form that is not clear to you. When I have answered all your questions, you can decide whether or not you want to be in the study. This process is called 'informed consent.' I will give you a copy of this form for your records.

PURPOSE AND BENEFITS

The purpose of the research is to identify Washington State University campus police officer's opinions on how they believe students perceive them as compared to their "mainstream" police counterparts. Scholars in campus policing have argued that campus police are not identified, under many circumstances, as "real cops" by student populations. However, it does not appear that this identification of campus police has been empirically studied.

\section{PROCEDURES}

I will ask you to answer four interview questions related to the research question stated above. The interview will take about a half-hour. Your participation is completely voluntary. You may refuse to answer any question, and you may stop the interview at any time. Only the researcher will have access to your responses. Furthermore, no names, ranks or any other identifiable characteristics will be attached to your responses. This will ensure that responses given cannot be linked to an individual participant.

\section{RISKS, STRESS, OR DISCOMFORT}

There should be no risks concerning stress, discomfort, embarrassment, legal risks, or invasion of privacy with the interview. This one-time, voluntary interview process will be completely anonymous. There will be no recording of names, ranks or any other type of identifiers. Only the researcher (interviewer) will have access to the interview data. The only possible concern may be a feeling of apprehension about discussing your perceptions of campus policing openly.

If at any time during the interview you feel apprehension or discomfort, you may stop the interview at any time. If at a later date you are still feeling discomfort, you may contact the researcher listed above.

Printed name of researcher

Signature of researcher

Date

Subject's statement

This study has been explained to me. I volunteer to take part in this research. I have had a chance to ask questions. If I have general questions about the research, I can ask the researcher listed above. If I have questions regarding my rights as a participant, I can call the WSU Institutional Review Board at (509) 335-9661. This project has been reviewed and approved for human participation by the WSU IRB.

$\begin{array}{ll}\text { Printed name of subject } \quad \text { Signature of subject } & \text { Date }\end{array}$

WSU Human Subjects Form 


\section{Appendix F}

\section{CPO Interview Questions}

1. How do you feel that the public (i.e. students) perceives you, in terms of your policing authority? In other words, do you feel that the public perceives you or treats you similar or differently than your "mainstream” police counterparts (i.e. municipal, county, state police)?

2. Can you give some examples that would illustrate your beliefs?

3. If members of the community (i.e. students) do not recognize your policing powers as similar to other "mainstream" departments - what do you believe accounts for this?

4. What would help increase community recognition of your policing authority? 


\section{Appendix G}

\section{WASHINGTON STATE 4. UNIVERSITY}

\section{MEMORANDUM}

TO:

James Wada

Educational Leadership \& Counseling Psychology, WSU Pullman (2136)

FROM: Malathi Jandhyala (for) Kris Miller, Chair, WSU Institutional Review Board (3140)

DATE: 3 August 2006

SUBJECT: Approved Human Subjects Protocol - New Protocol

Your Human Subjects Review Summary Form and additional information provided for the proposal titled "Perceptual Studies of Campus Police," IRB File Number 9214-a was reviewed for the protection of the subjects participating in the study. Based on the information received from you, the WSU-IRB approved your human subjects protocol on 3 August 2006.

IRB approval indicates that the study protocol as presented in the Human Subjects Form by the investigator, is designed to adequately protect the subjects participating in the study. This approval does not relieve the investigator from the responsibility of providing continuing attention to ethical considerations involved in the utilization of human subjects participating in the study.

This approval expires on 2 August 2007. If any significant changes are made to the study protocol you must notify the IRB before implementation. Request for modification forms are available online at http://www.ogrd.wsu.edu/Forms.asp.

In accordance with federal regulations, this approval letter and a copy of the approved protocol must be kept with any copies of signed consent forms by the principal investigator for THREE years after completion of the project.

Washington State University is covered under Human Subjects Assurance Number FWA00002946 which is on file with the Office for Human Research Protections.

If you have questions, please contact the Institutional Review Board at (509) 335-9661. Any revised materials can be mailed to the Research Compliance Office (Campus Zip 3140), faxed to (509) 335-1676, or in some cases by electronic mail, to irb@mail.wsu.edu.

Review Type: NEW Review Category: XMT OGRD No.: NF Date Received: 21 June 2006 Agency: NA 


\section{Appendix H}

\section{Identified Majors}

\begin{tabular}{|c|c|c|c|c|c|}
\hline & & Frequency & Percent & Valid Percent & $\begin{array}{c}\text { Cumulative } \\
\text { Percent }\end{array}$ \\
\hline \multirow[t]{36}{*}{ Valid } & Criminal Justice & 79 & 13.3 & 13.4 & 13.4 \\
\hline & Education & 114 & 19.2 & 19.3 & 32.7 \\
\hline & Sociology & 17 & 2.9 & 2.9 & 35.6 \\
\hline & Double major & 24 & 4.0 & 4.1 & 39.7 \\
\hline & Political Science & 27 & 4.6 & 4.6 & 44.2 \\
\hline & Communication & 34 & 5.7 & 5.8 & 50.0 \\
\hline & General Studies & 3 & .5 & .5 & 50.5 \\
\hline & Psychology & 26 & 4.4 & 4.4 & 54.9 \\
\hline & Undecided & 20 & 3.4 & 3.4 & 58.3 \\
\hline & $\begin{array}{l}\text { Hotel and } \\
\text { Restaurant } \\
\text { Management } \\
\text { Journalism }\end{array}$ & 2 & .3 & .3 & 58.6 \\
\hline & Public Relations & 2 & .3 & .3 & 59.7 \\
\hline & Liberal Arts & 1 & .2 & .2 & 59.8 \\
\hline & $\begin{array}{l}\text { Management } \\
\text { Operations }\end{array}$ & 2 & .3 & .3 & 60.2 \\
\hline & Wildlife Ecology & 1 & .2 & .2 & 60.3 \\
\hline & Biology & 9 & 1.5 & 1.5 & 61.9 \\
\hline & $\begin{array}{l}\text { Human } \\
\text { Development }\end{array}$ & 3 & .5 & .5 & 62.4 \\
\hline & Business & 44 & 7.4 & 7.5 & 69.8 \\
\hline & General Science & 1 & .2 & .2 & 70.0 \\
\hline & Marketing & 7 & 1.2 & 1.2 & 71.2 \\
\hline & Anthropology & 2 & .3 & .3 & 71.5 \\
\hline & Philosophy & 5 & .8 & .8 & 72.4 \\
\hline & Nursing & 15 & 2.5 & 2.5 & 74.9 \\
\hline & Pre-Med & 3 & .5 & .5 & 75.4 \\
\hline & Accounting & 9 & 1.5 & 1.5 & 76.9 \\
\hline & Zoology & 5 & .8 & .8 & 77.8 \\
\hline & $\begin{array}{l}\text { Operations } \\
\text { Management }\end{array}$ & 1 & .2 & .2 & 78.0 \\
\hline & Pharmacy & 4 & .7 & .7 & 78.6 \\
\hline & Pre-Law & 1 & .2 & .2 & 78.8 \\
\hline & $\begin{array}{l}\text { Fashion } \\
\text { Merchandising }\end{array}$ & 2 & .3 & .3 & 79.2 \\
\hline & Creative Writing & 1 & .2 & .2 & 79.3 \\
\hline & Engineering & 3 & .5 & .5 & 79.8 \\
\hline & Physical Therapy & 1 & .2 & .2 & 80.0 \\
\hline & English & 2 & .3 & .3 & 80.3 \\
\hline & Pre- Dent & 1 & .2 & .2 & 80.5 \\
\hline & Architecture & 5 & .8 & .8 & 81.4 \\
\hline & Chemistry & 2 & .3 & .3 & 81.7 \\
\hline
\end{tabular}




\begin{tabular}{|c|c|c|c|c|c|}
\hline & $\begin{array}{l}\text { Hospitality and } \\
\text { Business } \\
\text { Management } \\
\text { Sport } \\
\text { Management } \\
\text { Dietetics }\end{array}$ & $\begin{array}{r}9 \\
38 \\
2\end{array}$ & $\begin{array}{r}6.4 \\
.3\end{array}$ & $\begin{array}{r}6.4 \\
.3\end{array}$ & $\begin{array}{l}89.7 \\
90.0\end{array}$ \\
\hline & Advertising & 1 & .2 & .2 & 90.2 \\
\hline & Geology & 1 & .2 & .2 & 90.3 \\
\hline & Spanish & 1 & .2 & .2 & 90.5 \\
\hline & Finance & 5 & .8 & .8 & 91.4 \\
\hline & & 4 & .7 & .7 & 92.0 \\
\hline & History & 8 & 1.3 & 1.4 & 93.4 \\
\hline & Athletic Training & 12 & 2.0 & 2.0 & 95.4 \\
\hline & Sport Medicine & 1 & .2 & .2 & 95.6 \\
\hline & Public Relations & 3 & .5 & .5 & 96.1 \\
\hline & Broadcasting & 3 & .5 & .5 & 96.6 \\
\hline & Neuroscience & 4 & .7 & .7 & 97.3 \\
\hline & Actuarial Science & 1 & .2 & .2 & 97.5 \\
\hline & Interior Design & 2 & .3 & .3 & 97.8 \\
\hline & $\begin{array}{l}\text { Natural Resource } \\
\text { Sciences }\end{array}$ & 1 & .2 & .2 & 98.0 \\
\hline & Health Science & 1 & .2 & .2 & 98.1 \\
\hline & $\begin{array}{l}\text { Construction } \\
\text { Management }\end{array}$ & 2 & .3 & .3 & 98.5 \\
\hline & Bio engineering & 1 & .2 & .2 & 98.6 \\
\hline & Genetics & 1 & .2 & .2 & 98.8 \\
\hline & $\begin{array}{l}\text { Landscape } \\
\text { Architecture }\end{array}$ & 1 & .2 & .2 & 99.0 \\
\hline & MIS & 3 & .5 & .5 & 99.5 \\
\hline & $\begin{array}{l}\text { Speech and } \\
\text { Hearing Therapy }\end{array}$ & 2 & .3 & .3 & 99.8 \\
\hline & Entomology & 1 & .2 & .2 & 100.0 \\
\hline & Total & 590 & 99.5 & 100.0 & \\
\hline Missing & System & 3 & .5 & & \\
\hline Total & & 593 & 100.0 & & \\
\hline
\end{tabular}




\section{Appendix I}

\section{PPO Total Variance Explained for Four-Component Solution}

\begin{tabular}{|c|c|c|c|c|c|c|c|c|c|}
\hline \multirow[b]{2}{*}{ Component } & \multicolumn{3}{|c|}{ Initial Eigenvalues } & \multicolumn{3}{|c|}{ Extraction Sums of Squared Loadings } & \multicolumn{3}{|c|}{ Rotation Sums of Squared Loadings } \\
\hline & Total & $\%$ of Variance & Cumulative $\%$ & Total & $\%$ of Variance & Cumulative $\%$ & Total & $\%$ of Variance & Cumulative \% \\
\hline 1 & 6.435 & 33.867 & 33.867 & 6.435 & 33.867 & 33.867 & 4.878 & 25.671 & 25.671 \\
\hline 2 & 2.146 & 11.295 & 45.161 & 2.146 & 11.295 & 45.161 & 2.684 & 14.127 & 39.798 \\
\hline 3 & 1.675 & 8.818 & 53.979 & 1.675 & 8.818 & 53.979 & 2.386 & 12.558 & 52.356 \\
\hline 4 & 1.044 & 5.493 & 59.472 & 1.044 & 5.493 & 59.472 & 1.352 & 7.116 & 59.472 \\
\hline 5 & .931 & 4.902 & 64.374 & & & & & & \\
\hline 6 & .857 & 4.510 & 68.884 & & & & & & \\
\hline 7 & .761 & 4.008 & 72.892 & & & & & & \\
\hline 8 & .667 & 3.511 & 76.403 & & & & & & \\
\hline 9 & .645 & 3.393 & 79.796 & & & & & & \\
\hline 10 & .567 & 2.984 & 82.781 & & & & & & \\
\hline 11 & .538 & 2.834 & 85.614 & & & & & & \\
\hline 12 & .473 & 2.491 & 88.105 & & & & & & \\
\hline 13 & .454 & 2.389 & 90.494 & & & & & & \\
\hline 14 & .390 & 2.055 & 92.548 & & & & & & \\
\hline 15 & .355 & 1.871 & 94.419 & & & & & & \\
\hline 16 & .324 & 1.705 & 96.124 & & & & & & \\
\hline 17 & .310 & 1.629 & 97.753 & & & & & & \\
\hline 18 & .257 & 1.355 & 99.108 & & & & & & \\
\hline 19 & .169 & .892 & 100.000 & & & & & & \\
\hline
\end{tabular}

Extraction Method: Principal Component Analysis. 


\section{Appendix $\mathbf{J}$}

\section{CPO Total Variance Explained for four-Component Solution}

\begin{tabular}{|c|c|c|c|c|c|c|c|c|c|}
\hline \multirow[b]{2}{*}{ Component } & \multicolumn{3}{|c|}{ Initial Eigenvalues } & \multicolumn{3}{|c|}{ Extraction Sums of Squared Loadings } & \multicolumn{3}{|c|}{ Rotation Sums of Squared Loadings } \\
\hline & Total & $\%$ of Variance & Cumulative \% & Total & $\%$ of Variance & Cumulative \% & Total & $\%$ of Variance & Cumulative \% \\
\hline 1 & 6.915 & 36.396 & 36.396 & 6.915 & 36.396 & 36.396 & 4.246 & 22.348 & 22.348 \\
\hline 2 & 2.076 & 10.927 & 47.324 & 2.076 & 10.927 & 47.324 & 2.666 & 14.031 & 36.380 \\
\hline 3 & 1.503 & 7.912 & 55.235 & 1.503 & 7.912 & 55.235 & 2.525 & 13.288 & 49.668 \\
\hline 4 & 1.126 & 5.926 & 61.161 & 1.126 & 5.926 & 61.161 & 2.184 & 11.493 & 61.161 \\
\hline 5 & .902 & 4.746 & 65.907 & & & & & & \\
\hline 6 & .723 & 3.806 & 69.713 & & & & & & \\
\hline 7 & .691 & 3.637 & 73.349 & & & & & & \\
\hline 8 & .660 & 3.472 & 76.822 & & & & & & \\
\hline 9 & .603 & 3.176 & 79.998 & & & & & & \\
\hline 10 & .521 & 2.741 & 82.739 & & & & & & \\
\hline 11 & .500 & 2.631 & 85.370 & & & & & & \\
\hline 12 & .475 & 2.500 & 87.870 & & & & & & \\
\hline 13 & .415 & 2.184 & 90.055 & & & & & & \\
\hline 14 & .392 & 2.062 & 92.116 & & & & & & \\
\hline 15 & .379 & 1.996 & 94.112 & & & & & & \\
\hline 16 & .358 & 1.885 & 95.997 & & & & & & \\
\hline 17 & .308 & 1.618 & 97.615 & & & & & & \\
\hline 18 & .285 & 1.500 & 99.116 & & & & & & \\
\hline 19 & .168 & .884 & 100.000 & & & & & & \\
\hline
\end{tabular}

Extraction Method: Principal Component Analysis. 


\section{Appendix K}

\section{T-Test PP and CP Departments}

\section{Group Statistics}

\begin{tabular}{|l|l|r|r|r|r|}
\hline & Survey & $\mathrm{N}$ & Mean & Std. Deviation & $\begin{array}{c}\text { Std. Error } \\
\text { Mean }\end{array}$ \\
\hline DEPSCALE & Pullman & 291 & 13.4296 & 5.20653 & .30521 \\
& Campus & 289 & 14.3010 & 5.17902 & .30465 \\
\hline
\end{tabular}

Independent Samples Test

\begin{tabular}{|c|c|c|c|c|c|c|c|c|c|c|}
\hline & & \multicolumn{2}{|c|}{$\begin{array}{l}\text { Levene's Test for } \\
\text { Equality of Variances }\end{array}$} & \multicolumn{7}{|c|}{ t-test for Equality of Means } \\
\hline & & \multirow[b]{2}{*}{$\mathrm{F}$} & \multirow[b]{2}{*}{ Sig. } & \multirow[b]{2}{*}{$\mathrm{t}$} & \multirow[b]{2}{*}{ df } & \multirow[b]{2}{*}{ Sig. (2-tailed) } & \multirow[b]{2}{*}{$\begin{array}{c}\text { Mean } \\
\text { Difference }\end{array}$} & \multirow[b]{2}{*}{$\begin{array}{l}\text { Std. Error } \\
\text { Difference }\end{array}$} & \multicolumn{2}{|c|}{$\begin{array}{l}\text { 95\% Confidence Interval } \\
\text { of the Difference }\end{array}$} \\
\hline & & & & & & & & & Lower & Upper \\
\hline DEPSCALE & $\begin{array}{l}\text { Equal variances } \\
\text { assumed }\end{array}$ & .036 & .850 & -2.021 & 578 & .044 & -.87148 & .43124 & -1.71848 & -.02449 \\
\hline & $\begin{array}{l}\text { Equal variances } \\
\text { not assumed }\end{array}$ & & & -2.021 & 577.998 & .044 & -.87148 & .43124 & -1.71847 & -.02450 \\
\hline
\end{tabular}




\section{Appendix L}

\section{T-Test PP and CP Officers}

Group Statistics

\begin{tabular}{|l|l|r|r|r|r|}
\hline & Survey & $\mathrm{N}$ & Mean & Std. Deviation & $\begin{array}{c}\text { Std. Error } \\
\text { Mean }\end{array}$ \\
\hline COPSCALE & Pullman & 291 & 6.9691 & 2.94941 & .17290 \\
& Campus & 289 & 7.7336 & 3.01298 & .17723 \\
\hline
\end{tabular}

Independent Samples Test

\begin{tabular}{|c|c|c|c|c|c|c|c|c|c|c|}
\hline & & \multicolumn{2}{|c|}{$\begin{array}{l}\text { Levene's Test for } \\
\text { Equality of Variances }\end{array}$} & \multicolumn{7}{|c|}{ t-test for Equality of Means } \\
\hline & & $\mathrm{F}$ & Sig. & $\mathrm{t}$ & df & Sig. (2-tailed) & $\begin{array}{c}\text { Mean } \\
\text { Difference }\end{array}$ & $\begin{array}{l}\text { Std. Error } \\
\text { Difference }\end{array}$ & \multicolumn{2}{|c|}{$\begin{array}{l}95 \% \text { Confidence Interval } \\
\text { of the Difference }\end{array}$} \\
\hline COPSCALE & $\begin{array}{l}\text { Equal variances } \\
\text { assumed }\end{array}$ & .317 & .573 & -3.088 & 578 & .002 & -.76449 & .24758 & -1.25076 & -.27822 \\
\hline
\end{tabular}




\section{Appendix M}

\section{Collinearity Diagnostics}

\begin{tabular}{|r|r|}
\hline PP Department \\
\hline Collinearity Statistics \\
\hline Tolerance & VIF \\
\hline .761 & 1.314 \\
.927 & 1.078 \\
.943 & 1.060 \\
.941 & 1.063 \\
.987 & 1.013 \\
.764 & 1.309 \\
.893 & 1.120 \\
.953 & 1.049 \\
.497 & 2.013 \\
.500 & 1.998 \\
.748 & 1.336 \\
\hline
\end{tabular}

\section{CP Department}

\begin{tabular}{|r|c|}
\hline \multicolumn{2}{|c|}{ Collinearity Statistics } \\
\hline Tolerance & VIF \\
\hline .745 & 1.343 \\
.905 & 1.105 \\
.973 & 1.028 \\
.980 & 1.021 \\
.985 & 1.015 \\
.678 & 1.475 \\
& \\
.800 & 1.250 \\
.937 & 1.067 \\
.504 & 1.985 \\
.519 & 1.927 \\
.711 & 1.406 \\
\hline
\end{tabular}




\section{Collinearity Diagnostics (continued)}

\begin{tabular}{|r|c|}
\hline PP Officer \\
\hline \multicolumn{2}{|c|}{ Collinearity Statistics } \\
\hline Tolerance & VIF \\
\hline & \\
.761 & 1.314 \\
.927 & 1.078 \\
.943 & 1.060 \\
.941 & 1.063 \\
.987 & 1.013 \\
.764 & 1.309 \\
& \\
.893 & 1.120 \\
.953 & 1.049 \\
.497 & 2.013 \\
.500 & 1.998 \\
.748 & 1.336 \\
\hline
\end{tabular}

CP Officer

\begin{tabular}{|r|c|}
\hline \multicolumn{2}{|c|}{ Collinearity Statistics } \\
\hline Tolerance & VIF \\
\hline .745 & 1.343 \\
.905 & 1.105 \\
.973 & 1.028 \\
.980 & 1.021 \\
.985 & 1.015 \\
.678 & 1.475 \\
& \\
.800 & 1.250 \\
.937 & 1.067 \\
.504 & 1.985 \\
.519 & 1.927 \\
.711 & 1.406 \\
\hline
\end{tabular}




\section{Appendix N}

\section{PP Department Normal Probability Plot and Residuals Scatterplot}

\section{Normal P-P Plot of Regression Standardized Residual}

Dependent Variable: DEPSCALE

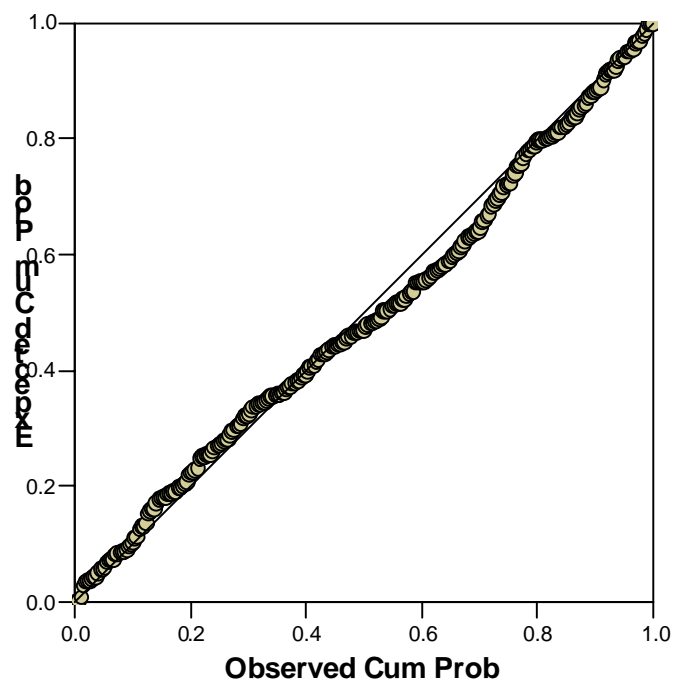

Scatterplot

Dependent Variable: DEPSCALE

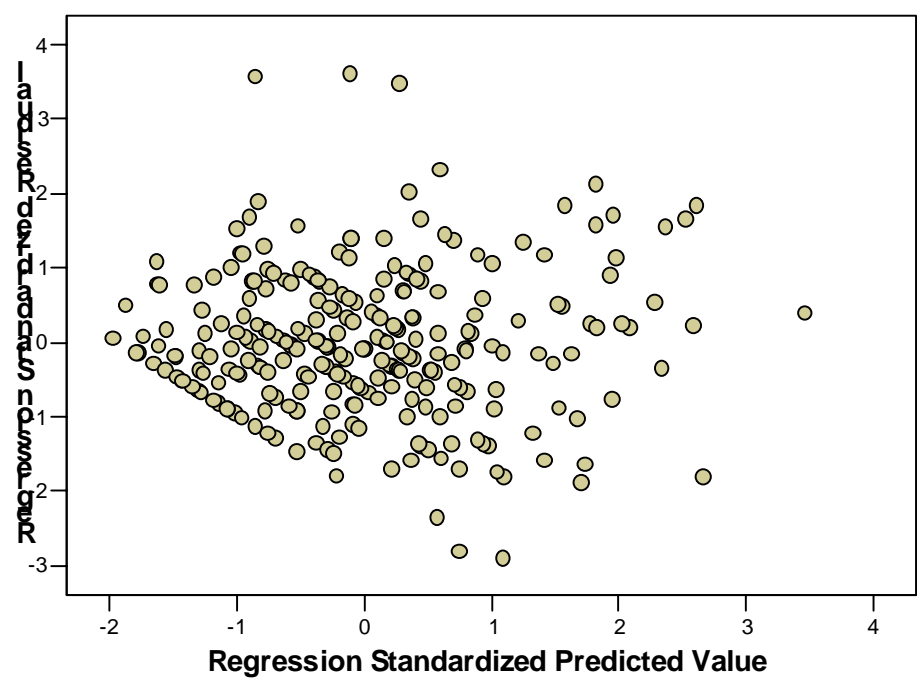




\title{
Appendix 0
}

\section{PP Officer Normal Probability Plot and Residuals Scatterplot}

\author{
Normal P-P Plot of Regression Standardized Residual
}

Dependent Variable: COPSCALE

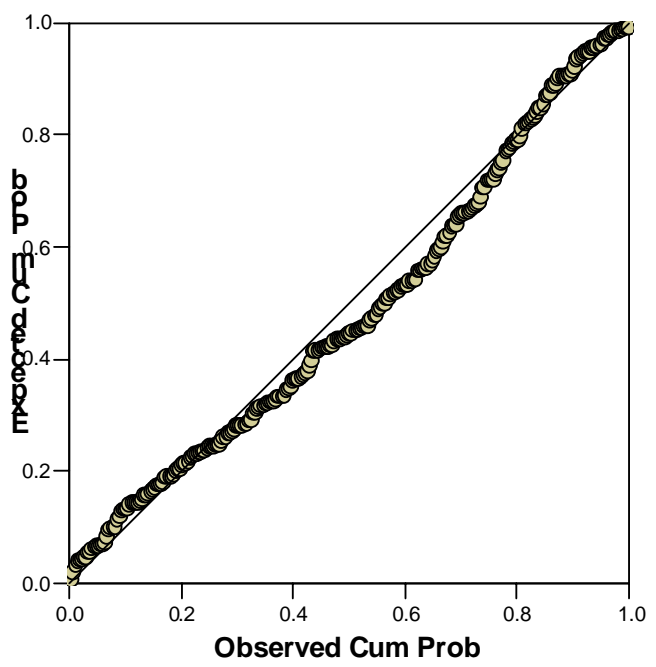

Scatterplot

Dependent Variable: COPSCALE

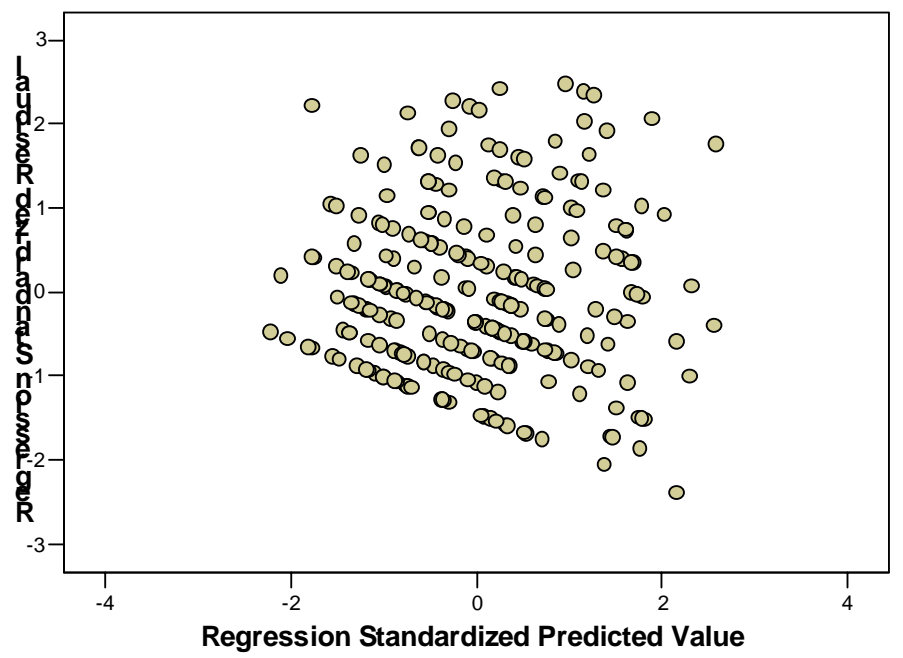




\section{Appendix P}

\section{CPO Department Normal Probability Plot and Residuals Scatterplot}

Normal P-P Plot of Regression Standardized Residual

Dependent Variable: DEPSCALE

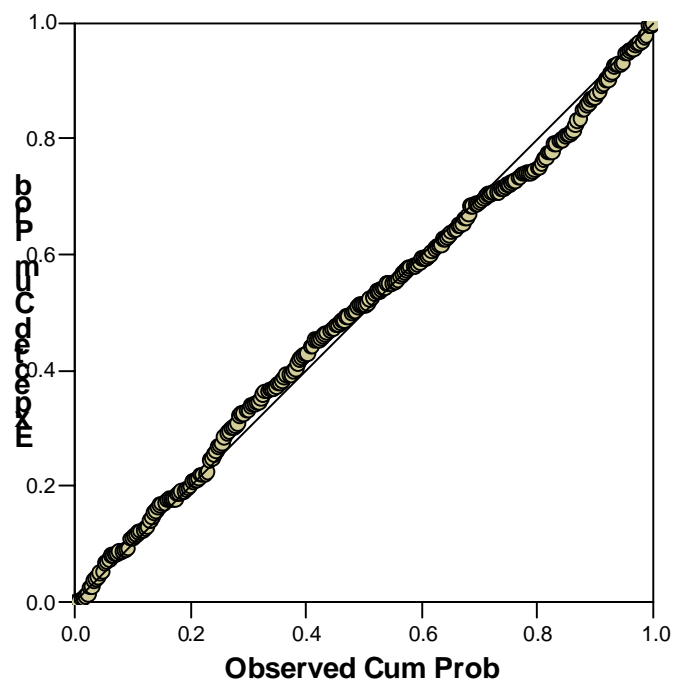

Scatterplot

Dependent Variable: DEPSCALE

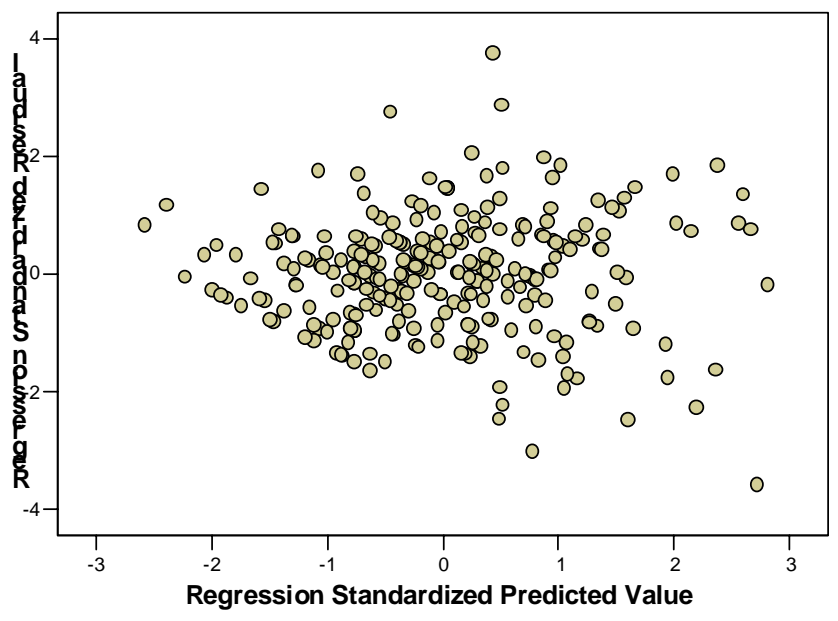




\section{Appendix Q}

\section{CPO Officer Normal Probability Plot and Residuals Scatterplot}

\section{Normal P-P Plot of Regression Standardized Residual}

Dependent Variable: COPSCALE

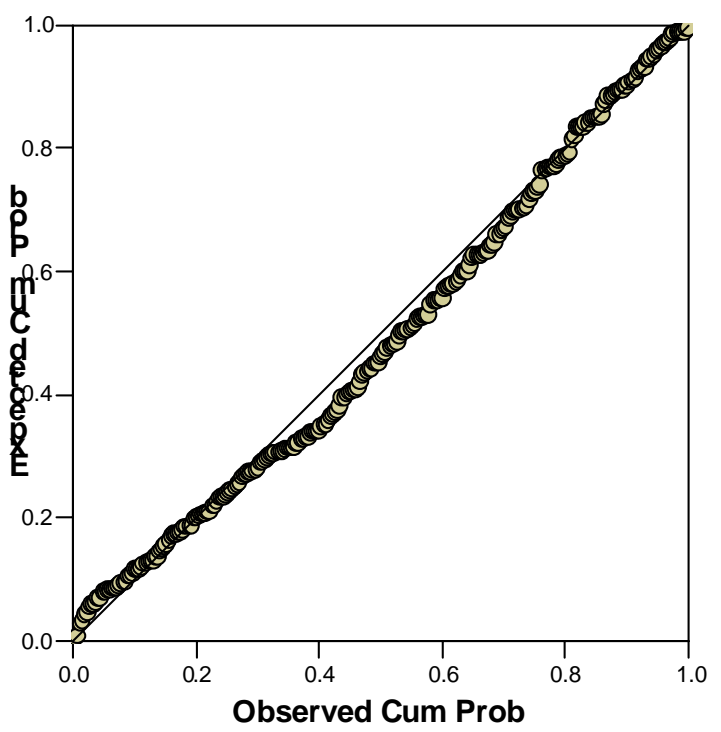

Scatterplot

Dependent Variable: COPSCALE

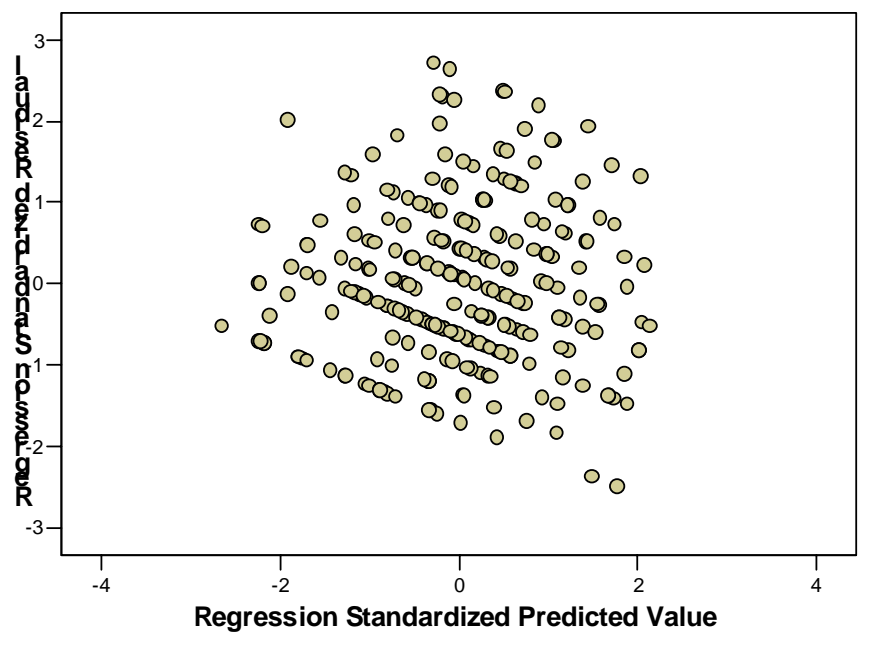




\section{Appendix R}

\section{PP Department Regression Model Summary}

\section{Model Summary}

\begin{tabular}{|l|l|r|r|r|}
\hline Model & $\mathrm{R}$ & R Square & $\begin{array}{c}\text { Adjusted R } \\
\text { Square }\end{array}$ & $\begin{array}{c}\text { Std. Error of } \\
\text { the Estimate }\end{array}$ \\
\hline 1 & $.733(\mathrm{a})$ & .537 & .517 & 3.62385 \\
\hline
\end{tabular}

a Predictors: (Constant), PosScale, Year, Race, Gender, S6Q4, S6Q5, UrbanRural, A Friend had negative contact with police, S6Q3, Had negative contact with an officer, Age

ANOVA(b)

\begin{tabular}{|l|l|l|r|r|r|c|}
\hline Model & & $\begin{array}{c}\text { Sum of } \\
\text { Squares }\end{array}$ & $\mathrm{df}$ & Mean Square & \multicolumn{1}{c|}{$\mathrm{F}$} & Sig. \\
\hline 1 & Regression & 3896.529 & 11 & 354.230 & 26.974 & $.000(\mathrm{a})$ \\
& Residual & 3361.874 & 256 & 13.132 & & \\
& Total & 7258.403 & 267 & & & \\
\hline
\end{tabular}

a Predictors: (Constant), PosScale, Year, Race, Gender, S6Q4, S6Q5, UrbanRural, A Friend had negative contact with police, S6Q3, Had negative contact with an officer, Age

b Dependent Variable: DEPSCALE 


\section{Continued}

\section{Coefficients(a)}

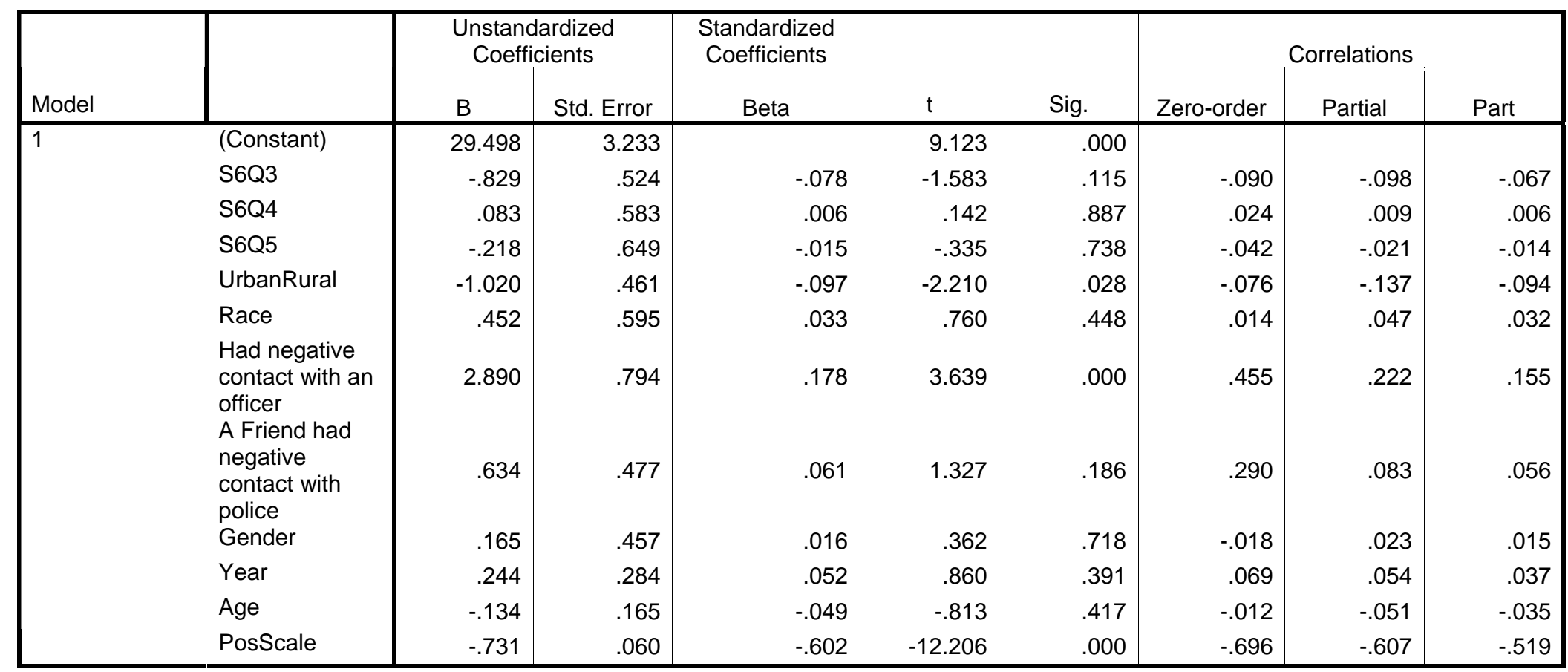




\section{Appendix S}

\section{PP Officer Regression Model Summary}

\section{Model Summary}

\begin{tabular}{|l|l|r|r|r|}
\hline Model & R & R Square & $\begin{array}{c}\text { Adjusted R } \\
\text { Square }\end{array}$ & $\begin{array}{c}\text { Std. Error of } \\
\text { the Estimate }\end{array}$ \\
\hline 1 & $.408(\mathrm{a})$ & .167 & .131 & 2.76622 \\
\hline
\end{tabular}

a Predictors: (Constant), PosScale, Year, Race, Gender, S6Q4, S6Q5, UrbanRural, A Friend had negative contact with police, S6Q3, Had negative contact with an officer, Age

ANOVA(b)

\begin{tabular}{|l|l|r|r|r|r|l|}
\hline Model & & $\begin{array}{c}\text { Sum of } \\
\text { Squares }\end{array}$ & df & Mean Square & F & Sig. \\
\hline 1 & Regression & 392.005 & 11 & 35.637 & 4.657 & $.000(\mathrm{a})$ \\
& Residual & 1958.901 & 256 & 7.652 & & \\
& Total & 2350.907 & 267 & & & \\
\hline
\end{tabular}

a Predictors: (Constant), PosScale, Year, Race, Gender, S6Q4, S6Q5, UrbanRural, A Friend had negative contact with police, S6Q3, Had negative contact with an officer, Age

b Dependent Variable: COPSCALE 



\section{Continued}

\section{Coefficients(a)}

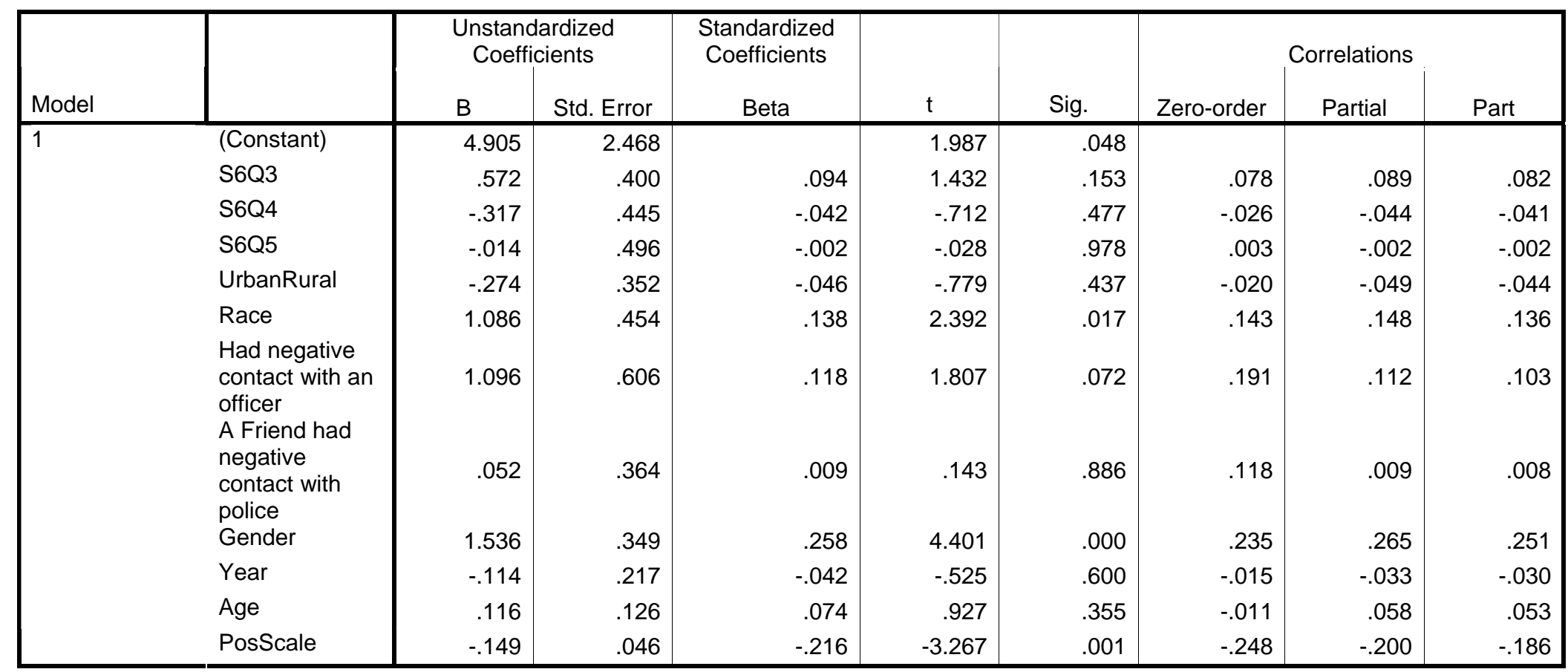




\section{Appendix T}

\section{CP Department Regression Model Summary}

\section{Model Summary}

\begin{tabular}{|l|l|r|r|r|}
\hline Model & R & R Square & $\begin{array}{c}\text { Adjusted R } \\
\text { Square }\end{array}$ & $\begin{array}{c}\text { Std. Error of } \\
\text { the Estimate }\end{array}$ \\
\hline 1 & $.709(\mathrm{a})$ & .503 & .482 & 3.73045 \\
\hline
\end{tabular}

a Predictors: (Constant), PosScale, S6Q4, UrbanRural, Race, S6Q5, Year, Gender, A Friend had negative contact with police, S6Q3, Had negative contact with an officer, Age

\section{ANOVA(b)}

\begin{tabular}{|l|l|l|r|r|r|r|}
\hline Model & & $\begin{array}{c}\text { Sum of } \\
\text { Squares }\end{array}$ & $\mathrm{df}$ & Mean Square & \multicolumn{1}{c|}{$\mathrm{F}$} & Sig. \\
\hline 1 & Regression & 3631.548 & 11 & 330.141 & 23.723 & $.000(\mathrm{a})$ \\
& Residual & 3590.393 & 258 & 13.916 & & \\
& Total & 7221.941 & 269 & & & \\
\hline
\end{tabular}

a Predictors: (Constant), PosScale, S6Q4, UrbanRural, Race, S6Q5, Year, Gender, A Friend had negative contact with police, S6Q3, Had negative contact with an officer, Age

b Dependent Variable: DEPSCALE 


\section{Continued}

\section{Coefficients(a)}

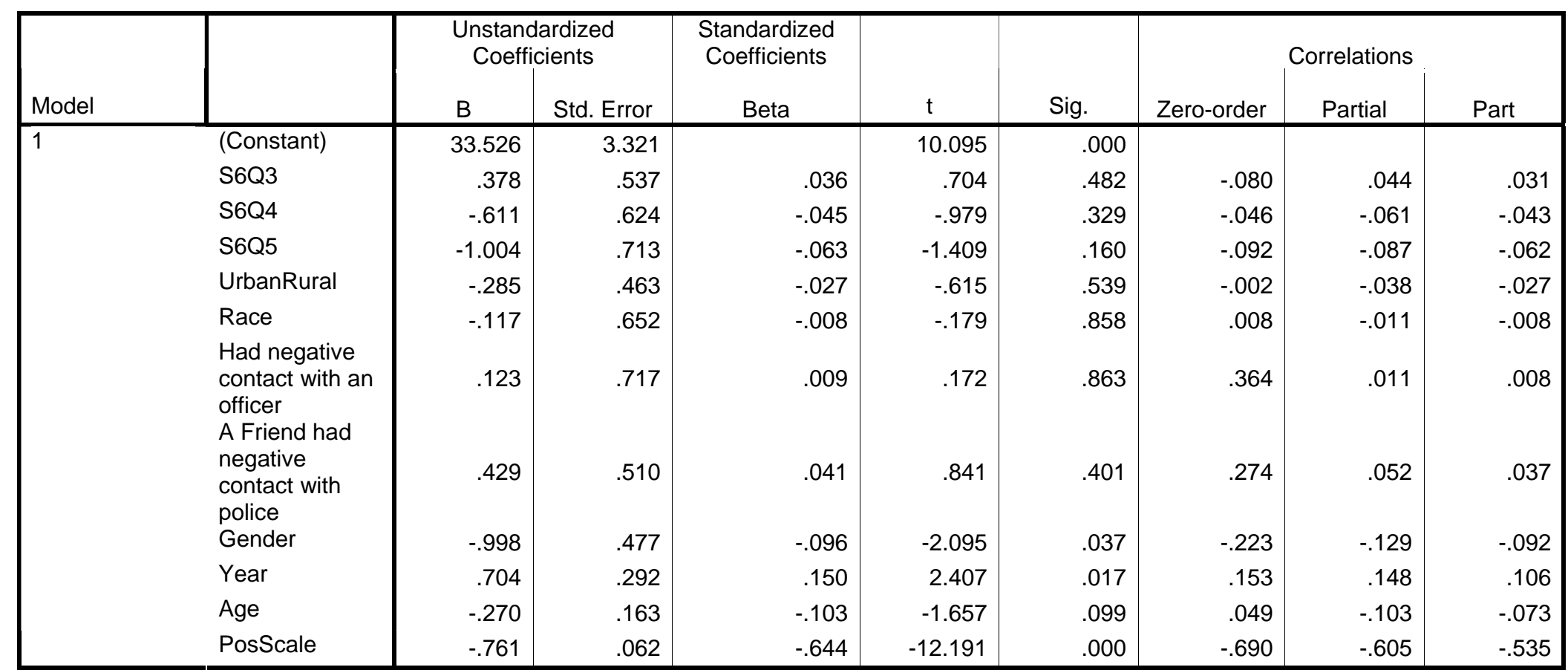




\section{Appendix U}

\section{CP Officer Regression Summary}

\section{Model Summary}

\begin{tabular}{|l|l|r|r|r|}
\hline Model & $\mathrm{R}$ & R Square & $\begin{array}{c}\text { Adjusted R } \\
\text { Square }\end{array}$ & $\begin{array}{c}\text { Std. Error of } \\
\text { the Estimate }\end{array}$ \\
\hline 1 & $.416(\mathrm{a})$ & .173 & .137 & 2.79563 \\
\hline
\end{tabular}

a Predictors: (Constant), PosScale, S6Q4, UrbanRural, Race, S6Q5, Year, Gender, A Friend had negative contact with police, S6Q3, Had negative contact with an officer, Age

\section{ANOVA(b)}

\begin{tabular}{|c|c|c|c|c|c|c|}
\hline Model & & $\begin{array}{l}\text { Sum of } \\
\text { Squares }\end{array}$ & df & Mean Square & $\mathrm{F}$ & Sig. \\
\hline \multirow[t]{3}{*}{1} & Regression & 420.959 & 11 & 38.269 & 4.897 & $.000(a)$ \\
\hline & Residual & 2016.408 & 258 & 7.816 & & \\
\hline & Total & 2437.367 & 269 & & & \\
\hline
\end{tabular}

a Predictors: (Constant), PosScale, S6Q4, UrbanRural, Race, S6Q5, Year, Gender, A Friend had negative contact with police, S6Q3, Had negative contact with an officer, Age

b Dependent Variable: COPSCALE 


\section{Continued}

\section{Coefficients(a)}

\begin{tabular}{|c|c|c|c|c|c|c|c|c|c|}
\hline \multirow[b]{2}{*}{ Model } & & \multicolumn{2}{|c|}{$\begin{array}{c}\text { Unstandardized } \\
\text { Coefficients }\end{array}$} & \multirow{2}{*}{$\begin{array}{c}\begin{array}{c}\text { Standardized } \\
\text { Coefficients }\end{array} \\
\text { Beta }\end{array}$} & \multirow[b]{2}{*}{$\mathrm{t}$} & \multirow[b]{2}{*}{ Sig. } & \multicolumn{3}{|c|}{ Correlations } \\
\hline & & B & Std. Error & & & & Zero-order & Partial & Part \\
\hline \multirow[t]{12}{*}{1} & (Constant) & 11.593 & 2.489 & & 4.658 & .000 & & & \\
\hline & S6Q3 & .733 & .403 & .121 & 1.820 & .070 & .103 & .113 & .103 \\
\hline & S6Q4 & -.227 & .468 & -.029 & -.486 & .627 & .005 & -.030 & -.028 \\
\hline & S6Q5 & -1.216 & .534 & -.131 & -2.276 & .024 & -.163 & -.140 & -.129 \\
\hline & UrbanRural & .328 & .347 & .054 & .944 & .346 & .091 & .059 & .053 \\
\hline & Race & .904 & .488 & .106 & 1.852 & .065 & .126 & .115 & .105 \\
\hline & $\begin{array}{l}\text { Had negative } \\
\text { contact with an } \\
\text { officer } \\
\text { A Friend had }\end{array}$ & .621 & .537 & .080 & 1.156 & .249 & .206 & .072 & .065 \\
\hline & $\begin{array}{l}\text { negative } \\
\text { contact with } \\
\text { police }\end{array}$ & .129 & .382 & .021 & .337 & .736 & .143 & .021 & .019 \\
\hline & Gender & .534 & .357 & .089 & 1.495 & .136 & .044 & .093 & .085 \\
\hline & Year & .007 & .219 & .003 & .033 & .974 & -.068 & .002 & .002 \\
\hline & Age & -.083 & .122 & -.054 & -.679 & .498 & -.092 & -.042 & -.038 \\
\hline & PosScale & -.200 & .047 & -.291 & -4.271 & .000 & -.318 & -.257 & -.242 \\
\hline
\end{tabular}

